\title{
THE INFLUENCE OF COACHES' PERSONAL FACTORS ON THE IMPACT OF COACH EDUCATION
}

A Dissertation
presented to
the Faculty of the Graduate School
at the University of Missouri-Columbia
In Partial Fulfillment
of the Requirements for the Degree
Doctor of Philosophy
JACK BROWN
br. Alex Waigandt, Dissertation Supervisor
MAY 2019


The undersigned, appointed by the dean of the Graduate School, Have examined the Dissertation Proposal entitled

THE INFLUENCE OF COACHES' PERSONAL FACTORS ON THE IMPACT OF COACH EDUCATION

Presented by Brown, Jack

A candidate for the degree of

Doctor of Philosophy

And hereby certify that, in their opinion, it is worthy of acceptance.

Alex Waigandt

Richard McGuire

David Bergin

Sara Gable 


\section{ACKNOWLEDGEMENTS}

First, I would like to thank the chair of committee, Dr. Alex Waigandt, without whom I would not be in this position today. I can't thank him enough for his patience with me as I struggled through this process. His wisdom proved to be invaluable in getting me to the finish line.

Next, I would like to thank Dr. Richard McGuire. Without Dr. McGuire, I may have never come to Columbia in the first place. He sat me down and sold me on the program, and I have followed his guidance ever since. When I wasn't sure I was ever going to finish this project, he had a "coaching moment" with me where he told me to stop making excuses and finish. It was exactly what I needed to hear. He has inspired me to always strive for more, and I can't thank him enough for the influence he has had on my development as both a coach and an academic.

Thank you to both Dr. David Bergin and Dr. Sara Gable for serving on this committee. Both of you have given me valuable insight and feedback that has made this paper what it is today. I am very appreciative for the time you have put forward for me, and thank you again for agreeing to be part of this process.

Thank you to my family for never giving up on me when it came to this paper, including the outbursts I would have when they would ask me about my progress. Thank you for the encouragement, revisions, advice, and financial support as I tried to make the Ph.D. a reality.

Finally, thank you to my loving wife who was a beacon of support throughout this process. You somehow walked the line between prodding and supporting me perfectly, and I can't thank you enough for believing in me throughout this process. There was a 
time when I really didn't know if I would finish, and you gave me reassurance and believed in me anyways. Thank you for being a happy distraction and helping me keep my life in balance. 


\section{TABLE OF CONTENTS}

Acknowledgements...........................................................

Table of Tables.............................................................vi

Abstract............................................................................

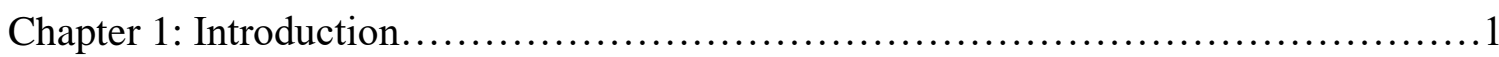

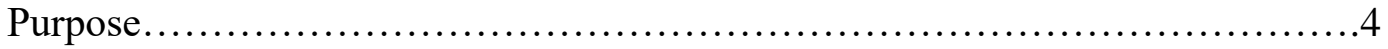

Chapter 2: Literature Review............................................10

Overview.......................................................... 10

Coach Education............................................................. 10

Teacher Factors in Professional Development.............................27

Coaching Effectiveness...............................................33

Positive Coaching..................................................45

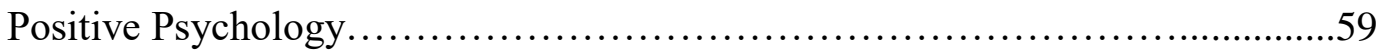

Missouri Institute for Positive Coaching.................................68

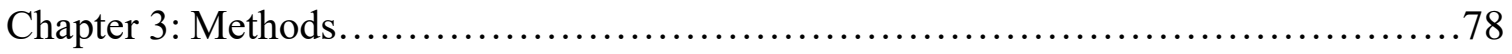

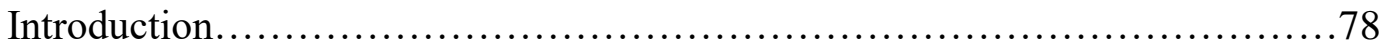

Participants....................................................82

Variables.......................................................... 84

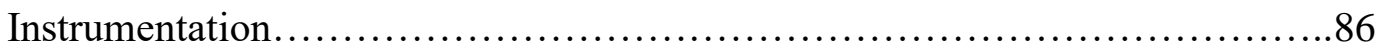

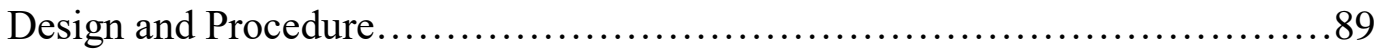

Data Analysis....................................................91

Profile of Participants...............................................91

Chapter 4: Results......................................................96 
Demographic and Descriptive Statistics..................................96

Research Question 1: Coaching Efficacy and Behavioral Change..................99

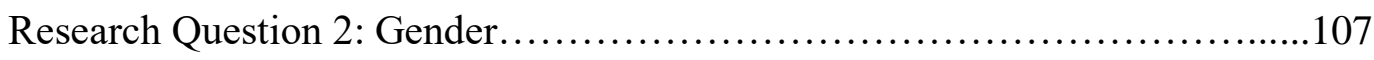

Research Question 3: Experience......................................108

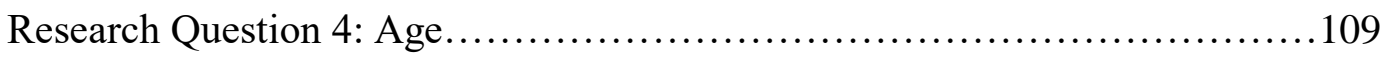

Research Question 5: Enrollment.........................................109

Research Question 6: Attitudes towards Continuing Education..................110

Research Question 7: Resistance to Change..............................111

Chapter 5: Discussion......................................................... 113

Conclusions............................................................ 116

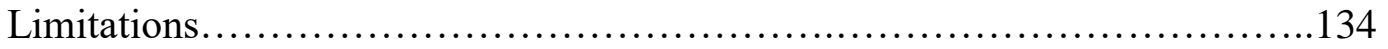

Recommendations for Future Research......................................136

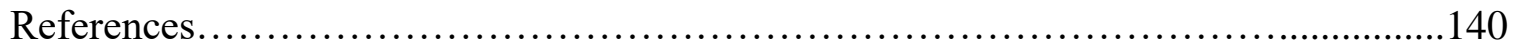

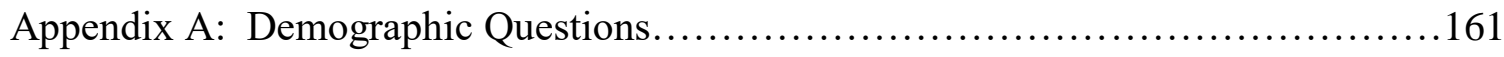

Appendix B: Revised Adult Attitudes Towards Continuing Education Scale...........164

Appendix C: Dispositional Resistance to Change Scale...............................165

Appendix D: Coaching Self Efficacy Scale........................................167

Appendix E: Measures of Behavioral Change and Perception of Education Program...169

Appendix F: Qualitative Responses: Self-reports of Behavioral Change................170

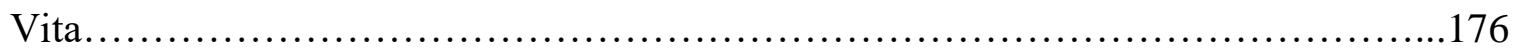




\section{TABLE OF TABLES}

Table 1. Participant Demographics............................................. 96

Table 2. Results of Coaching Efficacy Scale Paired Samples t-test ...................100

Table 3. Results of Chi-Squared for Behavior Change by Enrollment Status...........101

Table 4. Results of Independent Sample t-test for Coaching Efficacy Change by

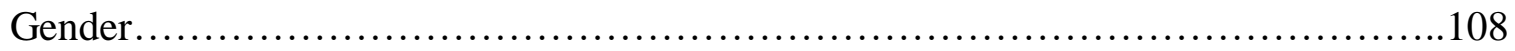

Table 5. ANOVA for Coaching Efficacy Scale (CES) Score Change Based on

Experience............................................................. 108

Table 6. ANOVA for Coaching Efficacy Scale (CES) Score Change Based on

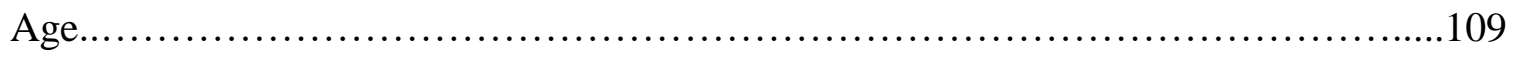

Table 7. Results of Independent Sample t-test for Coaching Efficacy Change by

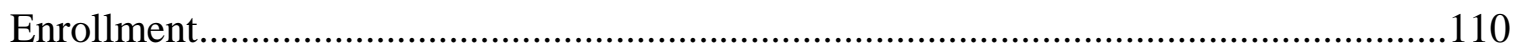

Table 8. Pearson Correlations between Revised Adult Attitudes towards Continuing Education Scale and Coaching Efficacy Score Change

Table 9. Pearson Correlations between Resistance to Change Scale (Incl. Subscales) and Coaching Efficacy Score

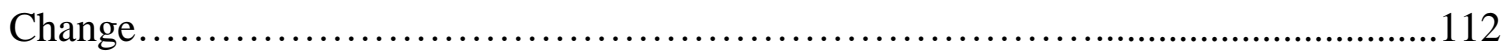




\begin{abstract}
Many coach education programs have been developed to address the increasing demand for qualified coaches. The majority of these programs are sport-specific, and research has focused on the validation of individual programs. Research has failed to consider the role of the coaches' characteristics and their impact on coach education outcomes. This mixed methods study examined changes in coaching efficacy and behavior change after coaches' attendance of a non-formal positive coaching education program. The current study considered the relationship between changes in coaching efficacy and coaches' age, gender, experience, enrollment status (i.e. voluntary v. required), attitudes towards continuing education, and resistance to change. There were 65 coaches who completed this study. Prior to the workshop, participants completed a demographic survey, the Revised Adult Attitudes towards Continuing Education Scale, the Dispositional Resistance to Change Scale, and the Coaching Efficacy Scale. Following the completion of the workshop, coaches answered a follow-up survey containing the same surveys and a qualitative item regarding behavioral change. Results suggest that the coaches who completed the online program experienced significant increases in coaching efficacy and behavioral change. There was a significant relationship between enrollment status and changes in coaching efficacy and coaches' behavioral change. The findings indicate that coaches who are required to attend education do not experience the same changes in coaching efficacy or behavior compared to those who attend voluntarily. It is necessary to convince coaches of the benefit of continuing education for their careers and the athletes with whom they work.
\end{abstract}

Keywords: coach education, positive coaching, coaching efficacy, coaching effectiveness 


\section{CHAPTER 1}

\section{INTRODUCTION}

There are currently over 21.5 million children between the ages of 6 and 17 who are involved in team sports in the United States (Kelly \& Carchia, 2013). The coaches of these athletes have the potential to tremendously impact athletes and their development through experiences in sport (Barnett, Smoll, \& Smith, 1992; Chi, 2004; Conroy \& Coatsworth, 2004; Duda \& Hall, 2001; Langan, Blake, \& Lonsdale, 2013; McGuire, 2012, 2016; Pepitas, Giges, \& Danish, 1999; Zuleger, 2014). Despite this potential, athletes of all ages are exposed to coaching behaviors that are detrimental to their psychoemotional, social, cognitive, and physical development (McGuire, 2012, 2016). Media has brought attention to stories of verbally and sometimes physically abusive coaches. Often, this abuse occurs under the guise of making athletes tougher to achieve victory and is justified through positive athletic results. Research suggests abusive coaching practices are tolerated because they are believed to be an essential part of winning and athletic success (Gervis \& Dunn, 2004; Stirling, 2013; Stirling \& Kerr, 2009; Tofler, Stryer, Micheli, \& Herman, 1996).

Abusive coaching practices create a variety of long-term negative effects including diminished emotional well-being (Stirling, 2013; Stirling \& Kerr, 2007; Stirling $\&$ Kerr, 2013), lowered self-confidence, disruptions of sexual perception, loss of confidence in others, feelings of anger, fear, sadness, and avoidance of situations related to the sport context (Cense \& Brackenridge, 2001). For over 40 years, the long-standing problem of abusive coaching has led to questioning how to create favorable experiences in athletics (Smith, Smoll, \& Curtis, 1979). To decrease abusive behaviors by coaches 
and enhance athlete performance, professionals have focused on coach education and certification.

Driven by an increased demand for qualified coaches at all levels (McCullick, Belcher, \& Scheumpp, 2005) and a desire to professionalize coaches (Lyle, 2007; Trudel \& Gilbert, 2006), coach education became a topic of increasing importance in western countries at the turn of the century (Gilbert \& Trudel, 1999). Continuing education is a necessary component of any technical or teaching profession (Institute of Medicine, 2010). Two primary types of coach education have emerged. First, a variety of education programs focused on professional knowledge (i.e., tactical and technical components of sport) were developed. These programs were created by the National Governing Bodies of various sports and served as a license to coach (Cassidy \& Kidman, 2010). Unfortunately, these professional knowledge programs have done little to alleviate abusive coaching behaviors. Other programs, such as positive coaching based programs, attempt to tackle the problem of abuse by fostering coaching effectiveness. Effectiveness based programs shifted from the traditional "what" of coaching and focus on the "how" and "why" representing a departure from the "win at all costs" mentality. These programs attempt to build coaches who value character development as much as athletic performance (Coté \& Gilbert, 2009; Cassidy \& Kidman, 2010).

Programs based on coaching effectiveness represent a departure from traditional coach education, focusing on professional, interpersonal, and intrapersonal skill development (Coté \& Gilbert, 2009). Models grounded in coaching effectiveness focus on character development and creating positive performance and psychological outcomes for athletes. This shift in focus has also been reflected in the values coaches hold as well. 
In a study of high school coaches, Gould, Lauer, Rolo, Jannes, and Pennisi (2006) found that coaches placed primary importance on psychological and social development while winning was identified as the least important factor. Coaches prefer educational programs that feature topics such as communicating with parents and athletes, motivational techniques, and character building (Vargas-Tonsing, 2007).

Coaching effectiveness education programs have demonstrated positive results. These programs report beneficial effects on coaching efficacy (Campbell \& Sullivan, 2005; Malete \& Feltz, 2000; Santos, Mesquita, Graca, \& Rosado, 2010; Sullivan, Paquette, Holt, \& Bloom, 2012; Trudel, Gilbert \& Werthner, 2010), specific coaching behaviors (Smith, Smoll, \& Curtis, 1979), athlete attrition (Barnett et al., 1992), athlete goal-orientation (Duda \& Hill, 2001), and athlete anxiety (Smith, Smoll, \& Barnett, 1995; Smith, Smoll, \& Cumming, 2007). Qualitative studies also suggest high levels of generalized confidence in the coach education process (Barnett et al., 1992; Langan et al., 2013; Smoll, Smith, Barnett, \& Everett, 1993).

There has been a large emphasis on the need to develop coach education programs over recent years (Gilbert \& Trudel, 1999; Langan et al., 2013). This emphasis has led to programs that lack a strong theoretical base and are different in goals and content. These issues have resulted in several problems within the coach education field. First, because education programs have different goals and methods, few general recommendations exist for developing effective coach education programs (Cushion, Nelson, Armour, Lyle, Jones, \& O’Callaghan, 2010; Langan et al., 2013). Second, the validation of programs is problematic, since no universal metric or outcome is used to determine the success of education programs. Third, the focus on practitioners 
attempting to validate their individual programs has led researchers to overlook coaches' demographic, dispositional, and personal data on the outcomes of the educational process. There has been no research conducted on how these factors impact the effectiveness of coach education. This area is of interest as it could potentially inform and provide recommendations for all types of coach education.

Other fields of research have demonstrated the importance of understanding how an individual's characteristics impact continued learning. Research within the field of teacher education has demonstrated the powerful effect teachers' personal and dispositional variables play on the continuing education process. Teachers share many similarities with coaches. Therefore, it is reasonable to assume similar effects may exist. This information could be a vital factor to informing educational practices and may be generalized across all coach education programs. Understanding the relationship between coaches' personal and motivational factors and the effects of coach education may help educators develop better understandings of the populations with which they work.

\section{Purpose}

The purpose of this study is to explore the relationship between a coach's personal (gender, experience, age, enrollment status) and dispositional factors (attitudes towards continuing education, dispositional resistance to change) and the effectiveness of a positive coaching-based education program. The present study will consider the benefits of the program by looking at coaching efficacy and behavior change and how individual differences among coaches relate to these outcomes. 
Q1: Do participants enrolled in the Missouri Institute for Positive Coaching Digital Workshop, as created by McGuire (2012, 2016), experience changes in coaching efficacy or coaching behavior?

H1: Coaches will report increased levels of coaching efficacy after completing the MIPC program. Coaches will report making conscious changes to their coaching behavior after their completion of the workshop. Rationale: Coaches with higher education degrees have been shown to have increased coaching efficacy (Santos et al., 2010). Coach education (including workshops and certifications) have been demonstrated to positively impact coaching efficacy (Campbell \& Sullivan, 2005; Malete $\&$ Feltz, 2000; Sullivan et al., 2012).

Q2: Are there differences in changes in coaching efficacy scores between male and female participants?

H2: Female participants will have greater positive changes in coaching efficacy scores on the CES compared to male participants.

Rationale: Women are higher consumers of continuing education within the field of teaching, even when accounting for gender differences within the profession. Women have an increased motivation to both learn and participate in continuing education activities (McGivney, 2004). The effect of gender on coach education has not been investigated. Because females in teacher education are more likely to positively regard and pursue continuing education (McGivney, 2004), this study hypothesizes 
that female participants will have greater positive changes in coaching efficacy than men.

Q3: Are there differences in changes in coaching efficacy scores based on coaching experience?

H3: Coaches who have been coaching longer will have smaller changes in coaching efficacy scores compared to coaches who are newer to the profession.

Rationale: Experience has been demonstrated to have a positive effect on coaching efficacy (Santos et al., 2010). The relationship between experience and coach education outcomes has not been measured. Within teacher education, experience plays a significant role in a teacher's pursuit of educational opportunities. Experienced teachers are less likely to pursue learning opportunities (Richter et al., 2011). Experienced teachers also demonstrate increased routine seeking behaviors, cognitive rigidity, and are less likely to consider new perspectives (Stan et al., 2013). Because of these findings, this study hypothesizes that coaches with more experience will be less likely to be open to new ideas and changing their own behavior. More experienced coaches will report lower increases in their coaching efficacy scores.

Q4: Are there differences in changes in coaching efficacy scores based on age categories? 
H4: Coaches who are in older age categories will report smaller positive changes in coaching efficacy scores compared to coaches in younger age categories.

Rationale: Research demonstrates older coaches are less likely to pursue continuing education, and do not feel the same need to develop as younger coaches (Blunt \& Yang, 2002). Within teacher education literature, findings also suggest that older teachers are less likely to pursue continuing education (Richter et al., 2013). Older coaches may feel a decreased need to change their behavior and have less appreciation for the educational material resulting in smaller changes in coaching efficacy scores.

Q5: Are there differences in changes in coaching efficacy based on the enrollment status (i.e. required or voluntary) of the coach?

H5: Coaches who voluntarily enroll in the workshop will have increased positive changes in coaching efficacy scores compared to coaches who are required to take the course by school administrators.

Rationale: Within the field of teacher education, research has demonstrated that when teachers have the will to learn, they are more likely to experiment with newly learned ideas and incorporate them into practice (Hargreaves, 1999). When a coach enrolls in the course voluntarily, it is reasonable to assume that there in an increased will to learn, especially in comparison to those whose attendance is required. Self-determination theory suggests that individuals are more likely to be 
intrinsically motivated when three basic needs are met. These needs are autonomy, relatedness, and a sense of competency (Ryan \& Deci, 2000). Because coaches who voluntarily enroll in the course will have had autonomy over their decision, they may be more intrinsically motivated to learn and integrate course material into their coaching practices. This study hypothesizes that coaches who voluntarily enroll in the course will have greater positive changes in coaching efficacy scores compared to the individuals who were required to enroll by their administrators.

Q6: Is there a correlation between attitudes and beliefs towards education, as measured by the Revised Adult Attitudes and Beliefs towards Continuing Education Scale, and changes in coaching efficacy?

H6: There will be a positive correlation between attitudes towards continuing education and changes in coaching efficacy.

Rationale: There has been no research on the effect of coaches' attitudes and beliefs on coach education. In teaching, attitudes towards continuing education have been shown to predict a teacher's pursuit of educational opportunities. Education programs fail to be effective when existing knowledge is taken for granted and the desire to see new opportunities is absent (Oosterheert \& Vermunt, 2001). When will to learn is present, teachers will experiment with newly learned ideas, and incorporate them into their own behavior (Hargreaves, 1999). High will to learn influences reflection-on-action (Schon, 1983), which is a powerful factor in changing coach behavior (Gilbert \& Trudel, 2001). This study hypothesizes that 
more positive attitudes towards continuing education will positively correlate with coaching efficacy.

Q7: Is there a correlation between dispositional resistance to change, as measured by the Dispositional Resistance to Change Scale, and changes in coaching efficacy? H7: There will be a negative correlation between dispositional resistance to change and changes in coaching efficacy.

Rationale: Dispositional resistance to change has not been assessed within coaching populations and coach education. In teaching literature, teachers who are high in dispositional resistance to change are less likely to seek out educational opportunities (Oreg et al., 2008). These teachers also report more negative feelings when faced with information that contradicts current practices and beliefs (Oreg et al., 2008), and are less likely to consider new perspectives (Stan et al., 2013). Coaches have been shown to demonstrate behaviors related to resistance to change, including holding onto traditionally accepted methods of coaching (Coakley, 1978). This study hypothesizes that there will be a negative correlation between resistance to change and coaching efficacy. 


\section{CHAPTER 2}

\section{LITERATURE REVIEW}

\section{Overview}

The purpose of this study is to investigate the relationship between coaches' personal factors and changes in coaching efficacy after attending a positive coachingbased education program. This review of literature will begin by introducing the pathways of coach learning and coach education models. This includes the different settings of coach education and existing learning mechanisms that enhance coach learning. This will be followed by the benefits of coach education with a focus on coaching efficacy, recommendations for coach education models, and coach perception of education and learning. Next, this section will focus on research from the field of teacher education. Factors related to teacher education, including age, experience, attitudes and beliefs, and dispositional resistance to change will be explored. Teaching literature will provide a basis of understanding for the current study that does not exist within coach education literature. Coaching models grounded in coaching effectiveness and related to athlete character development will be reviewed. Special emphasis will be given to the construct of positive coaching. Finally, the Missouri Institute for Positive Coaching Program will be outlined. This outline will include a validation of the program's principles and a summary of its teaching methods.

\section{Coach Education}

Coaches at all levels have the potential to create sport experiences that negatively affect athletes. Research suggests that the primary route to changing negative athlete outcomes is through coach education. Instead of focusing on how coaches learn 
behaviors, early research focused on how coaching behaviors mediated athletes' performance and personal development (Cushion et al., 2010). Beneficial coaching behaviors were identified, but information regarding the methods through which coaches acquire their knowledge was lacking. As attempts are made to improve coach behavior, it is incredibly important to understand the ways coaches learn. The following section will briefly outline the three pathways of coach learning including informal learning, non-formal learning, and formal learning.

Informal learning. Informal learning refers to the variety of contexts in which learning happens every day. Informal learning has been described as "a lifelong process where a person accumulates knowledge, skills, attitudes, and insights from everyday experiences and interactions" (Coombs \& Ahmed, 1974, p. 8). Informal learning is the primary pathway of learning for coaches and includes previous experiences as an athlete, informal mentoring, practical coaching experiences, and interactions with peer coaches and athletes (Abraham, Collins, \& Martindale, 2006; Bloom, Durand-Bush, Schinke, \& Salmela, 1998; Jones, Armour, \& Potrac, 2003). Coaches also engage in self-directed learning which includes searching the internet, watching videos, reading coaching books, manuals, journal articles, and magazines (Abraham et al., 2006; Erickson, Coté, \& Fraser-Thomas, 2008; Reade, Rodgers, \& Hall, 2008). Laios, Theodorakis, and Gargalianos (2003) found that coaches are committed to continual professional development. This professional development is most often self-directed.

Informal learning includes experiential learning, informal learning structures, and past athletic experiences. Experiential learning involves cyclical pathways where coaches evaluate experiences and incorporate these experiences into learned behavior 
(Moon, 2004). Experiential learning serves as the dominant learning pathway for coaches and can be problematic due to the lack of external feedback. This may lead to the continued use of ineffective coaching practices (Cushion et al., 2010). Informal learning structures involve relationships and the ways coaches learn from others around them including athletes, other coaches, professionals, and mentors (Bloom et al., 1998; Schempp, Templeton, \& Clark, 1998). Finally, coaches begin their acquisition of coaching knowledge long before they become a coach (Cushion, Armour, \& Jones, 2003). This include a coaches' past athletic experiences, as research shows coaches develop their understanding of coaching roles while they are still competing (Cushion et al., 2010; Lemyre, Trudel, \& Durand-Bush, 2007; Salmela, Draper, \& Desjardins, 1994). Research conducted by Salmela (1995) found that nearly all expert coaches had intense involvement in sport prior to coaching. Similarly, Gilbert and Trudel (2001) found that successful team-sport coaches had thousands of hours of sport experience across a variety of different sports before starting to coach.

Informal learning has limitations. Coakley (1978) noted that informal learning experiences "are the channels through which the traditional accepted methods of coaching become integrated into the behavior of aspiring young coaches" (p. 241). This type of knowledge transmission has not always been positive and has led to the passing down of incompetent coaching practices. The result has created a population of experienced yet ineffective coaches, since this type of learning happens without critical reflection or feedback (Cushion, Armour, \& Jones, 2006; Moon, 2004).

Coaches perceive informal education as essential to their development. In fact, coaches believe that the knowledge they receive from everyday experiences and 
interactions is more valuable than classroom or formal learning experiences (Cervero, 1999). As a result, researchers and coach educators have tried to find ways to incorporate informal learning structures into coach education. The two structures most examined are mentoring and reflection. Mentoring is a central part of coaching, as coaches are "initiated into the traditions, habits, rules, cultures and practices of the community they join" (Merriam, 1983, p. 37). Mentoring and informal learning practices primarily occur in contexts where the primary goal is not learning (Colley, James, Tedder, \& Diment, 2003). However, the greater mechanism of mentoring, coach interaction, has successfully been implemented within formal coach education contexts. Coaches have reported the benefit of allotting time in education programs for interacting with other coaches. In Cassidy, Portrac, and McKenzie's (2006) study, researchers interviewed rugby coaches following an educational intervention. Coaches reported that "it was as much about the melding of ideas and stuff," and that "to have that sort of forum where you could just talk and even argue, even disagree with guys...was really good.” (p. 153). The integration of informal learning structures, like coach interaction, can help to enhance more formal education practices.

Reflection is another integral part of effective experiential learning (Erickson et al., 2008). Gilbert and Trudel's (2001) experiential learning model examines reflective practice and defines it as "a process that mediates experience and knowledge and therefore is at the heart of all experience-based learning" (p. 17). The process includes three parts, including reflection on action (i.e., problem setting), reflection in action (i.e., experimenting), and retrospective reflection (i.e., problem setting and review of past action). The reflective process involves evaluating previous actions to have outcomes 
that are more positive in the future. Many coaches recognize the need to be self-sufficient in learning and to become a reflexive practitioner. Reflection helps bridge the gap between academic experiences and the real-world application of these experiences (Gilbert \& Trudel, 2001; Irwin, Hanton, \& Kerwin, 2004; Santos et al., 2010). After practicing the process of reflection, coaches had increased confidence in terms of providing their players with meaningful and productive learning experiences (Cassidy et al., 2006).

Non-formal learning. Non-formal learning has been described as an organized, systematic, educational activity that is carried on outside the framework of the formal education system (Coomb \& Ahmed, 1974). Most of the research in non-formal learning structures has come from education and is often conceptualized as continued personal development. These types of education opportunities include workshops, predetermined and highly structured sequences of activities, and didactic instruction with passive learning (Armour \& Yelling, 2004). The question regarding these activities revolves around their effectiveness in changing behavior, but research suggests that even a single 45-minute session can positively affect coaching behavior and athlete outcomes (Smith et al., 2007). Research has found that there are five key principles regarding effective professional development: deepening content knowledge for pedagogical skills, opportunities for practice, reflection and research, embedding learning in the workplace during the school day, sustainability, and a sense of collegiality and collaboration (Sparks, 2002).

In addition to these principles, researchers have made suggestions to create professional learning communities (PLC) within coaching communities to further 
professional development (Wenger, 1998). Armour and Yelling (2007) identified PLCs as being the most powerful source of professional learning for teachers in their study. Recent findings have suggested that PLCs are also beneficial in coaching contexts and assist in the exchange of ideas between coaches (Bertram \& Gilbert, 2011). Professional learning communities bridge the gap from a single episode of interaction to creating dialogue and support for coaches as they experiment with new ideas. These communities provide interactions similar to the informal learning structures of mentorship and reflection and encourage a constant exchange of ideas among colleagues.

Formal learning. Formal learning is defined as learning occurring in an "institutionalized, chronologically graded and hierarchically structured education system" (Coomb \& Ahmed, 1974, p. 8). This type of learning includes degree programs, certification programs, and long-term educational interventions. Despite the prevalence of formal education, it has some limitations. Studies have found that despite the overwhelming evidence for reflection as an analytical framework, most coaching education programs fail to incorporate this practice (Knowles, Borrie, \& Telfer, 2005; Nelson \& Cushion, 2006). Other research has found that many courses deviate from syllabus guidelines and teaching plans, which results in inconsistency in the repeatability of education programs (Hammond \& Perry, 2005). Finally, coaches complain that formal education programs focus on the development of knowledge that is limited to technical skill development. Without talk of application or practicality, this type of learning is of little significance and is contrary to the recommendations of research (Coté \& Gilbert, 2009). Despite these findings regarding formal education, many programs have 
addressed these issues and report positively impacting coach behavior. The effects of coach education will be outlined in the next section.

Effects of coach education. Coach education grounded in theory is effective at changing coach behavior and efficacy, which has been demonstrated to positively impact athlete outcomes. Many qualitative studies demonstrate generalized confidence in the effectiveness of coach education (Barnett et al., 1992; Langan et al., 2013; Smith \& Smoll, 1996; Smoll \& Smith, 1997). Langan et al.'s (2013) review evaluated coach education programs and found that coach education resulted in a variety of positive outcomes based on each program's theoretical approach. Mastery-based coach education programs improved goal-orientation, motivational climate, and decreased ego-orientation for athletes (Chi, 2004; Duda \& Hall, 2001; Maehr \& Zusho, 2009). Coach Effectiveness Training (CET), a program based on coaches' interpersonal development, increased interpersonal effectiveness, sport enjoyment, and athletes' approval of the coach while reducing athlete anxiety (Barnett, Smoll, \& Smith, 1992; Smith, 1979; Smoll \& Smith, 2006;). Other studies have shown that coach education may decrease athlete attrition and increase academic achievement and goal orientation. Langan et al.'s (2013) review of coaching studies identified a variety of factors that are positively impacted by coach education, including coaching efficacy.

Coaching Efficacy. The application of efficacy to coaching comes from Bandura's (1977) theory of self-efficacy. This theory states that self-efficacy is the belief that one can successfully perform an ability to reach a desired outcome. Self-efficacy is considered essential for motivation, as people constantly seek feedback for their actions in relation to their goals and intentions. As individuals are successful in doing what they 
intend, individuals become increasingly motivated and the behavior is more likely to be repeated. The belief that one can perform a task successfully will later affect that individual's effort and persistence during future performances (Caron, Vargas, \& Hawn, 2018; Stajkovic \& Luthans, 1998).

Coaching efficacy is defined by Feltz and colleagues (1999) as the "extent to which coaches believe they have the capacity to affect the learning and performance of their athletes" (p. 765). Coaching efficacy is an important construct, as it has been demonstrated to influence coaching behavior, athletes' performances, athletes' confidence/motivation levels, and athletes' satisfaction with their coach (Feltz, Chase, Mortiz, \& Sullivan, 1999). High coach efficacy scores are correlated with higher winning percentages and increased player satisfaction. Coaches with high efficacy were also more likely to be encouraging, instructional, and to deliver praise to athletes (Feltz et al., 1999). These behaviors have been proven to increase intrinsic motivation and positive performance outcomes for athletes (Amorose \& Anderson-Butcher, 2007). Together, these findings demonstrate that coaching efficacy affects both personal and performance outcomes for athletes. Coaching effectiveness, as outlined by Coté and Gilbert (2009), focuses on these two outcomes and states they are essential to creating positive sport experiences. Because of this connection, coaching efficacy is an essential part of coaching effectiveness, which will be considered at greater length later in this paper.

Sources of coaching efficacy. According to Bandura's self-efficacy theory (1986), self-efficacy comes from four sources. These sources are past performances, vicarious experiences, verbal persuasion, and physiological cues. Past performances 
represent a positive evaluation of previous action in relation to a specific goal. This forms a basis of mastery and is the most powerful source of self-efficacy. Vicarious experience is based upon the performance of others. As individuals observe others performing a task, they evaluate themselves in reference to those individuals and appraise their own skills. Verbal persuasion comes from verbal suggestions from outside sources. This is dependent on the credibility and expertise of the source of the suggestion. Finally, physiological cues are an individual's interpretation of their own arousal level which can be positive or negative. This affects efficacy in very specific ways. For instance, a person with higher efficacy will be more likely to perceive high levels of arousal as facilitative to performance. Those with less efficacy will be more likely to perceive high arousal as anxiety and believe it will negatively impact their ability to perform (Bandura, 1986). Feltz et al. (1999) studied these sources in relation to practical knowledge obtained by studying coaches and teacher-efficacy literature. The sources were modified to make them applicable to the practice and study of coaching.

There are four sources of coaching efficacy proposed by Feltz and colleagues (1999). These sources are extent of coaching experience/preparation, prior success, perceived skill of athletes, and school/community support. Coaching experience/preparation and prior success are based on prior performances and are directly linked to Bandura's (1986) model related to prior experience. The source of perceived skill of athletes comes from teaching literature, which suggests that teaching efficacy was based partly on the teachers' perception of their students' academic abilities (Smylie, 1988). Feltz et al. (1999) determined that coaches make a similar judgment when considering their athletes. The final source comes from school/community support. This 
support directly relates to verbal persuasion, as coaches feel empowered when supported and recognized by those around them.

Chase, Feltz, Hayashi, and Hepler (2005) conducted research with basketball coaches to validate and expand on Feltz et al.'s coaching efficacy model (1999). In their research, they discovered subthemes which added to the four sources of efficacy listed above. First, to the source of coaching experience/preparation, the authors added having the knowledge to prepare the team, past experiences in coaching, leadership skills, and coaches' development. Knowledge to prepare the team was characterized by seeing improvements in athlete's abilities and getting players to perform their best. Past experience was defined as having been in competitive environments before and learning from mistakes. Leadership skills focused on interpersonal skills and the development of a coaching philosophy. Finally, coaches' development was focused on coach education and learning from those around you.

The findings of Chase et al. (2005) are significant as they expand the previous sources of efficacy as proposed by Feltz et al. (1999) and highlight the importance of reflective coaching practices, coach development/education, and interpersonal relationships. These sources represent diverse knowledge types related to different types of skills required of coaches. These findings further fit within the model of coaching efficacy, as the construct has been demonstrated to be domain specific, with each domain of efficacy having a separate appraisal.

Domains of coaching efficacy. In the coaching efficacy model created by Feltz et al. (1999), there are four domains of coaching efficacy. These domains are motivational efficacy, character building efficacy, technical efficacy, and game strategy efficacy. 
Motivational efficacy is confidence in the ability of the coach to successfully motivate and inspire athletes to perform their athletic tasks. This includes teaching psychological skills and positively affecting the mental state of athletes. Technical efficacy is confidence in the coach's ability to correct errors and teach the skills of sport. Game strategy efficacy focuses on game time decision-making. It also includes the ability of the coach to identify teams' strengths, weaknesses, and to effectively lead successful performances. Finally, character building efficacy is the belief that the coach can help the athlete develop values and enhance the personal development of athletes. The focus on athletes' personal growth has received a lot of focus, as many individuals consider character building to be the fundamental purpose of sport (Rudd, 2005). The different domains of efficacy demonstrate that coaches are expected to perform a large number of functions (Cushion et al., 2010).

The current study examined all four domains of efficacy. Because the program that was examined was non-sport specific, motivational efficacy and character-building efficacy were of particular relevance. These types of efficacy fit within the stated goals of the positive coaching program, which is empowering athletes "to be prouder, happier, healthier, more fulfilled for their investment and motivated to come back and do more" (McGuire, 2012, 2016). Game strategy and technical efficacy were also included in the analysis. Although the program does not explicitly state goals of teaching game strategy or technique, the program does include lessons related to teaching and proper communication with athletes. Lessons focused on broad interpersonal skills may impact game strategy and technical efficacy as coaches learn how to better interact with their athletes. 
Educational effects on coaching efficacy. Access to athletes can be difficult and assessing coaching behavior can be problematic. Because of this, most research on coach education has focused on changes in coaching efficacy. To help with this measurement, Feltz et al. (1999) developed the Coaching Efficacy Scale (CES), which measures coaching efficacy and includes subscales related to each of the four domains. The CES was developed for use with high school coaches, which makes it particularly relevant for this study.

Informal and non-formal coach training/education programs have been shown to influence and benefit coaching efficacy. Regarding informal learning, communities of practice, where coaches could have meaningful discussions and received support from their peers, have a broad positive impact on self-efficacy (Bertram \& Gilbert, 2011). Other studies have found that short workshops and certification also positively impact coaching efficacy (Campbell \& Sullivan, 2005; Malete \& Feltz, 2000; Sullivan et al., 2012).

There are many findings that demonstrate the benefit of formal education on coaching efficacy. First, coaches with high education degrees perceive themselves as more competent. Academic environments, even those that are not sport specific, promote the development of professional competencies (i.e. communication, leadership, problem solving) which may enhance a coach's self-efficacy (Santos et al., 2010). Trudel et al., (2010) examined the effectiveness of large-scale training programs such as Canada's National Coaching Certification Program (CNCCP). In their findings, the authors found that CNCCP positively impacted coaching efficacy, knowledge, and coaching behaviors. Coaches with less experience felt that their coaching development is accelerated through 
formal coach education (Turner \& Nelson, 2009). These findings are supported by Chase et al., (2005) who suggest coach education serves as a source of coaching efficacy.

The benefits of coach education have not been found to evenly apply to the four domains of coaching efficacy. Sport specific education programs that focus on professional knowledge improve game strategy efficacy and technical efficacy. There are some non-sport specific programs that have been shown to benefit motivational efficacy, which will be outlined in the next section. Character building efficacy has not been included in coach education, as most programs are focused on enhancing athletic performance and do not enter the realm of personal development. This is particularly relevant since this study examines an education program that focuses on the development of personal characteristics which then foster improved athletic performance. More research is needed to determine the effects of these specific types of education programs on coaching efficacy and behavior change (Chase et al., 2005).

The findings listed above demonstrate that all types of learning environments can positively impact coaches, particularly regarding coaching efficacy. These findings support the use and benefits of all types of learning environments (i.e. informal, nonformal, formal) in coach education. Research suggests that the single most important factor for all coach education is the need to be grounded in theory (Langan et al., 2013).

Theoretical Basis of Programs. One of the largest criticisms of current coach education is that programs are not theoretically based. Many studies investigating the effectiveness of coach education initiatives either do not provide the theoretical framework of the program, or the intervention is not based on one. There are two primary coach education programs that are theoretically based and have received more 
focus than other programs. These are the Coach Effectiveness Training (CET) program and Mastery Approach to Coaching (MAC) program. CET is designed to enhance coaches' interpersonal skills to create a stronger relationship to their athletes and has been proven effective in its aim (Smith \& Smoll, 1979). It places a strong emphasis on positive versus aversive control of athlete behavior and the use of positive reinforcement (Smoll \& Smith, 2006). In Smith et al.'s (1979) study evaluating the effectiveness of CET, 31 little league baseball coaches were assigned to control and experimental groups. At the end of the season, the athletes revealed that CET trained coaches were better liked and rated as better teachers. The athletes of CET coaches reported having increased enjoyment over the course of the season and had significantly less dropout (95\%) from athletes compared to a control group (74\%) (Barnett et al., 1992). Despite its benefits, recent interest in CET interventions has begun to wane, as the program has proven ineffective at increasing positive psychological outcomes for athletes (e.g. increasing self-esteem, reducing fear of failure and anxiety) (Langan et al., 2013).

The Mastery Approach to coaching is a cognitive behavioral intervention based on achievement goal theory (AGT) and is the most widespread theory within coach education (Langan et al., 2013). Achievement goal theory identifies types of goals (i.e. intrinsic vs. extrinsic; mastery vs. outcome) that direct action (Maehr \& Zusho, 2009). AGT suggests that coaching behaviors effect how children define their success through their goal priorities (e.g. skill development, having fun, winning) (Duda \& Hall, 2001). These coaching behaviors have a significant impact on motivational climate and anxiety levels (Chi, 2004; Duda \& Hall, 2001). The focus of MAC training is on the creation of mastery-based climates where goals are centered on the development of skills. Mastery 
climates minimize social comparison and focus on self-referenced goals, personal development, and task mastery (Duda \& Ntoumanis, 2005; Smith et al., 2007; Walling, Duda, \& Chi, 1993). MAC based interventions are effective at decreasing fear of failure, anxiety, and increasing athlete participation and attendance. MAC programs are delivered in non-formal learning settings, such as workshops. The findings regarding MAC programs demonstrate brief education programs (e.g. $75 \mathrm{~min}$ ) create positive behavioral changes in coaches that effect athletes in beneficial ways (Smith et al., 2007). These findings suggest that coaches experience a change in their ability to effectively motivate and develop the psychological skills of their athletes. This type of program is one aimed at increasing the coach's efficacy, particularly in relation to the domain of motivational efficacy. These types of coach education, which are grounded in research, are effective in changing coach behavior, increasing coaching efficacy, and positively affecting athlete outcomes.

Coach perception of coach education. There is conflicting research regarding coaches' perception of formal learning programs. Traditionally, formal education programs have been looked down upon by coaches when compared to other informal means of acquiring knowledge (Gould, Gianinni, Krane, \& Hodge, 1990). Previously, coaches believed that the material in these courses was too abstract from everyday practice (Lemyre, et al., 2007), gave only a basic understanding of knowledge (Jones, Armour, \& Potrac, 2004), and offered little new information (Gilbert \& Trudel, 1999). Despite these sentiments, feelings regarding these programs have begun to shift. Erickson et al. (2008) found that coaches have a favorable view of education and wish to engage in formal learning. Other studies have found that youth sport coaches view 
formal coach education programs as beneficial to their growth as coaches (VargasTonsing, 2007; Wright, Trudel, \& Culver, 2007). Vargas-Tonsing (2007) found that youth coaches had the most favorable outlook regarding coach education and were the most likely to pursue it.

Responses to Coach Education. Coaches report a variety of responses to coach education. Coaches report that although much of the course content of coach education programs was of interest, not all the information was useful. In Nash's (2003) study, researchers interviewed soccer coaches who had recently completed a coach education program. One coach reported "with the coaching courses, some of the points given are really helpful, but other ideas I have tried and they sometimes don't work, especially in a group of 18 children" (p. 27). Some coaches mentioned that the ideas offered have little basis in reality. In addition to these complaints, coaches stated that education programs focused on the 'what' of coaching (e.g., scientific aspects, new training methods, and recent innovations in tactics/technique) instead of the 'how' of coaching (e.g., interpersonal/intrapersonal skill development) (Nash, 2003).

Coach education may serve to validate coaches' existing practices and behaviors. This confirmation appears related to coaching efficacy. For example, Turner and Nelson (2009) conducted a qualitative study with graduates of a coaching degree program. Graduates of the program reported feelings of increased efficacy, saying "[The education] definitely added value. The knowledge - the way I coach [sic]. I am better now than when I started. I have gained a lot of experience" (p. 17) and "I understand a lot more of what I do now. I can understand the theory - when [the athletes] say 'why,' I can explain. Before I couldn't do that" (p. 17). 
Coaches reported that many coach education and certification programs are far too brief. Coaches indicated these programs give a large amount of information without any talk of implementation, dialogue about the information, or future support. In Nash's (2003) study, a coach was quoted as saying, “it's basically—-here are the skills, try them out, here's your qualification. Thanks for coming, we'll never see you again!!!” (p. 28). This is one view regarding coaching education; the belief that one-off meetings with no follow-up seem to have little effect (Cushion et al., 2010). Emerging evidence, however, shows that one-off interventions grounded in research have positive effects. These include improving athlete goal-orientation, motivational climate, participation, attendance, and decreasing fear of failure, anxiety, and ego-orientation (Barnett et al., 1992; Smith et al., 2007).

As the quantity of coach education programs increase, it becomes valuable to develop a deeper understanding of the perspectives of coaches regarding education. However, there is little research on these perceptions, and the existing findings are typically feedback of recently experienced programs (Cassidy \& Kidman, 2010; Nash, 2003; Sproule, 2012). The effects of a perceived lack of importance of formal qualification in the coaching community have not been investigated. There has been a rise in required coach education programs like certification programs for coaching credentials, yet little research to explore the effectiveness of credentialing. These are important factors to consider when looking at coach education programs and coach education requirements.

One major limitation of coach education research is that there are no studies examining individual variables and the role of the coach in the learning process. The 
field of teaching contains knowledge and understandings which can be applied to the field of coach education regarding how individual variables effect teachers' pursuit of continuing education and its effectiveness (Blunt \& Yang, 2002; Oosterheert \& Vermunt, 2001; Oreg et al., 2008; Stan et al., 2013). Teachers and coaches share many similarities, and findings from research on teachers will guide and inform future research regarding coaches.

\section{Teacher Factors in Professional Development}

Professional learning and development is necessary for all occupations to adapt to the changes occurring in a person's career path (Stan et al., 2013) and is the result of "harnessing formal and informal learning opportunities, which offer the possibility to expand and deepen professional expertise" (Stan et al., 2013, p. 1722). Teachers are expected to embrace life-long learning (Knight, 2002). Research has suggested that teachers learn in different ways and pursue learning experiences related to their professional development at varying degrees (Patton \& Griffin, 2008). Teachers frequently forgo professional learning opportunities (Kwakman, 2003) and many educational innovations fail because teachers eventually abandon new behaviors for older, more comfortable routines (Verloop, Van Driel, \& Meyer, 2001). The personal factors affecting teacher education include attitudes and beliefs towards education, will to learn, dispositional resistance to change, and age and experience (Kwakman, 2003; Oosterheert\& Vermunt, 2001; Oreg et al., 2008).

Attitude and Beliefs towards Education. According to Blunt and Yang (2002), teachers' attitudes towards continuing education are a strong predictor of teachers' participation in continuous training programs. Attitudes towards learning is considered 
multidimensional and is measured on three components; enjoyment, perceived importance, and intrinsic value of learning activities. The authors suggest that educators need to pay more attention to the importance of attitude and the causal framework that ultimately leads to adults seeking educational opportunities.

Another significant factor related to teachers' attitudes towards continuing education is teachers' will to learn. Will to learn is described by Eekelen, Vermunt, \& Boshuizen (2006) as "a psychological state in which the learner has a desire to learn" (p. 410), and is considered a prerequisite for learning to occur in the workplace. This construct is important as coach education is frequently mandated by superiors or national governing bodies. This may result in teachers without the will to learn attending education programs, which may decrease the effectiveness of these programs.

The will to learn impacts education in a variety of ways. First, education programs fail to be effective when existing knowledge is taken for granted and the desire to see new opportunities is absent (Oosterheert \& Vermunt, 2001). Teachers hold strong individual beliefs about what makes up good teaching practices and are influenced by ideas formed early on in their career (Calderhead, 1996). This is similar to coaching, as coaches begin their acquisition of knowledge prior to becoming a coach and learn to coach through past experiences as an athlete (Cushion et al., 2003).

If the will to learn is present, it may lead teachers to begin to experiment with newly learned ideas. This process is called tinkering and has been shown to increase the dissemination and use of new ideas and is strongly related to teachers' will to learn (Hargreaves, 1999). A strong will to learn may also influence reflection-on-action (Schon, 1983), which Gilbert and Trudel (2001) suggest is a powerful factor within the 
world of coach education. Reflection is not guaranteed to change teacher behavior, but when done correctly, increases a teacher's understanding of the new information and helps them incorporate new ideas into their current practices (Schon, 1983). This process involves evaluating previous actions to have improved future outcomes and consists of three parts: reflection on action, reflection in action, and retrospective reflection (Gilbert \& Trudel, 2001; Irwin et al., 2006). The will to learn reflects a disposition to acquire new knowledge, but there are also dispositional characteristics that cause an individual to be open to or resist new ideas.

Dispositional Resistance to Change. There are many continuing education opportunities available for both teachers and coaches. However, attendance of these programs does not guarantee behavior change or improved outcomes. This is partially due to individual's resistance to change their current beliefs and behaviors. Teachers who are resistant to change are much less likely to voluntarily seek out new information/education and are more likely to have a negative view towards making changes (Oreg et al., 2008).

Resistance to change is a multidimensional construct consisting of four factors; routine seeking, emotional reactions to imposed change, short-term focus, and cognitive rigidity (Oreg et al., 2008; Saksvik \& Hetland, 2009). Routine seeking reflects the desire of individuals to enjoy stable environments (Stan et al., 2013; Oreg et al, 2008). Emotional reactions reflect the discomfort an individual experiences when faced with change. Short-term focus is how much an individual "is distracted by short-term inconveniences involved in change, such that they refrain from choosing a rationally 
valued long-term benefit" (Oreg et al., 2008, p. 683). Finally, cognitive rigidity deals with the ease in which people's minds are changed (Oreg et al., 2008; Stan et al., 2013).

Stan et al. (2013) compared teachers' attitudes towards continuous training to dispositional resistance to change. In their analysis, researchers found significant positive correlations between routine seeking and teachers' enjoyment of learning activities. Routine seeking and the perceived importance of adult education were also shown to be positively correlated. According to the authors, these findings suggest higher levels of educational enjoyment and perceived importance of education have already become routine within teachers' lives. The researchers found a negative correlation between the intrinsic value of adult education and short-term focus components suggesting that when teachers have a high intrinsic value of education they become more focused on long-term benefits of training rather than on short-term inconveniences (Stan et al, 2013). This is evident in coaching literature as well. Sproule (2012) suggests that expert coaches will be most likely to learn new techniques and behaviors if they can see the long-term benefits of the learning process.

These findings from teaching literature may help coach educators better understand the mindset of coaches entering coach education programs. Most importantly, these findings demonstrate the importance of showing coaches the long-term benefits of education, and how changing behaviors may positively impact coaching practices and outcomes. This is especially important with more experienced coaches.

Age and Experience. Both age and experience have been demonstrated to play a significant role in a teacher's pursuit of educational opportunities. Generally, teachers with more experience place more importance on continuous training. Despite 
experienced teachers' high appraisal of continuing education; they are less likely to pursue learning opportunities as they get older, especially from mid-career onwards (Richter et al., 2011). Stan et al. (2013) found that more experienced teachers demonstrate both increased routine seeking and cognitive rigidity when compared to their less experienced counterparts. The authors suggest that routine seeking may be a form of insecurity, especially when implementing new technologies in the classroom. The cognitive rigidity component may be the result of strongly embedded personal beliefs that are the result of self-confidence developed through years in the field (Oreg et al., 2008; Stan et al., 2013). Because of their level of expertise in the field, experienced teachers may be less likely to consider new perspectives (Stan et al., 2013).

Wayne, Suk Yoon, Zhu, Cronen, and Garet (2008) wrote a critique on current teaching research addressing several problems that exist in education evaluation. The authors state it is impossible to understand what works, why it works, and for whom it works in education. The authors argue that those teachers who participate in voluntary education opportunities may be different from those that do not. These suggestions, coupled with the attitude and age/experience findings, are extremely significant for educators as they demonstrate meaningful differences in the attitudes teachers hold towards education and how likely they are to pursue it. This is important for coach educators, as it may influence the way individual coaches pursue, absorb, and interact with new information.

Application to Coaching. The findings presented from the literature in teaching have support within the coaching field. It is widely accepted that principles from education may be applied to the coaching education literature. 
In Vargas-Tonsing's (2007) study on coaches' preferences for continuing education, $97 \%$ of all coaches believed that continuing education was important, and $87 \%$ said that it should be required. Despite these numbers only $46 \%$ of coaches stated that they planned to pursue further coach education. These results suggest that although coaches place an importance on education, there are various factors that prevent them from pursuing and/or accessing continuing education opportunities (Stan et al., 2013; Vargas-Tonsing, 2007).

The attitudes and beliefs of coaches are also important in this process. Coaches have been found to pursue educational opportunities for reasons of career satisfaction, necessity, development of knowledge, and intrinsic value (Gauthier, Schienke, \& Pickard, 2005; Robertson, 2005). These reasons greatly overlap with the reasons of teachers. Blunt and Yang (2002) discovered three constructs related to a teacher's pursuit of continuing education; enjoyment, perceived importance, and intrinsic value of learning activities.

Dispositional resistance to change is related to coaches' pursuit of educational opportunities. There are four constructs of dispositional resistance to change; however, the most significant domains in relation to coaching practices may be emotional reactions and cognitive rigidity. Saury and Durand (1998) found that expert coaches employ standardized routines and use well-established cognitive plans to develop their practices and guide their decisions. Many qualitative studies report coaches initially feeling resistant to education programs. In Falcao, Bloom, and Gilbert's (2012) study regarding the impact of coach training, one coach revealed, "Honestly, when we first started doing this I didn't think it was worth the time, worth the effort, and you know, you are going to 
be taking away from my practice time" (p. 439). Leduc, Culver, \& Werthner (2012) found that while some coaches changed elements of their practice, many others expressed unease with applying their learning, and "that they remained in disjuncture" (p. 1). These findings suggest that coaches may experience similar resistance to change as teachers and that this resistance may be related to experience and age.

The Role of Education. Coaches interact and approach continuing education with different attitudes and beliefs. This suggests a need to approach education differently based on the audience. Education in applied settings should increase the effectiveness of practitioners in their field. This means changing teacher behavior to create more favorable student outcomes of achievement. Research has demonstrated that the more preparation and education a teacher receives, the higher their students' achievement will be (National Commission on Teaching and America's Future, 1996).

Coaches are measured on the achievement of their athletes. Performance outcomes are the traditional standard by which coaches are evaluated. Additionally, sport is expected to have positive character and psychological outcomes (Gould et al., 2006; Horn, 2008). Increasing coaching effectiveness is the goal of coach education programs, but the two-dimensional model of performance and personal development makes this difficult. The following section will examine coaching effectiveness models and definitions, and frame these in terms of the current study.

\section{Coaching Effectiveness}

Coaches interested in performance excellence must become proficient at various and distinctive tasks (Cushion et al. 2010; Lyle, 2002). These tasks include tactical aspects of sport performance (i.e. game strategies, decision-making, team guidance, 
technical development, and problem solving) (Nash \& Collins, 2006). There are a variety of processes that extend beyond procedural or technical knowledge. Cushion et al. (2010) describes coaching as "a dynamic and fluid endeavor, inextricably linked to the constraints and opportunities of human interaction.” (p. 2). Coaching is a social process occurring in social environments with a multitude of interpersonal and intrapersonal processes occurring simultaneously (Coté \& Gilbert, 2009; Cushion et al., 2010). Because of these factors, coaching expertise cannot be defined by one-dimensional variables such as years in coaching, win/loss records, or athlete achievement (Coté \& Gilbert, 2009). The coaching effectiveness model created by Coté and Gilbert (2009) focuses on both performance and psychological outcomes of athletics and defines effective coaching in terms of these outcomes.

There have been a variety of conceptual models regarding the coaching process that have been developed. The coaching effectiveness model emphasizes non-traditional and non-sport specific aspects of coaching knowledge. More importantly, the coaching effectiveness model gives a lens to evaluate coaches beyond athletic performance outcomes. This model was selected for the current study, as it gives a framework to understand two directional coaching models focused on both performance and personal outcomes. This will assist in understanding the positive coaching education program outlined later in this section. The coaching effectiveness model has three main components related to coaching effectiveness: coaches' knowledge, athlete outcomes, and coaching contexts.

Coaches' knowledge. Coté and Gilbert's (2009) coaching effectiveness model has its roots in the triad of knowledge proposed by Collison (1996). Collison (1996) 
details three knowledge types: professional knowledge, interpersonal knowledge, and intrapersonal knowledge. Cushion et al. (2010) describes coaching as "a complex sociocultural process that involves a myriad of interaction variables" (p. 1), and relies on the quality of interactions between coach, athlete(s), and context (Cushion et al., 2006). Coté and Gilbert (2009) used Collison's (1996) triad of knowledge to break down the knowledge domains associated with effective coaching.

Professional Knowledge. Coaches' sport specific knowledge is considered "professional knowledge" and refers to the technical knowledge required to coach (Collison, 1996; Coté \& Gilbert, 2009). Many view expert coaching as an accumulation of professional knowledge, with a large emphasis on procedural knowledge (Abraham et al., 2006; Coté \& Gilbert, 2009; Denison \& Avner, 2012). Although professional knowledge has been shown to be a determinant in children's experiences of fun in sport (Visek, Achrati, Manning, McDonnell, Harris, \& DiPiertro, 2015), it is not enough to become an effective coach (Becker, 2009; Rieke, Hammermeister, \& Chase, 2009). Professional knowledge is often delivered and assessed through coach certification requirements in which the National Governing Bodies of various sports certify their coaches through a required education program (Fung, 2003). These types of programs primarily focus on coaching technique and strategy use (Feltz et al., 1999; Fung, 2003) and must be continually updated (Collison, 1996).

Interpersonal Knowledge. Coaches' interpersonal knowledge is essential to athlete performance (Coté \& Gilbert, 2009). The coach-athlete relationship has been shown to be a huge determinant of athletic success (Jowett, 2003; Jowett, 2006; Lorimer \& Jowett, 2009; Zuleger, 2014). Coach-athlete interactions are based on systems of 
complex social interactions that are reciprocal and influence athletic outcomes (Bowes \& Jones, 2006; Cushion et al., 2006; Cushion et al., 2010; Jowett, 2006). The coach-athlete relationship is measured on perceived levels of closeness, commitment, complementarity, and co-orientation (Jowett, 2003; Jowett \& Pocwardowski, 2007). Coté and Gilbert (2009) advocate for the interpersonal dimensions of knowledge, stating "it is important for coaches to continuously develop their interpersonal knowledge base so they can communicate appropriately and effectively with their particular athletes and other people" (Coté \& Gilbert, 2009, p. 310).

Many coaches recognize that their success is based upon their ability to get others to trust in their skills. Effective communication is essential for success and is intrinsically linked with concepts of leadership and good teaching (Santos et al., 2010). The need for strong interpersonal skills is emphasized due to collaboration with support teams including assistant coaches, physiotherapists, and strength and conditioning coaches (Mallet \& Coté, 2006).

Intrapersonal Knowledge. Intrapersonal knowledge greatly affects the ability of coaches to improve their coaching effectiveness and expertise (Coté \& Gilbert, 2009; Cushion et al., 2010; Gilbert \& Trudel, 2001). Researchers believe the primary mechanism of coach learning is through personal interpretations of previous experiences (Cushion et al., 2003; Gilbert \& Trudel, 2001). Without reflection, much of the value of experiential learning is diminished or lost (Cushion et al., 2010). Gilbert and Trudel (2001) created a model in experiential learning that utilizes active reflection to make the most of personal experiences. This process is one of looking back at practice, making sense of what occurred, and learning from these occurrences to become more effective in 
the future. Additionally, Cushion et al. (2010) suggests there is a proliferation of traditional coaching practices in sport, which are passed on to future coaching generations through observation and mentorship. Some of these behaviors are outdated, ineffective, negative, and/or maladaptive. Coaches must learn to critically reflect on current practices to continue their own development. (Cushion et al., 2010; Denison \& Avner, 2012). Intrapersonal skills include having a disposition toward continuous learning, being reflective, having a well-developed ethic of care, and demonstrating a strong work ethic (Collison, 1996).

Effective coaching relies on more than technical or tactical knowledge of sport. Unfortunately, the assumption is that the primary requirement to become an effective coach is high levels of professional knowledge (Coté \& Gilbert, 2009). This finding is supported by the fact that professional sport organizations rarely hire coaches who were not former elite athletes themselves (Mielke, 2008). Due to high levels of athlete abuse and the use of detrimental traditional coaching behaviors, coaching skills must extend beyond the traditionally valued beliefs and knowledge of current coaches. Because of the need for these changes, education programs that emphasize interpersonal and intrapersonal skill development will help coaches recognize the shortcomings of their currently held beliefs. As a result, coaches will learn to work towards positive psychological outcomes for athletes in addition to performance.

Athlete outcomes. Horn (2008) discusses two broad outcomes of effective coaching practices. First, performance outcomes are the traditional standard by which coaches are judged. These are measured by winning percentage or athletic development and improvement. Secondly, effective coaching must have positive psychological 
outcomes on the part of the athlete (e.g. high self-efficacy, self-esteem, intrinsic motivation, sport enjoyment). These outcomes are supported by Jowett's (2006) appraisal that coaches should be focused on enhancing athletic performance as well as the athlete's personal satisfaction. The Positive Coaching Alliance, a coaching education initiative, refers to coaches concerned with both athletic and psychological outcomes as a “double-goal coach" (Thompson, 2010). Thompson (2010) defines a double-goal coach as a coach who wants to win but seeks to use sport as a medium to teach life lessons. The goal of this process is to foster psychological well-being, which will result in improved performance outcomes.

In the coaching effectiveness model, Coté and Gilbert (2009) took the broad themes of performance and psychological outcomes and divided them into different categories. These categories, which are athlete competence, confidence, connection, and character, include aspects of both athletic performance outcomes and positive psychological outcomes (Coté et al., In press). These categories are consistent with findings in sport literature as being representative of desirable outcomes of athletes in the sport environment (Coté et al., In Press).

Athlete Competence. The effect of coach behaviors on athlete competence is well researched. Athlete competence is understood in terms of athletic performance and as a component of psychological development. The Leadership Scale for Sport (LLS) has served as the primary tool to understand how coaching behavior effects athlete outcomes (Chelladurai, 1993; Chelladurai \& Reimer, 1998). It contains five dimensions: training and instruction, democratic behavior, autocratic behavior, social support, and positive feedback (Sullivan \& Kent, 2003; Chelladurai \& Saleh, 1980). 
First, training and instruction (i.e. professional knowledge) is positively related to indices of an athlete's perceived competence (Amorose \& Horn, 2001). This is an example of how increased professional knowledge can benefit athletes. Democratic behaviors allow for athlete participation in the decision-making process and result in high levels of athlete satisfaction and perceptions of autonomy (Celladurai, 1993; Celladurai \& Saleh, 1980; Hollembeak \& Amorose, 2005). Autocratic behaviors have been associated with lower levels of athlete satisfaction, feelings of improvement, and confidence (Rieke \& Hammermeister, 2008). Social support is a determinant of athlete participation, as feelings of relatedness are an essential need related to achievement (Ryan \& Deci, 2000). In terms of interpersonal skills, findings show that positive feedback delivered appropriately has a positive impact on perceived competence (Amorose \& Horn, 2001; Horn, 2005). Research has demonstrated that athletes use a variety of sources to assess their competence, including performance outcomes, personal statistics, learning, and goal achievement (Horn \& Amorose, 1998; Hollembeak \& Amorose, 2005). Coaches must learn to manipulate these sources and the athlete's perception of these constructs to create higher levels of efficacy. Coaches provide guidance as athletes carry their competence and confidence back into the real world and become higher functioning members of society (Horn, 1987).

Confidence, connection, and character. There has been a shift in the importance of character development within coaching practice. Increasingly, coaches believe it is their role to develop positive psychological and social characteristics within their athletes. Beneficial coaching behaviors rooted in positive psychology can positively affect the personal development of athletes (Morton, 2014; Thompson, 2010). Several 
organizations have emerged that combine the themes of positive psychology with coaching practice. This has resulted in coaching populations with increased tools to enhance athletes' personal growth and development.

According to Coté and Gilbert (2009), "the coach-athlete relationship influences athletes' confidence and should be at the forefront of coaching strategies in any coaching contexts.” (p. 313). Additionally, studies using the Leadership Scale for Sport suggest that coaches' knowledge and behaviors have a direct impact on the athlete's psychological profile, effecting self-esteem, satisfaction, perceived competence, autonomy, relatedness, and intrinsic motivation (Amorose \& Anderson-Butcher, 2007; Chelladurai, 1993).

Coaches can foster positive psychological outcomes associated with sport participation. For instance, coaches can positively impact autonomous motivation and develop higher levels of intrinsic motivation through offering choices and praise (Amorose \& Anderson-Butcher, 2007; Ryan \& Deci, 2000). In their study on the effect of autonomy support on athlete motivation and performance, Amorose and AndersonButcher (2007) offered recommendations for increasing athletes' feelings of autonomy. These recommendations included offering choices to the athlete, minimizing controlling and threatening language, creating meaningful rationales for decisions, and acknowledging athletes' feelings and perspectives. In another study, Zuleger (2014) examined Olympic medal winners and their relationship with their coach. His findings support the recommendations of Amorose and Anderson-Butcher (2007). Zuleger (2014) found that the coaches in these relationships created environments that were characterized by empowering effective decision-making on the part of the athlete, open 
and honest communication, and the simplification of communication. In this study, coaches viewed the success of the athlete as contingent upon the ability to be autonomous. One coach even mentioned, "I have made it clear to him that these are all decisions that he ultimately is going to have to live with and feel good about" (Zuleger, 2014, p.59). Coaches believed the decision-making component developed the athlete's confidence, as athletes may have limited access to their coaches during the Olympic Games and may be forced to make decisions on their own.

Matosic and Cox's (2014) study examined how five perceived coaching behaviors, such as autonomy support, controlling use of rewards, negative conditional regard, intimidation, and excessive personal control, affected psychological outcomes in college athletes. The researchers found that when athletes perceived their coaches as having high levels of autonomy support, the athletes experienced the greatest level of psychological need satisfaction (i.e., autonomy, relatedness, and competence). The development of autonomy supportive environments created positive performance outcomes, as athletes were more motivated in their sporting experience.

Jowett and Pocwardowski (2007) developed a relationship model that characterizes the coach-athlete relationships. The $3 \mathrm{C}+1$ model measures levels of commitment, closeness, and complementarity, as well as co-orientation. In this context, effective coaches try to create caring relationships and create environments where athletes have opportunities to connect with others. Zuleger (2014) had similar findings to Jowett and Pocwardowski (2007) and described the relationships he observed as caring relationships with developed trust, an other-centered approach, and enhanced by the coach's passion. Developed trust was fostered by development over time, consistency, 
and a sense of commitment. Zuleger's (2014) study demonstrated that certain relationship dynamics are central to performance outcomes and to the personal and psychological development of the athlete.

Relationship quality between coach and athlete has been shown to predict an athlete's fear of failure (Sagar \& Jowett, 2015). When an athlete perceived their relationship with their coach as anxious or avoidant, the athlete experienced less basic need fulfillment (e.g. competence, autonomy, relatedness) (Felton \& Jowett, 2015). These findings demonstrate the importance of interpersonal skills, as they are a critical component related to athlete performance and psychological development.

The role of character development continues to be a key theme within coach education, as there are a variety of benefits to sport participation other than sport related constructs. Parents of young athletes expect sport participation to result in improved character and psychological skills (Rudd, 2005). Sport participation has been shown to result in higher grades, increased academic orientation, expectations, goal-attainment, confidence, self-esteem, connections and relationships with others, family attachment, assertiveness, emotional control and regulation, self-efficacy, well-being, fewer depressive symptoms, general health perceptions, life satisfaction, mental health, and avoidance of risky behaviors (Jeziorski, 1994; Linver, Roth, \& Brooks-Gunn, 2009).

In Gould et al.'s (2006) study, researchers surveyed coaches on coaching objectives, the role of sport in character development, and current problems in sport. To assess coaching objectives, coaches ranked four general objectives in order of importance. "The four general objectives included: (1) to have a winning team; (2) to help young people have fun; (3) to help young people develop physically and learn 
physical skills; and (4) to help young people develop psychologically and socially" (Gould et al., 2006, p. 31.). Coaches predominately ranked having young people develop psychologically and socially as the most important (42.5\%), followed by helping young people develop physically and learn physical skills (28.8\%). Helping young people have fun being ranked as third in importance (18.3\%). Only $11.8 \%$ associated having a winning team as the most important.

In the same study, researchers also asked coaches to rate the character benefits of high school sports. The resulting categories ranked in order of importance included teamwork, value of hard work, time management, goal setting, citizenship/abiding by the rule of society, motivation to be physically active, respect for self, self-control, competing fairly, respect for others, winning gracefully, fairness, accepting defeat, and not holding grudges. Coaches also revealed the problems encountered in high school sport, which included failures to take personal responsibility, lack of motivation/work ethic, poor communication skills, athletes having problems with parents, poor grades, poor leadership, trash talking, poor goal setting, alcohol use, poor stress management, and lack of respect toward coaches, officials, and other athletes (Gould et al., 2006). Other studies that investigated coaches' preferences in education found that coaches preferred education that featured topics such as communicating with parents and athletes, motivational techniques, and character building (Vargas-Tonsing, 2007). Coaches place primary importance on the psychological and social development of youth athletes (Gould et al., 2006; Vargas-Tonsing, 2007). These findings confirm the need for the twodimension model of coaching effectiveness and for coach education that goes beyond professional knowledge. 
Coaching contexts. The context of coaching is subject to a variety of factors. The process of identifying and labeling contexts is challenging. Contexts are considered permeable and all have unique characteristics. For instance, the developmental needs of athletes are considered context specific and differ across sports and participation levels (Bowes \& Jones, 2006).

Sport contexts are typically divided into two main categories: participation and performance (Lyle, 2002). Participation contexts do not emphasize athletic performance, outcome, and/or winning. In these contexts, athletes are less intensively engaged, and outcomes are centered on short-term goals, enjoyment, and positive health outcomes. Performance contexts revolve around preparation geared towards positively influencing athletic outcomes. The styles of coaching required for each performance context differ and coaches must be aware of their skills, behaviors, and the context with which they are operating in (Chelladurai, 2007; Lyle, 2002). The coach's effectiveness should be evaluated based on the coaching context.

Different coaching contexts require different styles of leadership. First, coaches involved with beginners or young athletes draw upon different bodies of knowledge than expert coaches, since they are more likely to have a profound effect on psychological and social growth as well as motor development (Coté \& Fraser-Thomas, 2007). This may be especially relevant since the current study focuses on high-school coaches. Athlete personality is another factor that must be considered. The coach's ability to change their leadership style based on the personalities of their athletes has been demonstrated to impact athlete success (Celladurai, 2007; Giacobbi, Whitney, Roper, \& Butryn, 2002). Athletes on successful teams perceived their coach to use the same amount of training 
and instruction throughout the season. Conversely, athletes on unsuccessful teams perceived a significant increase in their coaches' use of autocratic leadership behaviors over the course of the season (Turman \& Nelson, 2001). While it is necessary to tailor the coaching style to situational and individual needs, successful teams have coaches who are consistent in their approach and leadership styles.

The findings of Chelladurai (2007) and Giacobbi et al. (2002), emphasize the importance of the interpersonal and intrapersonal skill development of coaches. The levels and types of interpersonal and intrapersonal skills required of different sport contexts and situations may be different (Coté \& Gilbert, 2009). It is important that coaches be able to critically reflect on their sporting context and evaluate how to best interact with athletes in their specific environments.

\section{Positive Coaching}

The field of positive coaching is still early in its development. Positive coaching, which is heavily influenced by the field of positive psychology, focuses on individual strengths and values and helps improve well-being through sport participation. Positive coaching incorporates the principles of positive psychology into coaching theory to create a behavioral model for coaches. This behavioral model focuses on building strong and flourishing individuals, who will then perform well in athletics. Positive coaching is best defined by Woods (2016), who characterized positive coaching as the "blending of the concepts of positive psychology into the theoretical and empirical research on coaching leadership behavior, motivation, and training techniques to form a strengths-based coaching model" (p. 2). This approach stands in contrast to many sporting environments that are predominately concerned with improving performance through focusing on the 
improvement of weaknesses. Overall, the integration of positive psychology practices into athletics has been shown to positively impact athletes and foster positive emotions, engagement, relationships, meaning, achievement, and performance outcomes (Morton, 2014; Nicolas, Gaudrea, \& Franche, 2011). Positive coaching is not confined to a single age or sport context, and proponents of the program recommend its use at all levels of sport.

The frequently used term of "positive coaching" is a term that implies that coaching should be evaluated through multiple lenses. The reference of "positive" is not confined towards understandings of positivity. Rather, the term positive is used to refer to coaches who are concerned with more than competitive outcomes and intend to have a positive influence on athletes' lives. As outlined by Thompson (2010), the definition of positive coaching revolves around a concept referred to as the double-goal coach. Double-goal coaches strive to win and create positive performance outcomes and focus on the development of positive character traits, mental skills, and emotional outcomes. The current study will consider positive coaching as it is presented by the Missouri Institute for Positive Coaching (MIPC). The MIPC defines positive coaching as the sum of its 29 guiding principles, which will be outlined later in this section. The MIPC model of positive coaching is grounded in the coaching effectiveness model introduced earlier by Coté and Gilbert (2009).

Although positive coaching has a dual focus on performance and psychosocial/ emotional development there are specific domains that are unique to this style of coaching. In his review of positive coaching practices and literature, Woods (2016) identified three primary domains of positive coaching which include (a) leadership and 
relational style, (b) motivation, and (c) positive psychology. The next section will consider each of these domains in terms of the current literature and the Missouri Institute for Positive Coaching's curriculum.

Leadership and Relational Style. The role of the coach in constructing and delivering the athletic experience has been a focal point in research literature for a considerable time. There is no shortage of research that demonstrates the importance of the coach's relational style and its effect on the athlete experience (Jowett \& Lavallee, 2007; Chelladurai, 1978). Additionally, leadership skills have also been demonstrated to be a large source of coaching efficacy (Chase et al., 2005). Leadership style is primarily concerned with athlete satisfaction, self-esteem, and motivation to reach performance goals. Leadership and relational styles are inextricably linked with the interpersonal dimensions of coaching effectiveness (Coté \& Gilbert, 2009). These styles together contribute to four broad areas of development within the athlete. These areas include (a) intrapersonal development, (b) interpersonal development, (c) psychosocial development, and (d) sport-specific development (Jowett \& Chaundy, 2004; Jowett, 2003, 2004, 2006; Woods, 2014). These areas are central to the concept of both coaching effectiveness and positive coaching.

Leadership Styles. There are several models of leadership that relate directly to definitions of coaching effectiveness and positive coaching. These models include transformational and transactional leadership, servant leadership, and democratic leadership.

Transformational/transactional leadership. When considering coaching models, there have been few behavioral models that encapsulate the full scope of coaching 
behavior and the effect of this behavior on athletes. Many studies are limited by examining the behavior of "elite" or "expert coaches" (Cushion et al., 2010). Leadership, as defined by Northouse (2004), is a process of social influence in a group setting that results in the achievement of goals or objectives. Sport psychology literature has often considered leadership on a continuum with three types of styles: transformational, transactional, and laissez-faire behaviors (Bass, 1985). Others have presented laissezfaire behaviors as merely a type of transactional leadership (Nyberg, Bernin, \& Theorell, 2005). Transformational leaders inspire and motivate others, create an idealized influence, have an individual consideration, and stimulate intellectually. Transformational leaders attempt to alter awareness, introduce a vision, establish a mission, and transform an organization and its members (Bass \& Steidlmeier, 1999). Transformational leadership has been shown to have a positive effect on followers' motivation, commitment, and satisfaction (Bass \& Riggio, 2006; Price \& Weiss, 2013). These outcomes are consistent with the double goal nature of positive coaching and represent positive psychological outcomes associated with the sporting experience.

Transactional leadership can be separated into four categories: (1) contingent reward, where the leader uses rewards and incentives to achieve desired results; (2) passive management by exception: criticism, reprimands, and corrections are a response to undesirable behaviors; (3) active management by exception, where a leader constantly supervises and manages behavior to ensure successful results, and (4) laissez-faire behavior which is the absence of leadership (Nyberg et al., 2005; Price \& Weiss, 2013). Transactional types of leadership have been associated with autocratic leadership, in which a coach stresses authority and strict compliance (Chelladurai \& Saleh, 1980). 
Athletes with coaches high in transactional leadership report lower satisfaction (Chelladurai \& Saleh, 1980) and lower perceptions of autonomy (Hollembeak \& Amorose, 2005).

The Missouri Institute for Positive Coaching (MIPC) implements transformational leadership directly from the literature. MIPC states that the positive coach "has a clear understanding of the mission, the visions, and the purpose for the future of the company, or the group, and for their "Team." The Transformational Leader then shares this mission, vision and purpose, with great passion, emotion and enthusiasm, with his or her team" (http://mopositivecoaching.org).

This type of leadership is built into the foundation of the program and can be found in the principles like "develop and shape a coaching philosophy," "develop the realization that nothing of any real value is ever achieved without hard work and dedication," and "develop and foster the sense of meaning and purpose" (http://mopositivecoaching.org).

The program teaches seven key elements related to transformational leadership. These elements are having a mission/vision, creating shared goals/standards, transformation of leader/followers, individualized consideration, intellectual stimulation, inspirational motivation, and idealized influence (McGuire, 2012, 2016; http://mopositivecoaching.org). These elements represent the core of transformational leadership, and demonstrate its role within the Missouri Institute for Positive Coaching curriculum.

Democratic leadership. Democratic leadership is one of five dimensions featured on the Leadership Scale for Sport (Chelladurai \& Saleh, 1980). Democratic styles of leadership allow for athlete participation in the decision-making process (Chelladurai, 
1990; Chelladurai \& Saleh, 1980). This results in higher levels of athlete satisfaction (Chelladurai \& Saleh, 1980) and athletes' perception of autonomy (Hollembeak \& Amorose, 2005). The democratic leadership model has a significant limitation as it is not multi-dimensional and only focuses on the availability of decision-making opportunities presented to athletes by the coach. Although democratic leadership does not contain a performance aspect it represents a leadership behavior that is concerned with athlete involvement and well-being. Because of its focus on creating autonomy and athlete satisfaction, it is included with this discussion of positive coaching.

The Missouri Institute for Positive Coaching advocates for the creation of choice for athletes and a focus on athlete well-being. This can be considered as a shift towards democratic leadership styles. Democratic leadership can be found in the principles of the program like “create and nurture each individuals' self-worth and self-esteem, promote and protect the priority of each individual's well-being and happiness," and "develop self-confidence by allowing individuals to make decisions for oneself, about oneself, and by oneself" (http://mopositivecoaching.org).

When considering each of these principles the program recommends very specific actions for each statement. For nurturing self-worth, the program advocates for fostering feelings of competence, achievement, and acceptance with the athletes. Protecting wellbeing is accomplished by creating balance within the athletic environment, especially considering many of the athletes that coaches work with are also students. Finally, the program advocated for coaches to allow their athletes to make more decisions. The MIPC program states that when coaches allow more opportunities for the athletes to make decisions, athletes will learn to make better decisions in the future and in high- 
pressure environments. Additionally, the increased choices given to athletes will help foster intrinsic, internal, and approach motivation. This is in line with self-determination theory where autonomy is a key component of intrinsically motivated individuals (Ryan \& Deci, 2000),

The Servant Leader. The servant leadership model is an athlete-centered "upsidedown" leadership model taken from management and organizational contexts and applied to sport psychology (Rieke \& Hammermeister, 2008). A servant leader is someone who places another individual's needs, aspirations, and interests above their own (Greenleaf, 1977). The emphasis is that those being led are of the primary importance, while the leader is seen to be the least significant. In the sporting context, this translates to the idea that the athlete comes first (Rieke \& Hammermeister, 2008). Dimensions of servant leadership include building community, stewardship, awareness, foresight, listening, conceptualization, healing, empathy, persuasion, and commitment to the growth of people.

Servant leadership is measured through the use of the Revised Servant Leader Profile (RSLP), which includes measures of power and pride (the inverses of the measure of a servant leader), the serving of others, the empowerment and development of others, and levels of participatory leadership, courageous leadership, inspiring leadership, and visionary leadership (Page \& Wong, 2000; Rieke \& Hammermesiter, 2008). Hammermeister, Burton, Pickering, Chase, Westre, and Baldwin (In Press) conducted a study using the servant leadership model to assess how coaching behaviors impacted multisport college athletes' levels of intrinsic motivation, mental skills, and sport satisfaction. Hammersmeister et al. (In Press) found that athletes coached by servant 
leaders had significantly higher levels on all three constructs compared to those coached by "non-servant" leaders. Rieke and Hammermeister (2008) duplicated this study with high school basketball players. First, they found athletes with servant coaches had higher levels of satisfaction and felt they were improving with training and instruction. Second, athletes coached by servant coaches had higher levels of intrinsic motivation, goal-setting ability, self-confidence, and commitment. Third, trust and inclusion was a key factor in athletes' team performance expectations. A significant positive correlation was found between trust/inclusion and seasonal wins.

In Hammermeister et al.'s (In Press) study another type of leadership emerged. This type of leadership was identified as the benevolent dictator. This coaching style involves a coach who develops relationships and serves the athletes on their team, but still exhibits power and control. Both benevolent dictators and servant coaches enhanced athlete satisfaction and had athletes with higher levels of interest, enjoyment, and competence. However, while athletes coached by benevolent dictators had increased perceived competence, they also had more tension and pressure. Athletes coached by servant leaders had stronger task orientation, resulting in more self-confidence (Hammermeister et al., In Press).

The findings of Hammermeister et al. (In Press) and Rieke and Hammermeister (2008) demonstrate the effectiveness of the servant coach leadership model and the need to consider the extent to which a coach looks to serve his athletes. The servant coach model fits within the effectiveness and positive coaching models as the servant leader creates both positive athletic and psychological outcomes. Servant leadership is supported by the findings of Jowett and Cockerill (2003), who found that athlete-centered 
relationships are high in many variables that serve as powerful predictors of success. These include mutual respect, trust, care, concern, support, open communication, shared knowledge, and understanding.

More importantly, leadership behaviors have been found to be most effective when they are consistent over the course of a season (Turnman, 2001). It is necessary for a coach to solidify their coaching style and leadership behaviors and maintain consistency. This lends support to positive coaching as a style of coaching with guidelines for behavior and leadership, which can help foster continuity in coaching behavior over time.

The Missouri Institute for Positive Coaching places the athlete's experience and well-being at the center of the athletic experience. The program states goals of nurturing the self-esteem of athletes, promoting well-being, cooperating with athletes, and showing gratitude towards athletes (McGuire, 2012, 2016; http://mopositivecoaching.org). The servant leadership model can by summarized in the following quote from the MIPC program:

"people who are focused primarily on giving, on sharing of themselves with others, always have total control over their giving. They control who they give to, what they give, how much they give, how often they give, and, most importantly, they control why they give. Whenever people give of themselves unconditionally, they always feel great about themselves, and they rarely feel frustrated. "Unconditionally" here means that they are giving with no expectation of "getting" anything in return" (http://mopositivecoaching.org). 
The program also encourages consistency in leadership behavior, as recommended by Turnman (2001). First, the program insists that coaches develop a coaching philosophy to serve as the foundation of their actions. Secondly, the principles suggested by the program guide coaching style and behavior. This has the potential to create consistency in behavior and leadership style throughout the season.

Relational Style. Research demonstrates the coach-athlete relationship's effects on performance and psychological outcomes. In his study on Olympic track and field medalists, Zuleger (2014) uncovered significant factors related to the performance of the coach-athlete dyad. The relationships he investigated demonstrated the importance of the elements of developed trust, an other-centered approach, and the coach's passion. Developed trust was characterized as being consistent throughout the relationship, involving high levels of commitment to each other, and as being developed over time. Other-centered approaches involved the coach focusing on the needs of the athlete and putting the athlete first. The coach's passion was identified as being central to positive performance outcomes, as well as personal and psychological development. These findings are consistent with other literature regarding the formation and maintenance of a positive coach-athlete dyadic relationship. It is important to consider aspects of the coach-athlete relationship and relationship strategies, as interpersonal relationships are a key element of positive coaching.

The Coach-Athlete Dyad. Poczwardowski and Jowett (2007) developed the 3C+1 model to help describe the coach-athlete dyad. The $3 \mathrm{C}+1$ model was created within the Integrated Research Model of the Coach-Athlete Relationship, which consists of antecedents, components, and outcomes. Antecedents are the factors individuals bring to 
their relationships. These include the coach's and athlete's gender, previous experiences, and the values they each desire in a relationship. Components include coach and athlete behaviors, feelings, improvements, and maintenance strategies. Finally, outcomes include performance results and personal satisfaction with the relationship (Jowett \& Poczwardowski, 2007).

Developed within this research model, the $3 \mathrm{C}+1$ model consists of closeness, commitment, and complementarity (Jowett, 2003, 2006). Closeness is defined as feeling familiar with the other member in the relationship, while commitment refers to a willingness to stick with the other partner and manifests through trust. Complementarity is a type of behavioral interaction in which both individuals in the relationship work towards a common goal (Jowett \& Poczwardowski, 2007). These 3 C's reflect how individuals perceive the relationship's effectiveness, quality, and characteristics in the context of the relationship. The $3 \mathrm{C}$ model gave researchers a theoretical framework to understand and describe the coach-athlete dyad (Jowett \& Ntoumanis, 2004; Jowett, 2006). Co-orientation was later added to the model and is concerned with metaperspective (e.g. how an individual thinks another person feels about them). This " $+1 \mathrm{C}$ " focuses on how the athlete perceives the state of the first three C's as viewed from the coach's perspective. Research has shown that the perception of the state of the relationship is as important as the quality of the relationship itself (Jowett \& Poczwardowski, 2007).

Olympiou, Jowett, and Duda (2008) investigated how the coach-athlete relationship affected motivation levels in athletes. They looked at athletic populations from a variety of sports and competitive levels ranging from international to recreational. 
The researchers used the Perceived Motivational Climate in Sport Questionnaire (PMCSQ) and the Coach Athlete Relationship Questionnaire and discovered that climates promoting role importance, cooperation, and improvement, resulted in athletes experiencing higher levels of closeness, commitment, and complementarity with their coach (Olympiou et al., 2008). On the other hand, coaches who were ego involved and created environments featuring punitive responses to mistakes, rivalry, and unequal recognition decreased the athlete's perception of closeness, commitment, and complementarity.

Both leadership and relational styles play a significant role in mediating athlete outcomes. These are integral components within the coaching effectiveness model. As such, these topics form a foundational component of positive coaching. The Missouri Institute for Positive Coaching (MIPC) teaches a variety of principles related to creating effective relationships with athletes. In the MIPC's chapter called "Cultivating positive and caring relationships," positive relationships are characterized by respectful communication, developing a sense of cooperation, utilizing positive instruction/responding, and sharing gratitude.

The program offers specific recommendations for each aspect of these principles. First, respectful communication can be maintained by remaining composed and keeping language positive during stressful situations. Developing a sense of cooperation is described as working with others so that everyone can improve. Positive instruction/responding is about focusing on desired behaviors instead of errors/mistakes. Finally, gratitude can be expressed by thanking athletes for their efforts daily (McGuire, 2012, 2016; http://mopositivecoaching.org). This has been demonstrated to be an 
effective relationship maintenance strategy which can help relationships sustain difficult times (Morton, 2014).

Motivation. Motivation is a key domain within positive coaching. The goal of all coaches is to create highly motivated athletes who have a strong inner desire (i.e., intrinsic motivation) to be involved, compete, and achieve in sport. Motivation has been shown to lie on a continuum. On one side is intrinsic motivation, where the joy of participation serves as the only reward. On the other side are varying levels of extrinsic motivation, where motivation comes from outside the inherent rewards of participation. These frequently include monetary rewards, trophies, medals, social recognition, and others.

Self-Determination Theory (SDT) proposes that to have intrinsically motivated athletes, three basic needs must be fulfilled. These needs are autonomy, relatedness, and competence (Ryan \& Deci, 2000). Autonomy refers to the ability to make decisions for and about oneself. When these opportunities are present, the result is known as autonomous motivation. This has been shown to be fostered through positive feedback, the creation of meaningful rationales, acknowledging the athlete's perspective, and minimizing threatening language (Matosic \& Cox, 2014; Ryan \& Deci, 2000). These behaviors are directly related to positive coaching practices, as positive coaches attempt to create intrinsically motivated athletes by creating meaningful rationales, using active constructive responding, and providing positive feedback (McGuire, 2012, 2016).

There has been a variety of research that supports the use of autonomy supportive environments and its benefit on performance. In Zuleger's (2014) investigation into the coach-athlete relationship of Olympic medal winners in track and field, he found that 
these relationships were characterized by autonomy supportive environments, caring relationships, and mental strength. Specifically, autonomy supportive environments were characterized by three subthemes: (1) empowering effective decision-making, (2) open and honest communication, and (3) the simplification of communication. Coaches in Zuleger's (2014) study viewed the athlete's success to be contingent on their ability to be autonomous.

Open and honest communication was defined as the ability of the coach and athlete to effectively communicate their thoughts and feelings without fear of consequence. Coaches described this process as central to the athlete's ability to be independent. The process also fostered feelings of relatedness and trust in the coachathlete relationship (Zuleger, 2014). Keeping communication simple was defined by concise technical and strategic guidance, as well as large amounts of support, encouragement, and affirmation. Athletes had a role in the development of communication cues, which furthered their sense of autonomy and control of their experience.

Matosic and Cox's (2014) study examined how five perceived coaching behaviors (i.e., autonomy support, controlling use of rewards, negative conditional regard, intimidation, and excessive personal control) affected the psychological and performance outcomes of college athletes. When athletes perceived their coaches as having a high level of autonomy support, they experienced the greatest level of psychological need satisfaction (autonomy, relatedness, and competence). The development of these autonomy supportive environments created positive performance outcomes as athletes 
were more motivated. Additionally, athletes also experienced increased psychological benefit through the fulfillment of basic needs (autonomy, relatedness, and competence).

The Missouri Institute for Positive Coaching (MIPC) teaches coaches to foster motivation in athletes in a variety of ways. The construct of motivation is evident in the MIPC principles of "develop intrinsic, internal, approach, and positive motivation," and "develop the desire to strive wholeheartedly toward personal excellence" (McGuire, 2016, p. 25; http://mopositivecoaching .org). The program offers recommendations to give choices, focus on positive outcomes, and avoid the use of extrinsic motivators. Also, it encourages coaches to create experiences that influence the development of a desire to improve and to celebrate these improvements. The program advocates for the use of praise, which has been shown to be an effective tool in fostering autonomous motivation (Matosic \& Cox, 2014).

\section{Positive Psychology}

Positive Psychology has recently emerged as a response to the existing sicknessbased models of psychology. In these sickness-based models, psychologists are predominately concerned with fixing existing conditions, disorders, and problems, rather than focusing on maximizing an individual's wellness (Seligman, Steen, \& Peterson, 2005). Sheldon and King (2001) described positive psychology as "the scientific study of ordinary human strengths and virtues." Positive psychology urges "psychologists to adopt a more open and appreciative perspective regarding human potentials, motives, and capacities." (p. 216). Ultimately, positive psychology is concerned with the study of positive subjective states, positive individual traits, and positive institutions (Seligman \& Csikszentmihalyi, 2000). This perspective has resulted in the creation of well-being 
theory (Seligman, 2011), which assesses five measurable traits related to human flourishing. These traits include positive emotion, engagement, relationships, meaning and achievement (PERMA).

PERMA. The acronym PERMA has become one of the foundational cornerstones of the positive psychology movement. The elements of PERMA were determined by three properties including: (1) the elements that contribute to well-being, (2) people pursue the elements for their own sake, (3) and are defined and measured independently of the other elements (Seligman, 2011).

Positive Emotion and Engagement. The first two elements of PERMA, positive emotion and engagement, are the subjective variables of the model. Positive emotions consist of both happiness and life satisfaction and are measured in the moment. This is frequently referred to as the "happiness" component of well-being. Engagement is measured retrospectively by answering questions like "did time stop for you?" and "were you completely absorbed by the task?" This concept ties into flow states which are described as:

“a sense that one's skills are adequate to cope with the challenges, at hand, in a goal-directed, rule-bound action system that provides clear clues as to how well one is performing. Concentration is so intense that there is no attention left over to think about anything irrelevant or to worry about problems. Self-consciousness disappears, and the sense of time becomes distorted. An activity that produces such experiences is so gratifying that people are willing to do it for its own sake" (Csikszentmihalyi, 1990, p. 71). 
Positive coaching incorporates these findings into its principles, as coaches "promote and protect the priority of each individual's well-being and happiness," (p. 192) and "emphasize engagement in the process" (McGuire, 2012, p. 193).

Relationships. Relationships have been shown to be one of the most powerful predictors of life-satisfaction. For example, individuals who are married consistently report high levels of happiness, life-satisfaction, and subjective well-being (Argyle, 1987; Myers, Feltz, Chase, Reckase, \& Hancock, 2008; Oishi, Schimmack, Diener, \& Suh, 1998). Happier people tend to be more social, active, energetic, and have better interpersonal relationships (Lyumbomirksy, Kind, \& Diener, 2005). Other research has demonstrated feelings of connectedness are essential to intrinsic motivation (Ryan \& Deci, 2000) and are even related to athletic performance. The Missouri Institute for Positive Coaching provides guidelines and recommendations for creating meaningful relationships, stating the need to "communicate respectfully with those you lead, just as you would wish to be communicated with by those who lead you," as well as, "develop a spirit of cooperation" (McGuire, 2016, p. 25).

Meaning. Meaning is defined by Seligman (2011) as belonging to and serving something bigger than the self. It is measured as both a subjective and retrospective state. The objective judgments of history, logic, and opinion can override the subjective assessment that a previous experience was meaningful. Meaning is different from the other constructs related to well-being, since not all meaningful experiences will elicit positive emotions. For instance, someone may loathe writing a doctoral dissertation but still experiences a deep sense of purpose as they write it. For many, meaning may manifest as serving a higher purpose in life, and it can be obtained through a variety of 
avenues. For instance, researchers have demonstrated that religiosity, which provides a strong sense of meaning and purpose in someone's life, is related to a variety of health benefits (Emmons, 1999). Other studies have shown that individuals who pursue a variety of meaningful goals report higher levels of life-satisfaction (Oishi et al., 1998). Sport may provide these types of opportunities for meaning if the environment is cultivated correctly.

Positive coaching contains several recommendations for meaning within the sporting context, as coaches are encouraged to "foster a sense of meaning and purpose," and "to develop the desire to strive wholeheartedly toward personal excellence" (p. 193). Individuals are taught "that nothing of any real value is ever achieved without hard work and dedication" (McGuire, 2012, p. 193). These principles help guide the coaches' understanding of the value of meaning in the athletic process.

Accomplishment. Seligman (2011) states that individuals strive to achieve things for their own sake. In this regard, people engage in activities solely to master the task. Others have goals related to performance outcomes but are still heavily invested in activities to master skills. Accomplishment is related to the basic need of competence within self-determination theory (SDT). In order to fulfill the need of competence, individuals must accomplish certain levels of mastery and outcomes. Ryan and Deci (2000) have shown that when the three basic needs of SDT are met, individuals will see increases in intrinsic motivation, life satisfaction, performance, and well-being.

Positive coaching promotes feelings of accomplishment by teaching the value of hard work and by celebrating individual achievement and success at all levels (McGuire, 2012, 2016). It also differentiates between winning and the definition of success. In the 
context of positive coaching, success is defined by effort and mastery. Positive coaching also promotes optimism towards experiences. These findings allow athletes to experience high levels of achievement throughout their sport experience.

Other features of positive psychology. Positive psychology has a variety of other features central to its meaning and implementation. Some of these features include using a strengths-based focus and expressing gratitude.

The strengths-based element of positive psychology focuses on helping individuals discover and incorporate personal strengths into their daily lives. These strengths and virtues are considered valuable in society, but also serve a function (Peterson \& Seligman, 2004). In a typical strengths exercise, individuals are administered inventories that help reveal their personal and emotional tendencies. Next, individuals are asked to think of ways to incorporate these strengths into their daily lives. There are several benefits related to the use of the strengths, including:

"a sense of ownership and authenticity, a feeling of excitement while displaying the strength, a rapid learning curve, a sense of yearning to find new ways to use it, a feeling of inevitability in using the strength, invigoration rather than exhaustion while using the strength, the creation and pursuit of personal projects that revolve around it, and finally, joy, zest, enthusiasm, and even ecstasy while using the strength" (Seligman, 2011, p. 39).

Strengths exercises have been demonstrated to help those who have preexisting conditions including depression. These findings are supported by the principles set forth by the Missouri Institute of Positive Coaching, as coaches are directed to "identify and build upon each person's strengths" (McGuire, 2012, p. 129). 
Positive Psychology in Positive Coaching. The phrase positive coaching frequently refers to the influence of positive psychology on coaching practices. This influence has been outlined by this review through including principles from the Missouri Institute of Positive Coaching (MIPC). There are several findings within research that support the use of positive psychology in coaching and sport contexts. This section will outline these findings and demonstrate how the MIPC addresses and teaches these principles.

First, positive coaching places a large emphasis on the use of strengths and the power of the coach-athlete relationship. In the application of strengths, many coaches have used inventories to uncover their athletes' strengths and incorporate these strengths into daily use. The use of sport psychology consultants and personality inventories is on the rise as coaches seek to understand their athletes better (Gordon \& Gucciardi, 2011; Ludlam, Butt, Bawden, Lindsay, \& Maynard, 2015). Coaches believe that if they can understand the personality of their athletes, they may be better able to accommodate them. This supports findings by Jowett $(2003,2006)$, who found that coaches who take the individual personalities of athletes into consideration have more success. A focus on strengths allows for athletes to have increased feelings of competence, as they get to practice the skills in which they are proficient. This in turn may foster feelings of increased intrinsic motivation (Ryan \& Deci, 2000).

Second, positivity and praise are a large part of the positive coaching model. Praise has been shown to be a positive mediator when individual athletes were confronted with negative feedback or performance situations with high levels of perceived pressure. Praise in these circumstances helped athletes maintain high levels of intrinsic motivation 
(Matosic \& Cox, 2014). These findings support the principles of positive psychology, which call for a shift towards focusing on the positive and what went right, rather than on the negative (Seligman, 2011).

Finally, positive coaching is centered on the positive impact coaches can have on athletes in both the athletic arena and as a person. There has been a shift in perspective, as coaches now place character outcomes above performance outcomes. This results in coaches holding themselves to a higher standard, as they must model behaviors for their own athletes. Positive coaching requires coaches to become more aware of their own actions, so they may serve as proper role models (McGuire, 2012, 2016).

Positive Psychology in the Missouri Institute for Positive Coaching program. The Missouri Institute for Positive Coaching (MIPC) incorporates many of the components of positive psychology into its curriculum. Specifically, the program has principles and teaching for the model of PERMA, creating a strengths-based focus, providing positive feedback, and modeling correct behavior.

Each component of the PERMA model is addressed by the Missouri Institute for Positive Coaching. Positive emotions are indicated in the principles "develop the desire to have fun," "promote and protect each individual's happiness," and "model, promote, and nurture positive emotions" (McGuire, 2016, p. 25; http://mopositivecoaching.org). This is addressed by maintaining balance, allowing athletes to be themselves, and giving opportunities for athletes to enjoy their sporting experience. Engagement is developed by fostering flow experiences and developing skills of focus. In relation to positive relationships, the program advocates for communicating respectfully, sharing gratitude, fostering a sense of cooperation, and responding/instructing properly. Meaning can be 
developed through developing a sense of purpose, teaching the importance of hard work, and striving towards personal excellence. Finally, achievement is realized through celebrating individual's accomplishments and identifying and building upon each person's strengths (McGuire, 2012, 2016; http:// mopositivecoaching.org).

Fostering a strengths based focused is represented by the MIPC principle “identify and build upon each person's strengths" (McGuire, 2016, p. 25; http://mopositivecoaching.org). The program advises caution when developing an athlete's skills and advocates for placing the predominant focus on the strengths of the athletes. MIPC still mentions the necessity of developing an individual's weakness but advises to not let this dominate the coaches' time and attention. Through this process coaches can foster increased competence in their athletes, which may lead to higher levels of intrinsic motivation.

The MIPC program also focuses on praise and positive communication with the principle of "utilize positive, active constructive instruction/responding" (McGuire, 2016, p. 25; http://mopositivecoaching.org). The program provides specific instruction related to this principle. The program defines instruction as in the moment, easy fixes to technical and performance related behaviors. Responding requires more deliberation and must be separated from emotional reactions. In regards to instruction, the program advocates for approaching instruction positively, placing the emphasis on "how" to do something correctly, focusing on right, not wrong behaviors, emphasizing the importance of consistent practice, communicating belief, encouraging the athlete, and celebrating improvement. Positive and constructive responding, which is more thoughtful, can be addressed through observing and listening carefully, celebrating success, identifying what 
went wrong and why, maintaining composure, and catching athletes doing something right. These principles will help create favorable behavioral outcomes without diminishing the motivation of the athlete (McGuire, 2012, 2016; http://mopositvecoaching.org).

Finally, the program advocates for "[choosing] to model and develop positive character...relentlessly!” (McGuire, 2016, p. 25; http://mopositvecoaching.org). The Missouri Institute for Positive Coaching (MIPC) places the athletes' experience at the center of the coaching model. Coaches must strive to "win kids with sport" (McGuire, 2012), and to create experiences that develop positive character. The MIPC program advises each coach to determine which character qualities they would like to develop in their athletes. After determining this, the program states that if the coach desires to see those behaviors in the athlete, then the coach must "teach, model, practice, and inspire" those qualities and behaviors all the time (McGuire, 2012, 2016; http://mopositivecoaching.org). This process is assisted using construction models, in which a coach breaks down a desired quality/characteristic into specific behaviors. For instance, a coach could take the construct of confidence and break it down into specific behaviors that represent and demonstrate confidence. This allows the coach to control their own actions and model these specific behaviors to better inspire positive character outcomes. These construction models will be outlined further in the Missouri Institute for Positive Coaching learning mechanisms section of this paper.

The principles outlined here demonstrate the use of positive psychology within the MIPC program. These principles are the foundation and first step for the changes coaches wish to see implemented by their athletes. The previous sections have 
considered the behaviors that make up positive coaching, and how the Missouri Institute for Positive Coaching teaches and addresses these behaviors. The following section will look at the Missouri Institute for Positive Coaching program more closely, with a large emphasis on the course's curriculum, learning settings, and teaching mechanisms. The next section also includes a discussion of the MIPC program and domains/sources of coaching efficacy.

\section{Missouri Institute for Positive Coaching}

The Missouri Institute for Positive Coaching (MIPC) was developed and created by McGuire (2012, 2016). The MIPC created its own brand of positive coaching which is based on 29 principles. The MIPC defines Positive Coaching as:

"being built upon the understandings, strategies, and techniques proven to be most effective for creating optimal performance and achieving personal excellence, while also honoring and upholding all of the highest principles and cherished values of education and sport, such as integrity, respect, responsibility, discovery and service. The mission of this project is to promote POSITIVE COACHING in sport at all levels, and to enhance lives and society, by 'Winning Kids with Sport'.” (McGuire, 2012, p. 191).

MIPC's mission aligns with the current trend towards models of coaching effectiveness (Coté and Gilbert, 2009). Although the organizations operational definition of positive coaching may be different, MIPC shares many of the goals of "positive coaching" with similar organizations such as the Positive Coaching Alliance (Thompson, 2010). These goals are primarily concerned with coaches serving as role models who value personal 
development as much as athletic achievement and use sport as a vehicle for physical, psychological, emotional, and social development.

Principles of Positive Coaching. The MIPC has a set of guiding principles that help define what it is and instruct coaches on how to coach effectively. It is through the aggregate of these principles that Positive Coaching is defined. The following 29 principles of Positive Coaching form the foundation of the MIPC program:

\section{Discover the Calling}

- Reflect on personal values and foundational beliefs.

- Identify goals and purposes of the sport experience.

- Develop and shape coaching philosophy.

- Adopt the role of the learner.

- Choose to model and develop positive character...relentlessly!

\section{Build the Foundation}

- Create and nurture each individual's self-worth and self-esteem.

- Promote and protect the priority of each individual's well-being and happiness.

- Develop and foster the sense of meaning and purpose.

- Develop a healthy attitude toward competition.

- Develop the desire to have fun.

\section{Cultivate Positive and Caring Relationships}

- Communicate respectfully with those you lead, just as you would wish to be communicated with by those who lead you.

- Develop a spirit of cooperation.

- Demonstrate and utilize positive, active, constructive instruction.

- Demonstrate and utilize positive, active, constructive responding.

- Develop and model the regular sharing of gratitude.

\section{Empower Growth Mindsets}

- Develop and model a positive approach to achieving SuCCCCCCCess and emphasize engagement in the process. 
- Develop the realization that nothing of any real value is ever achieved without hard work and dedication.

- Develop intrinsic motivation, internal motivation, approach motivation, and positive motivation.

- Develop self-confidence by allowing individuals to make decisions for oneself, about oneself, and by oneself.

\section{Inspire Passionate Hearts}

- Develop the desire to strive wholeheartedly toward personal excellence.

- Identify and build upon each person's strengths.

- Model, promote, and nurture positive emotions.

- Develop the perspective of optimism as defining the sport culture.

- Celebrate and savor individuals' experiences of achievement and success, both in and out of sport.

\section{Produce and Achieve Optimal Performances}

- Develop and model the skills of "Thinking Right" in sport.

- Develop and model the skills of focus and self-control.

- Develop and model the skills of the 7 C's of SuCCCCCCCess.

- Develop and model the skills of mental toughness.

- Develop and nurture an environment that supports flow experiences.

(McGuire, 2012, p. 192-193)

The MIPC's Principles of Positive Coaching form a framework that contains a variety of theories taken from sport psychology, coaching theory, and positive psychology. From the sport psychology literature, the program includes topics such as focus, thought control, mental toughness, flow, and motivation. From coaching theory, there are topics on modeling behavior, goals, and communication/relationships. And from the field of positive psychology, there are topics including gratitude, strengths, PERMA, and well-being. These principles, 
which have been outlined by this paper, provide the theoretical basis for the existence of the program.

Learning Settings and Mechanisms. The MIPC education program is delivered in a variety of settings and with a variety of populations. Coaches from youth sport to the highest competitive levels across a wide range of sports have been through the MIPC program. The program spans informal, non-formal, and formal learning environments. The MIPC offers opportunities ranging from conference presentations, weekend seminars, Digital Workshops, and an online master's degree. This allows coaches to interact with the program in a variety of environments. This study focuses on high school coaches enrolled in the Digital Workshop, which is considered a non-formal learning environment.

MIPC also uses several learning mechanisms outlined in this paper to be effective. Specifically, these mechanisms include mentoring and opportunities for reflection. Concerning mentoring, the MIPC program was created by coaches for coaches, and is most frequently delivered by coaches. Coaches present and teach the principles of positive coaching and how they have personally integrated these principles into their own practice. This allows for a more direct and accessible conversation to the material, as abstract ideas are immediately given real-world context. During seminars and workshops, coaches are given opportunities to interact with each other and facilitators to increase their understanding of the course material. These interactions give coaches opportunities to learn from one another and talk through their ideas. However, as research has shown, coaches must also critically reflect on their ideas and practice to 
have positive behavior change (Gilbert \& Trudel, 2001; Irwin et al., 2006; Santos et al., 2010).

To address the concerns regarding reflection, the MIPC uses two different methods. The first is the identification of the values and goals of sport. Coaches are asked to reflect on what is important in the sport experience and what they personally value. Afterwards, they are asked to write a personal philosophy of coaching. Through this philosophy, coaches can organize their thoughts and put into place personal principles that will govern their actions. The second method is the use of construction models. With construction models, coaches are asked to start with a desired characteristic or value they wish to develop within their athletes (i.e. confidence, pride, gratitude, etc.). From this, coaches develop specific activities and experiences that assist in the development of this characteristic every day. According to McGuire (2012),

"The construction model concept is built upon the presence of valued intentions, purposeful planning, skilled instruction, coupled with active learning experiences, and positive modeling, all provided in a safe, supportive nurturing environment" (p. 21).

These methods bring intentionality and reflective practice to the coaching process, and force coaches to think about their behavior before and after their interactions with their athletes.

MIPC Digital Workshop. The Digital Workshop was used as the focus of this study. The Digital Workshop is a non-formal education program, as it is delivered outside of the traditional mechanisms of learning and can be classified as continuing education. The workshop reaches many coaches from different backgrounds (mainly 
high school coaches) and offers a lot of access to these populations. The Digital Workshop is comprised of 13 lessons. These lessons correspond with the principles of positive coaching outlined above, and are:

1. Introduction

2. Thinking Right in Sport

3. Scientific Foundations

4. Discover the Calling

5. Build the Foundation

6. Building Construction Models

7. Positive \& Caring Relationships

8. Empower Growth Mindsets

9. Building Effective Teams

10. Inspire Passionate Hearts

11. Teaching the Skill of Focus

12. Mental Toughness

13. Achieve Optimal Performance

(http//mopositivecoaching.org)

Each lesson contains a video of the founder of the program, Dr. McGuire, presenting the principles outlined in each lesson. These videos are followed up by written content to be reviewed by the participant. Each lesson takes between 20 minutes to an hour to complete. At the completion of each lesson, there is an 8-item quiz that participants must pass to move onto the next section.

At the end of the course, participants are awarded a certificate which certifies and completes their involvement. At the current time, there are 5000 individuals either currently enrolled in the course or who have completed the course.

As outlined throughout this review, the MIPC program has a foundation in theoretically proven principles, which was offered as the single most important 
recommendation for coach education (Langan et al., 2013). This study will use the MIPC Digital Workshop to assess personal differences in coaches and their relationship to the coaches' educational outcomes. The current study will use changes in coaching efficacy and changes in behavior as a baseline to understand these relationships. The following section will consider both sources and domains of coaching efficacy and their relevance to the Missouri Institute for Positive Coaching Digital Workshop.

Coaching Efficacy. The model of coaching efficacy was adapted from Bandura's (1986) self-efficacy model by Feltz and colleagues (1999). The model includes four main sources of efficacy. As outlined earlier, these include coaching experience/preparation, prior success, perceived skill of athletes, and support. Subthemes were later added to the coaching experience/preparation source, which includes knowledge to prepare the team, past experiences in coaching, leadership skills, and coaches' development. Many of these sources of efficacy are represented by the MIPC program in different ways.

McGuire $(2012,2016)$ outlines the ways in which the MIPC program aligns with the sources of efficacy proposed by Feltz et al (1999). The MIPC program most broadly fits within the subthemes of coaching experience and knowledge to prepare the team. The first subtheme fulfilled by the program is coaches' development. Coaches' development was described as pursuing education to increase and enhance coaching skills to increase coaching ability. Educational programs of all levels have been demonstrated to increase coaching efficacy, and the MIPC program fits within this broad definition of continuing education (Chase et al., 2005; Santos et al., 2010). Secondly, knowledge to prepare the team is addressed by the MIPC workshop through teaching the skills of communication, 
developing a sense of meaning/purpose, and developing a healthy attitude towards competition. These principles help guide coaches to become more effective at giving feedback, fostering relationships, and preparing teams for game day scenarios. Finally, the program addresses leadership skills by requiring coaches to develop a philosophy of coaching. This is considered by the program to be a fundamental step towards reflective and intentional coaching practices. The creation of a coaching philosophy may help to create consistency for coaches as demands shift over the course of a season. Consistency in leadership style has been demonstrated to be one of the most impactful factors related to athlete satisfaction and importance (Turnman, 2001).

Domains of efficacy in positive coaching. The four domains of coaching efficacy outlined by Feltz et al. (1999) include motivational efficacy, character building efficacy, technical efficacy, and game strategy efficacy. The current study considers all four types of efficacy in relation to the MIPC program.

Motivational efficacy is described by Feltz and colleagues (1999) as the ability of a coach to effectively manage an athlete's mental state and develop psychological skills. This type of efficacy is relevant to the MIPC program, as the program focuses on mental skills training and creating motivated athletes with a desire to compete. This is found in the lesson entitled "Inspiring Passionate Hearts" (McGuire, 2016, p. 67). In this lesson, the program outlines the process for developing a desire to strive towards excellence, identifying and building on personal strengths, modeling positive emotions, developing optimism, and celebrating achievement. The current study views motivational efficacy as an essential domain when considering the MIPC curriculum. 
Character building efficacy is the second most prominent domain of efficacy related to the MIPC Digital Workshop. Character building efficacy is defined as the belief that the coach can help the athlete develop values and enhance athletes' personal development. McGuire (2016) outlines principles like "choose to model and develop positive character...relentlessly!" and "develop a spirit of cooperation" (p. 25). Other principles like "develop the realization that nothing of any real value is ever achieved without hard work and dedication" further solidify the role of character development within the program (p. 25). Character building has not been thoroughly considered when considering education programs (Chase et al., 2005). Because of the unique goals of the MIPC as a non-sport specific education program, character building efficacy is an essential component of understanding the effect of the program on coaching efficacy.

Technical efficacy and game strategy efficacies are the final domains of coaching efficacy. Technical efficacy is the ability of the coach to recognize, instruct, and develop good technique. Game strategy efficacy is the ability of the coach to recognize teams' strengths/weaknesses, create and communicate a game plan, and make changes in game time scenarios. These types of efficacies are not explicitly stated in the goals or curriculum of the Missouri Institute for Positive Coaching (MIPC). However, as subscales of the Coaching Efficacy Scale (CES), they were included in the current study for a several reasons. First, continuing education of all types has been shown to enhance general levels of coaching efficacy (Santos et al., 2010). Since the current study considers a non-sport specific education program, it is interesting to see if the traditional domains affected by sport specific programs will be affected by the MIPC Digital Workshop. Secondly, the MIPC Digital Workshop focuses on communication, the 
utilization of active/constructive instruction/responding, engagement in the process, and the development of mental toughness/focus/self-control. Each of these factors could potentially enhance a coaches' effectiveness in teaching skills and enhancing game day performances. Because of these factors, technical and game strategy efficacy were included in the study to assess the programs effects on these variables.

The goal of this study is not to validate the MIPC program, but rather to focus on the relationship of personable variables to coaches' experiences and outcomes with the MIPC Digital Workshop. The current study will consider all four domains of coaching efficacy to understand the full effects of the MIPC program. 


\section{CHAPTER 3}

\section{METHOD}

\section{Introduction}

The purpose of this study was to understand the relationship between demographic, dispositional, and personal factors and the benefits of coach education. This study sought to help coach educators better understand the populations with whom they interact. The design and premise for this study was influenced by teacher education and is applicable to coaching based on the similarities between teachers and coaches. The findings of this study may help coach educators create consistent recommendations throughout all forms of coach education.

The Missouri Institute for Positive Coaching Digital Workshop was selected due to the volume of coaches entering the program, access to the program and the coaches, as well as its place within the emerging trend of programs grounded in coaching effectiveness. These programs ask coaches to make a paradigm shift in their beliefs and behaviors to a "double-goal" mentality and focus on psychological outcomes in addition to performance outcomes. Because of the increased likelihood of a paradigm shift creating conflict with traditional sport practices, personal and dispositional variables may influence the effects of this type of education. The research questions for this study are:

Q1： Q1: Do participants enrolled in the Missouri Institute for Positive Coaching Digital Workshop, as created by McGuire (2012, 2016), experience changes in coaching efficacy or coaching behavior? 
H1: Coaches will report increased levels of coaching efficacy after completing the MIPC program. Coaches will report making conscious changes to their coaching behavior after their completion of the workshop. Rationale: Coaches with higher education degrees have been shown to have increased coaching efficacy (Santos et al., 2010). Coach education (including workshops and certifications) have been demonstrated to positively impact coaching efficacy (Campbell \& Sullivan, 2005; Malete \& Feltz, 2000; Sullivan et al., 2012).

Q2: Are there differences in changes in coaching efficacy scores between male and female participants?

H2: Female participants will have greater positive changes in coaching efficacy scores on the CES compared to male participants.

Rationale: Women are higher consumers of continuing education within the field of teaching, even when accounting for gender differences within the profession. Women have an increased motivation to both learn and participate in continuing education activities (McGivney, 2004). The effect of gender on coach education has not been investigated. Because females in teacher education are more likely to positively regard and pursue continuing education (McGivney, 2004), this study hypothesizes that female participants will have greater positive changes in coaching efficacy than men.

Q3: Are there differences in changes in coaching efficacy scores based on coaching experience? 
H3: Coaches who have been coaching longer will have smaller changes in coaching efficacy scores compared to coaches who are newer to the profession.

Rationale: Experience has been demonstrated to have a positive effect on coaching efficacy (Santos et al., 2010). The relationship between experience and coach education outcomes has not been measured. Within teacher education, experience plays a significant role in a teacher's pursuit of educational opportunities. Experienced teachers are less likely to pursue learning opportunities (Richter et al., 2011). Experienced teachers also demonstrate increased routine seeking behaviors, cognitive rigidity, and are less likely to consider new perspectives (Stan et al., 2013). Because of these findings, this study hypothesizes that coaches with more experience will be less likely to be open to new ideas and changing their own behavior. More experienced coaches will report lower increases in their coaching efficacy scores.

Q4: Are there differences in changes in coaching efficacy scores based on age categories?

H4: Coaches who are in older age categories will report smaller positive changes in coaching efficacy scores compared to coaches in younger age categories.

Rationale: Research demonstrates older coaches are less likely to pursue continuing education, and do not feel the same need to develop as younger coaches (Blunt \& Yang, 2002). Within teacher education literature, 
findings also suggest that older teachers are less likely to pursue continuing education (Richter et al., 2013). Older coaches may feel a decreased need to change their behavior and have less appreciation for the educational material resulting in smaller changes in coaching efficacy scores.

Q5: Are there differences in changes in coaching efficacy based on the enrollment status (i.e. required or voluntary) of the coach?

H5: Coaches who voluntarily enroll in the workshop will have increased positive changes in coaching efficacy scores compared to coaches who are required to take the course by school administrators.

Rationale: Within the field of teacher education, research has demonstrated that when teachers have the will to learn, they are more likely to experiment with newly learned ideas and incorporate them into practice (Hargreaves, 1999). When a coach enrolls in the course voluntarily, it is reasonable to assume that there in an increased will to learn, especially in comparison to those whose attendance is required. Self-determination theory suggests that individuals are more likely to be intrinsically motivated when three basic needs are met. These needs are autonomy, relatedness, and a sense of competency (Ryan \& Deci, 2000). Because coaches who voluntarily enroll in the course will have had autonomy over their decision, they may be more intrinsically motivated to learn and integrate course material into their coaching practices. This study hypothesizes that coaches who voluntarily enroll in the course will 
have greater positive changes in coaching efficacy scores compared to the individuals who were required to enroll by their administrators.

Q6: Is there a correlation between attitudes and beliefs towards education, as measured by the Revised Adult Attitudes and Beliefs towards Continuing Education Scale, and changes in coaching efficacy?

H6: There will be a positive correlation between attitudes towards continuing education and changes in coaching efficacy.

Rationale: There has been no research on the effect of coaches' attitudes and beliefs on coach education. In teaching, attitudes towards continuing education have been shown to predict a teacher's pursuit of educational opportunities. Education programs fail to be effective when existing knowledge is taken for granted and the desire to see new opportunities is absent (Oosterheert \& Vermunt, 2001). When will to learn is present, teachers will experiment with newly learned ideas, and incorporate them into their own behavior (Hargreaves, 1999). High will to learn influences reflection-on-action (Schon, 1983), which is a powerful factor in changing coach behavior (Gilbert \& Trudel, 2001). This study hypothesizes that more positive attitudes towards continuing education will positively correlate with coaching efficacy.

Q7: Is there a correlation between dispositional resistance to change, as measured by the Dispositional Resistance to Change Scale, and changes in coaching efficacy? H7: There will be a negative correlation between dispositional resistance to change and changes in coaching efficacy. 
Rationale: Dispositional resistance to change has not been assessed within coaching populations and coach education. In teaching literature, teachers who are high in dispositional resistance to change are less likely to seek out educational opportunities (Oreg et al., 2008). These teachers also report more negative feelings when faced with information that contradicts current practices and beliefs (Oreg et al., 2008), and are less likely to consider new perspectives (Stan et al., 2013). Coaches have been shown to demonstrate behaviors related to resistance to change, including holding onto traditionally accepted methods of coaching (Coakley, 1978). This study hypothesizes that there will be a negative correlation between resistance to change and coaching efficacy.

\section{Participants}

Participants in this study were 65 coaches who were enrolled in the Missouri Institute for Positive Coaching Digital Workshop. Coaches were predominately high school coaches. All coaches in the state of Missouri were offered the Digital Workshop free of charge. Schools, athletic associations, and individual coaches outside the state were charged for their enrollment. The method of the coaches' enrollment could be placed into three categories. First, there were coaches who were signed up for the workshop by their administrators (e.g. Superintendents, Principals, and Athletic Directors) and required to take the workshop. Forty-three percent of participants reported being enrolled through this method. Secondly, there were coaches who were signed up for the workshop by administrators and then offered the chance to take the workshop, but it was not required. This only made up $17 \%$ of participants in the study. Coaches in the 
first two categories had the program paid for by their administration. Finally, there were coaches who signed up for the workshop on their own or through an athletic association and paid for the workshop themselves. This constituted $40 \%$ of participants.

Coaches could enroll and start the workshop whenever they desired and complete lessons at their own pace. Only one school in the study required completion of the workshop by a certain date. During the coaches' enrollment in the workshop, coaches were asked if they would like to participate in a study to measure the effectiveness of coach education and the relationship between personal variables educational outcomes. Participants were informed their participation in the study was completely voluntary and confidential. The time taken by coaches to complete the workshop was extremely variable. Some coaches finished the workshop in 2 weeks while others took 8 months to complete their involvement.

\section{Variables}

Independent Variables

- Age. Age served as an independent variable in this study and was recorded by offering categories in the initial survey. The categories were 18-24, 25$34,35-44,45-54,55-64,65-74,75$ or older.

- Gender. Gender served as an independent variable within this study and was recorded in the initial survey. Participants could select Male or Female.

- Experience. Experience served as an independent variable within this study and was recorded in the initial survey. Participants were offered the choice of $0-4$ years, $5-10$ years, $11-15$ years, 15 years or more. The option 
of "I am not a coach," was also included, as some school districts have their non-coaching personnel enroll in the course.

- Enrollment Status. Enrollment status served as an independent variable within this study and was recorded in the initial survey. Coaches either signed up for the course on their own or were required to take the Digital Workshop by an administrator (e.g. Superintendent, Principal, Athletic Director). On the survey, participants were offered choices of required or independent enrollment.

- Attitudes and beliefs towards education. Attitudes and beliefs towards education served as an independent variable within this study. The variable was measured via the Revised Adult Attitudes towards Continuing Education Scale to determine coaches' attitudes and beliefs towards education level.

- Dispositional resistance to change. Dispositional resistance to change served as an independent variable within this study. The variable was measured with the Resistance to Change Scale to determine coach's dispositional resistance to change level.

\section{Dependent Variables}

- Coaching efficacy. Coaching efficacy served as the dependent variable in this study. The Coaching Efficacy Scale was used to determine coaching efficacy before and after the implementation of the education program. 
- Behavior Change. Coaches were asked if they had changed some aspect of their coaching behavior after their attendance of the education program. The options for this question were (1) yes or (2) no.

\section{Instrumentation}

The scope and purpose of the research was outlined to participants at the start of the MIPC Digital Workshop and again prior to opening the survey. The initial material was a researcher-compiled survey which included demographic information related to coaching (i.e. age, experience, gender, and enrollment status). In addition to this survey, several other materials were included in the initial assessment. This included the Revised Adult Attitudes Towards Continuing Education Scale (Blunt \& Yang, 2002), Resistance to Change Scale (Oreg et al, 2008), and Coaching Efficacy Scale (Feltz et al., 1999). Revised Adult Attitudes toward Continuing Education Scale. The Revised Adult Attitudes towards Continuing Education Scale (R-AATCES) instrument was used to assess coaches' attitudes regarding educational opportunities (see Appendix B for scale). The R-AATCES was constructed through an extensive literature review and expert adult education panel review (Darkenwald \& Hayes, 2006). The scale has been used in a variety of contexts including with teachers (Efthymios, Stella, Sofia, 2010), business managers (Erickson, 1990) and athletic trainers (Horn, 2005). The original instrument is a 22-item scale that uses a 5-point Likert scale where 1 represents strongly disagree and 5 represents strongly agree. The revised scale was narrowed down to 9-items to increase response rates, while maintaining validity and reliability. The Cronbach reliability of the scale was .90 in one study (Darkenwald \& Hayes, 2006). The R-AATCES was used by 
the current study to assess coaches' views on continuing education. These views were then compared to changes in coaching efficacy from pre- to post-workshop.

Resistance to Change Scale. The Resistance to Change Scale (RTCS) was developed by Oreg (2003) to measure "an individual's tendency to resist or avoid making changes, to devalue change generally, and to find change aversive across diverse contexts and types of change" (p. 680). The scale includes four subscales including (a) routine seeking, (b) emotional reaction to imposed change, (c) short-term focus, and (d) cognitive rigidity.

Students with higher scores on the Resistance to Change Scale demonstrated a decreased likelihood of engaging in voluntary learning and changing of class schedules. In work settings, the scale was compared with individuals' affective responses to changes in their work environment, and alpha coefficients for the scale were .91 for the total resistance-to-change score, while the subscales fell between .8 and .86 (Oreg et al., 2008). The RTCS has been demonstrated to be effective in identifying an individual's avoidance of incorporating new practices and behavior into their daily routines across a variety of demographics and populations.

The Resistance to Change scale was used in this study to assess coaches' dispositional resistance to change. This included considering all four subscales. The Resistance to Change scale and its subscales were then compared with changes in coaching efficacy to see if the constructs were correlated.

Coaching Efficacy Scale. The Coaching Efficacy Scale (CES) was developed by Feltz and colleagues (1999) to measure coaching efficacy (See Appendix D for scale). It consists of 24 items answered on a Likert Scale from 0 (Not at all confident) to 9 
(Extremely confident). All items begin with the phrase, "How confident are you in your ability to...". These statements directly relate to coaching efficacy, which is defined as the belief that coaches can successfully carry out the duties expected of them (Feltz et al., 1999). These demands are situation and context specific, so it is necessary that a scale measuring self-efficacy be directed towards the demographic it is attempting to measure (Bandura, 1997).

Efficacy has been shown to be domain-specific, although the separate domains correlate with each other (Bandura, 1997). The CES contains four domains which are motivation efficacy, game strategy efficacy, technique efficacy, and character-building efficacy (Myers, Feltz, \& Wolfe, 2008). The character-building efficacy is of particular interest in this study due to its importance within the construct of positive coaching (McGuire, 2012, 2016) and the model of coaching effectiveness (Coté \& Gilbert, 2009).

The Coaching Efficacy Scale was developed primarily for use with high school coaches which makes it ideal for the current study (Feltz et al., 1999). Coaching efficacy has been demonstrated to predict coaching behavior, player satisfaction, and athletic success. These findings support the use of coaching efficacy as an outcome measure of a coach education program. Additionally, coach education and leadership development have both been shown to serve as sources of coaching efficacy (Chase et al., 2005). These factors together justify the use of the CES to determine the relationship between personal and dispositional characteristics and the effects of a coach education program (Feltz et al., 1999).

In the current study, Coaching Efficacy Scale scores were the dependent variable. The scale was used to measure changes in coaching efficacy from pre-workshop to post- 
workshop. These scores were then compared to the demographic variables, attitudes towards continuing education, and resistance to change. All four domains of coaching efficacy (i.e. motivational, character-building, technical, game strategy) were measured and considered for the current study.

Qualitative measures. To explore the types of behavioral changes that coaches made after completing the workshop, an open-ended qualitative question was included in the post-workshop survey. First, this item included the yes or no question "have you changed your coaching practice in some way?" This was followed by another item that asked, "If yes, please give up to three examples." This question was open response and had no character limit.

\section{Design and Procedure}

The purpose of this study was to assess the relationship between demographic,

personal, and disposition variables and coaching efficacy after a coach's completion of an online positive coaching education program. The intervention in this study was the Missouri Institute for Positive Coaching Digital Workshop. The current study used a one group, pretest-posttest design. This type of study was chosen for several reasons. First, the studies focus was on the relationship of between-subject effects of personal variables and coaching efficacy and not the validation of the education program. Changes in coaching efficacy was considered as both a baseline for the study and as a preliminary investigation on the effects of the program. The second reason was access to coaches. Access to high school coaches is extremely limited, and coaches are notorious for hectic schedules. Recruiting coaches to sign up for a study regarding education was considered to be extremely difficult. It was believed that administrators would be unlikely to sign 
their coaches up for a study in which coaches could potentially not receive the education while others did. Finally, many of the coaches who took the course had situational variables that made their experience with the course unique. This made the comparison to a control group more difficult. For instance, some coaches completed the course and surveys in 2 weeks. Other coaches took 8 months to work through the material. This creates an unknown variable which is difficult to replicate with a control group. Creating an appropriate amount of time between the pre-/post-test measures would have been arbitrary and have potentially impacted the findings.

After receiving permission from the Human Subjects Committee at The University of Missouri, surveys were administered online to each coach at the start and completion of the Missouri Institute for Positive Coaching Digital Workshop.

After logging into the MIPC Digital Workshop, coaches were directed to a "START HERE" page. On this page, coaches were given a brief description of the study and a link to the pre-workshop survey. Before clicking on the begin survey button, participants were advised that clicking on the link served as their consent to participate in the study.

The pre-workshop survey included a demographic survey, as well as the Revised Adult Attitudes towards Continuing Education Scale, Resistance to Change Scale, and Coaching Efficacy Scale. Coaches were identified by their email addresses, which were kept separate from their responses to maintain confidentiality. Coaches' progress in the course was monitored through the MIPC website.

After completing the workshop, coaches were prompted to complete the postworkshop survey on the MIPC Digital orkshop page. This was offered to all coaches, 
regardless of if they had taken the first survey of the study. Post-workshop surveys without a corresponding pre-workshop survey were not considered. Secondly, coaches who had completed the course but had not completed the post-workshop survey were sent a series of emails to conclude their participation in the study. These emails included a link to the post-workshop survey and a \$10 Amazon gift card as incentive for participation. After completing the post-workshop survey, these participants received their gift card through the email on record.

\section{Data Analysis}

The study considered the relationship between personal factors and changes in coaching efficacy after the completion of the coach education program. The factors considered in this study were age, gender, experience, enrollment status, attitudes and beliefs towards continuing education, and resistance to change.

Results obtained through the online survey were entered into SPSS Statistics for analysis. The method of analysis used was based on the specific research question. All data analysis used an alpha level of .05 for significance.

Profile of Participants. Sixty-five individuals completed both surveys. Male participants made up $64.1 \%$ of the sample and $47.2 \%$ of all participants reported as having enrolled voluntarily in the course. The largest age group was the 25-34 age group, with the mean falling in the 35-44 age category. The majority of coaches fell in the highest experience group, as 21 coaches reported having more than 15 years of coaching experience. The mean for experience was within the 5-10-year range. Most coaches reported having received prior coach education (57\%), while $43 \%$ had not. 
The majority of coaches were high school level coaches. Participants primarily reported being employed as high school teachers who also coached sport teams (40\%). Other participants identified as being school employees with the sole responsibility of coaching $(21.5 \%)$. The third group identified as coaching at the school, but described their employment as unaffiliated with the school district or that they worked as a volunteer $(29.2 \%)$. Finally, $9.2 \%$ of participants described their positions as other.

Coaches reported a range of education levels, with the majority having a master's degree (37\%). The second highest education level was bachelor's degree (35\%), followed by some postgraduate work (14\%), some college (9\%), and associate's degree (5\%). The majority of participants were from Missouri (39\%), with the second most from Wisconsin (22\%). Participants also reported being from Texas (13\%), Florida (5\%), Tennessee (3\%), New Hampshire (3\%), and Alabama (2\%).

When considering the sports represented by the participants, there were 19 different responses with many coaches identifying multiple sports. The most common sports coached by the participants were football (23\%), basketball (20\%), and track and field $(14 \%)$. The other sports that had multiple coaches were soccer $(11 \%)$, swimming $(9 \%)$, cross country $(8 \%)$, baseball $(8 \%)$, softball $(6 \%)$, wrestling $(5 \%)$, cheer $(5 \%)$, and diving (3\%). The remaining sports had only one coach and were dance, archery, tennis, volleyball, rugby, gymnastics, and rowing.

Research Question 1. Question 1 focused on the overall effect of the education program on coaching efficacy for all participants. This question measured if participants undergoing the education experienced a change in coaching efficacy after their completion of the program (Gravetter, Wallnau, \& Daniel, 2007). Because there was 
only one test group, a paired sample t-test was used to determine if there was a significant change in CES after the completion of the Digital Workshop. Paired sample t-tests are used in pre/post-designs in which there is a single intervention group (Waigandt \& Wang, 2010). Each of the four subscales of the CES were evaluated.

Behavioral Change and Qualitative Measures. The question regarding participant behavior change had two options: (1) yes or (2) no. Behavioral change was compared to personal variables (i.e. gender, age, experience, enrollment status). Since all variables were categorical, this analysis used a chi-squared test. Secondly, the study compared behavioral change with attitudes towards continuing education, resistance to change, coaching efficacy scores, and changes in coaching efficacy scores. Since this analysis considered continuous independent variables with a categorical dependent variable, the study used a binary logistic regression.

The qualitative element of RQ1 was focused on understanding the specific ways in which coaches change their coaching behaviors after completing the workshop. Answers to this question were broken up into segments and coded based on the concepts identified in each segment. Once all codes were identified, the codes were listed and grouped into larger overarching themes. All the codes and themes were confirmed by an outside researcher for reliability and consistency.

Research Question 2: Gender. Research Question 2 used an independent sample t-test to determine if there were significant differences in changes in coaching efficacy based on gender. Independent samples t-tests are used to determine if there are mean differences on treatment conditions between two categorical groups (Gravetter et al., 2007). 
Research Question 3: Experience. Research Question 3 considered experience and its relationship to changes in coaching efficacy. A one-way analysis of variance (ANOVA) was used to determine if there were differences in changes in coaching efficacy based on experience. ANOVA testing is used when comparing a categorical independent variable with a continuous dependent variable.

Research Question 4: Age. Research Question 4 considered age in relation to changes in coaching efficacy. As with RQ3, this analysis used a one-way ANOVA test to determine if there were significant differences in changes in coaching efficacy based on age.

Research Question 5: Enrollment. Research Question 5 was concerned with if there were significant differences in changes in coaching efficacy based on enrollment status. Coaches were either required to take the course by school administrators (i.e. Superintendents, Principals, Athletic Directors) or voluntarily chose to take the course. Because the independent variable had two categories, this analysis used an independent sample t-test to determine if there were differences in coaching efficacy based on enrollment status.

Research Question 6: Attitudes towards Continuing Education. The sixth question considered attitudes and beliefs towards continuing education in relation to changes in coaching efficacy. This question used the Revised Adult Attitudes towards Continuing Education Scale and changes in Coaching Efficacy Scale scores. Because both variables were continuous, a Pearson correlation was used to determine if there was a significant relationship between the variables. Secondly, this question also looked at RAATCES scores from before and after the workshop to see if there were significant 
changes. A paired sample t-test was used to determine if there were significant changes in attitudes towards education after coaches' completion of the workshop.

Research Question 7: Resistance to Change. Question 7 investigated the connection between dispositional resistance to change and changes in coaching efficacy. Dispositional resistance was measured by the Resistance to Change Scale (RTCS). Because both the RTCS scores and changes in Coaching Efficacy Scale scores were continuous, a Pearson correlation was used to determine if the values were significantly related. A paired sample t-test was also used to determine if resistance to change experienced a change after completion of the workshop. 


\section{CHAPTER 4}

\section{RESULTS}

The purpose of this study was to investigate the relationship between coaches' demographic, personal, and dispositional factors and the effects of coach education. The demographic variables surveyed included gender, experience (i.e. years in coaching), age, and required versus voluntary enrollment in a coach education program. Attitudes and beliefs towards continuing education and dispositional resistance to change were also assessed. This study analyzed differences in coaching efficacy after the completion of the Missouri Institute for Positive Coaching Digital Workshop.

\section{Demographic and Descriptive Statistics}

Sixty-five individuals completed the study $(\mathrm{N}=65)$. Sixty-four percent of participants were male and $47.2 \%$ of participants reported voluntarily enrolling in the course. The largest age group was the 25-34 group, with the mean age range falling in the 35-44 category. The sample consisted of mostly experienced coaches, as 21 coaches had more than 15 years of coaching experience. The mean years of experience was within the 5-10-year range. Most coaches reported having received prior coach education (57\%), while $43 \%$ had not.

The majority of coaches were high school level coaches. Participants reported being employed as high school teachers who also coached sport teams (40\%). Other participants identified as being school employees with the sole responsibility of coaching $(21.5 \%)$. The third group identified as coaching at the school but described their employment as unaffiliated with the school district or they worked as a volunteer (29.2\%). Finally, 9.2\% of participants described their positions as other. 
Coaches reported a range of education levels, with the majority having a master's degree (37\%). The second most reported having a bachelor's degree (35\%), followed by some postgraduate work (14\%), some college (9\%), and associate's degree (5\%). The majority of participants were from Missouri (39\%), with the second most from Wisconsin (22\%). Participants also reported living in Texas (13\%), Florida (5\%), Tennessee (3\%), New Hampshire (3\%), and Alabama (2\%).

When considering the sports represented by the participants, there were 19 different responses with many coaches identifying multiple sports. The most common sports coached by the participants were football (23\%), basketball (20\%), and track and field (14\%). The other sports that had multiple coaches were soccer (11\%), swimming (9\%), cross country (8\%), baseball (8\%), softball (6\%), wrestling (5\%), cheer (5\%), and diving (3\%). The remaining sports had only one coach and were dance, archery, tennis, volleyball, rugby, gymnastics, and rowing. Table 1 below provides a summary of the demographics of the participants in this study.

Table 1

\section{Participant Demographics}

$\mathrm{N} \%$

Age (in years)

4

$6.7 \%$

25-34

19

$31.7 \%$

$35-44$

16

$26.7 \%$

45-54

9

$15.0 \%$

55-64

3

$5.0 \%$

65-74

9

$15.0 \%$

75 or older

0

$0 \%$

Gender 
Female

Male

Coaching Experience (in years)

Not a Coach

$0-4$

5-10

11-15

15 or more

Enrollment

Voluntary

Required by Administrator

Employment Status

Teacher

Coach only

Unaffiliated with school/volunteer

Other

Education

Some College

Associate's Degree

Bachelor's Degree

Some Postgraduate Work

Master's Degree

Prior Coach Education

Yes

No

State

Alabama

Florida

Missouri

New Hampshire

Tennessee
$31.3 \%$

41

$64.1 \%$

$4.7 \%$

$17.2 \%$

20

$31.3 \%$

9

$14.1 \%$

21

$32.8 \%$

25

$47.2 \%$

28

$52.8 \%$

26

$40.0 \%$

14

$21.5 \%$

19

$29.2 \%$

6

$9.2 \%$

6

$9.3 \%$

3

$4.6 \%$

23

$35.9 \%$

9

$14.0 \%$

24

$37.5 \%$

36

$57.1 \%$

27

$42.8 \%$

\section{1}

$1.5 \%$

3

$4.6 \%$

34

$52.3 \%$

2

$3.0 \%$

2

$3.0 \%$ 
Texas 8

$12.3 \%$

Wisconsin

Sport Coached

Football

Basketball

Track and Field

9

$13.8 \%$

Soccer

7

$10.7 \%$

Swimming

6

$9.2 \%$

Cross Country

5

$7.6 \%$

Baseball

5

$7.6 \%$

Softball

4

$6.1 \%$

Cheer

3

$4.5 \%$

Diving

2

$3.0 \%$

Archery

1

$1.5 \%$

Crew

1

$1.5 \%$

Dance

1

$1.5 \%$

Gymnastics

1

$1.5 \%$

Rugby

1

$1.5 \%$

Tennis

1

$1.5 \%$

Volleyball

1

$1.5 \%$

Wrestling

1

\section{Research Question 1}

Research question 1 was concerned with changes in coaching efficacy and behavior after completion of the MIPC Digital Workshop. This question served as the baseline metric for the study. Coaching efficacy was measured by the Coaching Efficacy Scale (CES). The CES measures motivational efficacy, technical efficacy, game strategy efficacy, and character-building efficacy using 4 subscales. A paired samples t-test was used to determine if there was a significant change in CES scores. The mean CES scores 
for pre- and post-workshop, as well as the mean changes in scores are included in Table 2 below.

Table 2.

Results of Coaching Efficacy Scale Paired Samples t-test

\begin{tabular}{lcccc}
\hline & $\begin{array}{c}\text { Pre- } \\
\text { Workshop }\end{array}$ & $\begin{array}{c}\text { Post- } \\
\text { Workshop }\end{array}$ & $\begin{array}{c}\text { Mean } \\
\text { Change }\end{array}$ & $\begin{array}{c}\text { Paired } \\
\text { Samples t- } \\
\text { test }\end{array}$ \\
\hline Coaching Efficacy Total & $7.71(.74)$ & $8.16(.69)$ & $.45(.51)$ & $7.130^{* * *}$ \\
Game Strategy Efficacy & $7.59(.91)$ & $7.94(.87)$ & $.35(.62)$ & $4.592^{* * *}$ \\
Motivational Efficacy & $7.54(.84)$ & $8.11(.76)$ & $.58(.75)$ & $6.204 * * *$ \\
Character Building Efficacy & $8.04(.73)$ & $8.53(.59)$ & $.48(.66)$ & $5.882^{* * *}$ \\
Technical Efficacy & $7.83(.86)$ & $8.24(.77)$ & $.41(.55)$ & $5.977 * * *$ \\
\hline
\end{tabular}

Note. $M=$ Mean. $S D=$ Standard Deviation. Efficacy scores range from 1 (not at all confident) to 9 (extremely confident). $* * * p<.001$

As displayed in the table, scores on the Coaching Efficacy Scale and all subscales rose significantly $(\mathrm{p}<.001)$ from pre-workshop to post-workshop. All increases were found to be significant at an alpha level of less than .001 .

\section{Qualitative Reports of Behavioral Change}

After completing the course, participants were asked if they had implemented changes to their coaching behavior. If participants answered yes, they were asked to provide up to three examples of how they had changed their behavior. The responses were coded and grouped into themes. Out of the 65 participants, 48 coaches stated they had changed their coaching behavior. Forty of those 48 participants provided feedback and examples. This yes/no response was analyzed and compared to the participant's gender, experience, age, and enrollment status. Because these variables were categorical, 
the study used a chi-squared test. Only enrollment proved to be significant. Those individuals who voluntarily enrolled in the program were significantly more likely to report a change in behavior after their completion of the course, $x^{2}(1)=5.450, p=.020$. These findings can be found in table 3 below.

Table 3

Results of Chi-Squared for Behavior Change by Enrollment Status

\section{Enrollment Status}

\begin{tabular}{|c|c|c|}
\hline Behavioral Change & Voluntary & Mandatory \\
\hline Yes- Changed Behavior & $22(85 \%)$ & $16(57 \%)$ \\
\hline No- Did not Change Behavior & $4(15 \%)$ & $12(43 \%)$ \\
\hline
\end{tabular}

Note. $x^{2}=5.450^{*}, d f=1$. Number in parentheses indicate column percentages. $*_{p}=.020$.

Other factors were also considered to see if they were related to behavior change. These factors included initial Coaching Efficacy Scale (CES) score, change in CES score, Revised Adult Attitudes towards Continuing Education Scale score, and Resistance to Change Scale score. Since behavioral change was categorical (e.g. yes or no) and the dependent variables were continuous, a binary logistic regression was used to look at the interactions. The model with initial CES score was found to be significant; $\beta=1.008, \mathrm{R}^{2}=.082, \mathrm{p}=.029$. This model suggests that higher initial CES scores were more likely to report making behavior changes. The model with change in CES scores was also found to be significant; $\beta=-1.412, \mathrm{R}^{2}=.078, \mathrm{p}=.036$. This suggests that the larger the CES score change, the more likely behavioral change would occur.

When considering the qualitative responses, not all responses included three clear examples and many responses were difficult to divide. The full transcript of responses can be found in Appendix F. Sixteen codes were identified from the responses, which 
were sorted into 5 main themes. These themes were intentional coaching, positivity, mental skills, athlete autonomy, and gratitude. The following section will outline these themes and their subthemes.

Intentional Coaching. Intentional coaching was the most common theme among the participants' responses, as there were 23 segments that reflected the participants' shift towards intentional coaching practices. These intentional practices were characterized by a greater understanding of the science of coaching, modeling desired behavior, developing team culture, and planning and reflecting on coaching behaviors for desired athlete outcomes.

Understanding the science of coaching. After completing the course, several participants stated they felt increased confidence in their abilities due to a better understanding of the science of coaching. One coach stated that the course helped him in "learning the science behind what it takes to perform our best" and that he now had "science to back up his coaching." Other coaches referenced specific concepts as being helpful, such as "like the anchor idea, [I] will use more right-thinking ideas, use more mental skill development ideas" and "I now know that mental strength is as important as physical strength."

Modeling desired behavior. When it comes to changing athlete behavior, many participants stated that they themselves would need to change their own behavior to inspire that change in their athletes. Some responses were very straightforward such as "model desired behavior" and "lead by example." Others were more specific, as one participant stated, "I plan to be a better model of stability for my athletes!" Many coaches cited ways they could be more positive, which they believed would help their 
athletes be more positive. This was reflected in statements like "choosing to not focus on what went wrong," and "I am focusing on recognizing and working on the good things rather than pointing out things that are wrong." Finally, one coach summed it all up, saying "I am working on being a better example in all aspects of the sport to my athletes." These statements reflect the coaches' attempts to change their own behavior to change behavior in their athletes.

Developing team culture. Participants reflected the need to take time out of practice to work on team building and team culture. One participant stated, "just the concept of taking breaks from drills to work on team building/morale," while another said, "[we will] make sure we include time for players to mentally focus on their job and role on the team." Coaches even designed activities to become more social, as one coach maintained, "I have been creating more opportunities for interaction with team members in dryland activities."

Reflecting and planning coaching behaviors. Coaches reported a variety of ways in which the course changed their approach to coaching, including a push to intentionally develop the qualities and characteristics they wished to see in their athletes. The broadest responses were reflected by coaches stating that they had come up with a coaching philosophy after taking the course. One coach stated, "I have written down my philosophy of coaching, and give [sic] it a lot of thought. It has changed the way I approach each day." Another coach stated, "I am new, so I am looking for a good foundation to start a coaching career. This program, and the items within, seem like a fit for what I want to accomplish as a coach and teacher". 
With regards to actual coaching practices, responses revolved around simple changes the participants made. One coach stated, "I sit my athletes down and explain to them the reasons behind thinking and practice exercises." Other participants had larger shifts in perspective, which is summarized by the following quote:

"Through this program, I have come to learn that positive coaching also includes structuring practices and meets to be more supportive and developmental towards the focus, self-confidence, and value of athletes, and how to structure each day to help support those larger goals."

These statements together suggest that many coaches made a push towards becoming more reflective and aware of their own behaviors and shortcomings. Another coach stated, "reading through the 12 questions of fulfilling team experiences made me realize some areas that I am deficient in. I do not praise or check in with my athletes enough.” The program reminded and prompted coaches to reflect on their own behaviors and determine where they could improve.

Positivity. Positivity was the second most reported change by the participants. Positivity was characterized by providing positive feedback and focusing on what went right in contrast to mistakes and shortcomings.

Positive feedback. Positive feedback was reported as a major change for coaches. This was both a change in behavior and a change in frequency with regards to being positive. Behaviorally, one participant mentioned "I haven't been able to use this yet, but when I do it will allow me to be more positive with the students." Others said they were "choosing to be more positive in every aspect," and were going to "stress positive thought." With regards to frequency, participants mentioned they would "seek out 
opportunities to give positive feedback." Finally, some coaches mentioned that they would try to turn negative situations around, detailing, "I am working at turning negatives into positives."

Focusing on what went right. Participants reported a shift towards focusing on good things from practices and competitions. Coaches stated they would try to "catch [the athletes] doing something good," and were "choosing to not focus on what went wrong." Another reflected the goal of "focusing more on recognizing and working on the good things rather than pointing out things that are wrong."

Mental Skills/Toughness. Participants reported changes to how they perceive and handle mental skills and mental toughness. This change was two-dimensional, as coaches reported experiencing both a change in perspective regarding the importance of mental skills and a change in their ability to teach and implement mental skills on their teams.

Importance of mental skills. Participants reported an increase in their appraisal of the importance of mental skills within their teams and athletic programs. One coach stated, "I now know that mental strength is as important as physical strength." Other coaches recognized the importance of taking more time to devote towards the development of mental skills, which was reflected by the statements "[just the concept of] taking breaks from drills to work on team building/morale," "getting the 'mind right' as well as the body," and "make sure we include time for players to mentally focus on their job and role within the team."

Implementation of mental skills. Coaches reported having an increased knowledge when it comes to mental skills and their ability to teach them. Coaches expressed having 
increased "ways to promote focus," and "ways to teach mental toughness." Others said "we are already installing the 7 c's of success," and "I plan to use what I have learned when we start practice this summer. As a staff we are going to use the model of mental toughness." One stated that they had taught mental skills to their team, and "emphasized process over outcome." In a very detailed account, one participant states:

"I can do a better job of teaching my athletes the skills necessary to achieve Mental Toughness. Getting more specific on this- I can help my students understand the Focus component of Mental toughness much better- by guiding them through time orientation, positive self-talk, composure, concentration and confidence."

Athlete Autonomy. Participants reported becoming more supportive of athlete autonomy. This was characterized by listening to and acknowledging the athletes' perspectives and giving more choices to the athletes.

Acknowledging athletes' perspective. Coaches reported a shift in their frequency of acknowledging the athletes' perspectives. Coaches listened to their athletes more as well as gave meaningful rationales behind decision-making. One coach made a change to "listen and pay more attention to the athletes' view of my training." Other coaches reported attempts to foster more understanding and knowledge within athletes, as one said, "I sit my athletes down and explain to them the reasons behind thinking and practice exercises."

Give the athletes choices. Giving athletes more choices was the most occurring subtheme in the study, and coaches reported different ways of incorporating this into their coaching behavior. Some coaches reported giving options in practice, stating "I give my 
athletes practice and drill options at practice instead of forcing them into groups," and "I let my athletes guide and come up with their own warm-ups on certain days." Other coaches reported using choice with team and culture development, reporting "I had them set practice rules for the group and decide on punishments." These findings represent a push towards autonomy supportive environments.

Gratitude. Coaches made a shift towards increasing their gratitude. This was reflected in coaches expressing gratitude towards their athletes and giving athletes more opportunities to express gratitude.

Gratitude towards athletes. Coaches increased their expression of gratitude towards their athletes. This revolved around the athletes' effort and attendance at practice. One coach stated, "I thank them for coming to workouts," while another said, "I am grateful to my athletes and thank them for their effort at practice."

Athlete gratitude towards others. Coaches expressed a need to teach and have their athletes express gratitude towards other people. One coach said, "I had them write letters of gratitude to their parents for their help getting them to practice and attending their games."

Research Question 2: Gender. First, using an independent samples t-test, the study determined that there were no significant differences in coaching efficacy between genders before starting the workshop, $\mathrm{t}(59)=1.780, \mathrm{p}=.08$.

The study used an independent sample t-test to compare changes in coaching efficacy from pre- to post-workshop with gender. Changes in coaching efficacy were determined by finding the difference between pre- and post-workshop Coaching Efficacy 
Scale scores. There were no significant differences between coaching efficacy changes based on gender. The findings regarding gender are listed in Table 4 below.

Table 4

Results of Independent Sample t-test for Coaching Efficacy Change by Gender

\begin{tabular}{|c|c|c|c|c|c|c|c|c|c|}
\hline & \multicolumn{6}{|c|}{ Gender } & \multirow[t]{3}{*}{$95 \% \mathrm{CI}$} & \multirow[b]{3}{*}{$\mathrm{t}$} & \multirow[b]{3}{*}{ df } \\
\hline & \multicolumn{3}{|c|}{ Male } & \multicolumn{3}{|c|}{ Female } & & & \\
\hline & $\mathrm{M}$ & SD & $\mathrm{n}$ & M & SD & $\mathrm{n}$ & & & \\
\hline $\begin{array}{l}\text { Coaching } \\
\text { Efficacy } \\
\text { Change }\end{array}$ & .40 & .53 & 41 & .57 & .50 & 20 & $-.46, .11$ & 1.20 & 59 \\
\hline
\end{tabular}

Note. $M=$ mean change in CES scores from pre- to post-workshop. $95 \% C I=95 \%$ Confidence Interval of the Mean Difference $* p<.05$

Research Question 3: Experience. Prior to beginning the workshop, significant differences existed in coaching efficacy between different experience categories, $F(4,59)$ $=6.144, \mathrm{p}<.001$. Coaches with more experience had higher overall coaching efficacy. Analysis of variance testing was used to consider the relationship between changes in Coaching Efficacy Scale (CES) scores from pre- to post-workshop and experience categories. Coaching experience groups did not significantly differ in CES changes, $F(4,59)=2.147, \mathrm{p}=.086$. The findings related to experience can be found in Table 5 below.

Table 5

Analysis of Variance for Coaching Efficacy Scale (CES) Score Change Based on Experience

\begin{tabular}{llccccc}
\hline & & $S S$ & $d f$ & $M S$ & $F$ & $p$ \\
\hline Changes in Coaching & Between Groups & 2.135 & 4 & .534 & 2.147 & .086 \\
& & & & & & \\
Efficacy Scale scores & Within Groups & 14.665 & 59 & .249 & & \\
& Total & 16.799 & 63 & & & \\
& & & & & &
\end{tabular}


Research Question 4: Age. Before starting the workshop, there were no significant differences on Coaching Efficacy Scale scores between age categories, $F(5$, $54)=1.779, \mathrm{p}=.133$. ANOVA testing was used to determine if there were significant differences in changes of coaching efficacy from pre- to post-workshop based on age category. The findings regarding age were not found to be statistically significant, $F(5$, $54)=1.730, p=.143$. The findings for age are found in Table 6 below.

Table 6

Analysis of Variance for Coaching Efficacy Scale (CES) Score Change Based on Age

\begin{tabular}{llccccc}
\hline & & $S S$ & $d f$ & $M S$ & $F$ & $p$ \\
\hline Changes in Coaching Efficacy & Between Groups & 2.237 & 5 & .447 & 1.730 & .143 \\
Scale scores & Within Groups & 13.959 & 54 & .258 & & \\
& & & & & & \\
& Total & 16.195 & 59 & & & \\
& & & & & & \\
\hline
\end{tabular}

Research Question 5: Enrollment. The effect of enrollment status was assessed in the current study. Enrollment status was characterized as either voluntary or required by school administrators. This included School Superintendents, Principles, and Athletic Directors. Since there were only two categories, the study used an independent samples t-test to determine if there were significant differences in coaching efficacy between enrollment categories before starting the workshop. The t-test determined enrollment category significantly impacted initial Coaching Efficacy Scale (CES) scores, $t(51)=$ $3.00, p=.004$, as coaches who voluntarily enrolled reported higher levels of coaching efficacy.

The study considered enrollment status in relation to changes in coaching efficacy scores from pre- to post-workshop. Using an independent samples t-test, the study 
determined there were significant differences in changes in coaching efficacy scores based on enrollment, $\mathrm{t}(51)=3.961, \mathrm{p}<.001$. Participants who described their enrollment as required had a .22 score increase after their completion of the course. Those participants that reported voluntary enrollment experienced a .73 mean score increase after the Digital Workshop. The findings can be found in Table 7.

Table 7

Results of Independent Sample t-test for Coaching Efficacy Change by Enrollment Status Enrollment Status 95\% CI

\begin{tabular}{|c|c|c|c|c|c|c|c|c|c|}
\hline & \multicolumn{3}{|c|}{ Voluntary } & \multicolumn{3}{|c|}{ Mandatory } & & \multirow[b]{2}{*}{$\mathrm{t}$} & \multirow[b]{2}{*}{$\mathrm{df}$} \\
\hline & $\mathrm{M}$ & $\mathrm{SD}$ & $\mathrm{n}$ & $\mathrm{M}$ & SD & $\mathrm{n}$ & & & \\
\hline Enrollment & .73 & .51 & 25 & .22 & .43 & 28 & $.25, .77$ & $3.96 * *=$ & 51 \\
\hline
\end{tabular}

Note. $M=$ Mean Change in Coaching Efficacy Scale scores, 95\% CI =95\% Confidence Interval of the Mean Difference $* * * p<.001$

\section{Research Question 6: Attitudes towards Continuing Education. The} participants' attitudes towards continuing education were compared to changes in coaching efficacy from pre- to post-workshop. Attitudes towards continuing education were determined by the Revised Adult Attitudes towards Continuing Education Scale (RAATCES), and changes in coaching efficacy were determined by finding the difference between pre- and post-workshop Coaching Efficacy Scale (CES) scores. A Pearson correlation was used to determine if scores on the R-AATCES were significantly related to changes in CES score. There were no significant correlations found between either the R-AATCES pre-test or R-AATCES post-test when compared to changes in CES. The findings can be found in Table 8 below. 
Table 8

Pearson Correlations between Revised Adult Attitudes towards Continuing Education Scale and Coaching Efficacy Score Change

\begin{tabular}{lccc}
\hline & $\mathbf{1}$ & $\mathbf{2}$ & $\mathbf{3}$ \\
\hline 1. Attitudes towards Education (pre-workshop) & 1 & & \\
2. Attitudes towards Education (post-workshop) & $.673 *$ & - & 1 \\
3. Change in Coaching Efficacy & -.134 & -.039 &
\end{tabular}

Although scores on the R-AATCES did not significantly correlate with CES score changes, scores on the R-AATCES did change significantly from pre- to post-workshop. A paired sample t-test determined that after the completion of the workshop, participants experienced a significant increase in their attitudes towards continuing education, $t(2,64)$ $=2.110, \mathrm{p}=.039,$. This indicated a positive shift in perceptions towards continuing coach education.

Research Question 7: Resistance to Change. Resistance to change was compared to changes in coaching efficacy to determine if there was a relationship between the two constructs. Resistance to change was measured by the Resistance to Change Scale (RTCS) and changes in coaching efficacy were determined from the difference of pre- and post-workshop Coaching Efficacy Scale (CES) scores. A Pearson Correlation was used to determine if there was a relationship between RTCS scores and changes in CES scores. All four Resistance to Change Scale subscales (e.g. Routine Seeking, Emotion Reaction, Short-Term Focus, and Cognitive Rigidity) were included in this analysis. The results can be found in Table 9 below. 
Table 9

Pearson Correlations between Resistance to Change Scale (Incl. Subscales) and Coaching Efficacy Score Change

\begin{tabular}{lccccc}
\hline & $\mathbf{1}$ & $\mathbf{2}$ & $\mathbf{3}$ & $\mathbf{4}$ & $\mathbf{5}$ \\
1. Resistance to Change Total & - & & & & \\
2. Routine Seeking & .87 & - & & & \\
3. Emotion Reaction & .89 & .67 & - & - & - \\
4. Short Term Focus & .86 & .69 & .75 & .23 & -.02 \\
5. Cognitive Rigidity & .55 & .35 & .35 & .21 & \\
6. Coaching Efficacy Score Change & .16 & .24 & .07 &
\end{tabular}

There was no significant relationship between the RTCS and its subscales' scores and changes in CES scores after the completion of the course. Resistance to Change Scale scores did not significantly change from pre- to post-workshop, $t(1,64)=.581, \mathrm{p}=$ .595 . 


\section{CHAPTER 5}

\section{DISCUSSION}

The following chapter will provide a summary of this study, discuss the results reviewed in Chapter 4, discuss the limitations for the current study, and provide recommendations for future research. Through this discussion, the study will provide insight for both researchers and educators and further inform the field of coach education.

The purpose of this study was to investigate the relationship between coaches' personal factors and changes in coaching efficacy after attending a coach education program. The education program selected for this study was the Missouri Institute for Positive Coaching Digital Workshop. The current study is in response to an increase of coach education programs at all levels (McCullick, Belcher, \& Scheumpp, 2005; Lyle, 2007; Trudel \& Gilbert, 2006). Despite the increase in coach education programs, there has been little research on the demographics and characteristics of coaches and how these factors relate to coaches' consumption of continuing education. In the field of teaching, where continuing education is considered essential, researchers have looked at many factors including age, gender, experience, will to learn, attitudes towards continuing education, and resistance to change (Blunt \& Yang, 2002; Eekelen, Vermunt, \& Boshuizen, 2006; Kwakman, 2003; Patton \& Griffin, 2008; Oosterheert\& Vermunt, 2001; Oreg et al., 2008; Verloop, Van Driel, \& Meyer, 2001). This study examined these factors within coach education.

This study looked at changes in coaching efficacy after coaches' completion of an online coaching education program grounded in positive coaching/coaching effectiveness. More importantly, the current study looked at how personal variables (i.e., 
age, gender, experience, enrollment), attitudes and beliefs towards continuing education, and dispositional resistance to change related to changes in coaching efficacy from the time of enrollment to the completion of the course.

For the current study, coaches enrolled in the Missouri Institute for Positive Coaching Digital Workshop were asked to fill out the pre-workshop survey prior to beginning the workshop. After their completion of the workshop, they were asked to continue their participation in the study by completion of the post-workshop survey. Coaches who did not take the survey after finishing the course were sent reminders via email periodically. Sixty-five coaches completed both the pre- and post- workshop surveys. The pre-workshop survey included a demographic survey (i.e. age, gender, experience, enrollment status), the Revised Adult Attitudes Towards Continuing Education Scale (R-AATCES), the Resistance to Change Scale (RTCS), and the Coaching Efficacy Scale (CES). The post-workshop survey included the R-AATCES, RTCS, CES, and an open-ended qualitative item regarding changes in coaching behavior.

The majority of participants were male (64\%), in the 24-34 age category, and reported having more than 15 years of coaching experience (30.4\%). Most coaches reported their participation in the course as required (52.8\%), as compared to voluntary (47.1\%). Coaches in the study were well educated, as the majority of participants reported having either a master's (37\%) or bachelor's degree (35\%). They were primarily from the state of Missouri (52\%), followed by Wisconsin (22\%) and Texas $(12 \%)$

Paired sample t-tests of Coaching Efficacy Scale scores from pre-workshop to post-workshop found a significant increase in coaching efficacy after the completion of 
the Digital Workshop. This effect was found across all four subscales of game strategy efficacy, motivational efficacy, character building efficacy, and technical efficacy. In addition to the improvement in coaching efficacy, qualitative reports from coaches suggested that coaches were making significant and specific behavioral changes. Out of the 65 participants, 48 coaches reported that they had implemented changes to their coaching behavior. Forty of the 48 coaches provided written answers to the qualitative prompt for examples of behavior change. Sixteen codes were identified and sorted into 5 main themes from the qualitative responses. These themes were intentional coaching, positivity, mental skills, athlete autonomy, and gratitude.

Differences in changes in coaching efficacy based on personal factors were also examined. Personal factors such as age, gender, experience, and enrollment status were explored. Only enrollment status proved to have significant differences in coaching efficacy changes. Participants who reported voluntarily enrolling in the program had a significantly higher increase in coaching efficacy after completion of the education program.

Finally, the study looked at the relationship between attitudes towards continuing education and resistance to change and how these factors related to changes in CES. Neither of these factors, as determined by their respective scales, were found to significantly correlate with changes in coaching efficacy. It should be noted that the attitudes and beliefs towards education did see a significant change from pre-workshop to post-workshop. Scores on the R-AATCES increased by a mean of .97 after the completion of the Digital Workshop. This represented an increase in positive attitudes 
towards continuing education.

\section{Conclusions}

As demand for qualified coaches increases, the demand for coach education programs grounded in coaching effectiveness also increases. This is especially relevant for youth and high school coaches, as they interact with athletes at a critical period of psychological, social, and emotional development (Coté \& Fraser-Thomas, 2007). Coaching effectiveness-based programs are focused on the two-directional model of coaching success, which focuses on performance excellence and positive psychological/character outcomes for all athletes (Coté \& Gilbert, 2009). Programs grounded in this framework have been shown to be effective at positively impacting goalorientation, motivational climate, ego-orientation, and coaching efficacy (Langan et al., 2013; Maehr \& Zusho, 2009). Short ( 75min) coach education interventions have been demonstrated to be effective at creating positive behavioral changes in coaches (Smith et al., 2007). Current research offers no general recommendations for coach education; however, many individuals programs have been validated (Langan et al., 2013).

The current study investigated the Missouri Institute for Positive Coaching Digital Workshop after a review of coach education literature. Coach educators and researchers lack a clear understanding of coaches entering coach education programs. Researchers have yet to consider the educational needs of coaches or the obstacles that might negatively impact coaches' experiences with coach education. The current study utilized teacher education as a framework to understand how personal characteristics relate to coaches' pursuit and consumption of coach education. 
The current study used the Coaching Efficacy Scale (CES) to measure the effects of the Missouri Institute for Positive Coaching (MIPC) Digital Workshop. The Coaching Efficacy Scale has frequently been used to assess the effectiveness of other coach education programs (Campbell \& Sullivan, 2005; Malete \& Feltz, 2000; Sullivan et al., 2012). This study attempted to understand personal variables in relation to changes in scores on the CES, as well as gain insight into behavior changes coaches were making after their completion of a coach education program.

Coaching Efficacy. Changes in coaching efficacy from pre- to post-workshop were examined. Participants in the program experienced significant increases in coaching efficacy. This held true across all four subscales. The largest mean increases occurred in the motivational efficacy and character-building efficacy sub-scales. This finding is important, especially when considering the content and goals of the MIPC Digital Workshop. The program seeks to create sport experiences that are focused on both positive psychological and performance outcomes. The Missouri Institute for Positive Coaching, which is a non-sport specific coach education program, focuses on theories from sport psychology, positive psychology, and coaching theory. Some of the listed principles of its program include, "promote and protect the priority of each individual's well-being and happiness," "develop intrinsic motivation, internal motivation, approach motivation, and positive motivation," and "identify and build upon each person's strengths." Character and motivational efficacy score increases were consistent with the emphasis of the program and increased more than technical and game strategy efficacies. These findings support the mission of the education program and suggest that the program is effective in its aim. 
All subscales increased from the start of the workshop to its completion. Because the MIPC program is primarily focused on universal coaching principles instead of sport specific ones, it is interesting that the game strategy and the technical efficacy sub-scale scores would increase after the completion of the workshop. Typically, these scales have been shown to have significant increases after a coach's attendance of a sport specific training program (Chase et al., 2005; Nash, 2003). One explanation for this occurrence is that education programs, even those that are not sport specific, have been shown to increase all types of coaching efficacy (Santos et al., 2010). Consequently, completion of a coach education program of any type may lead to increased feelings of competence and empowerment in carrying out all types of coaching duties. This necessitates further investigation. Additionally, the Missouri Institute for Positive Coaching Digital Workshop teaches lessons related to communication and instruction which may enhance all efficacies. These components are evident in principles like "demonstrate and utilize positive, active, constructive instruction/responding," and "develop and model the skills of focus, self-control, and mental toughness" (McGuire, 2016, p. 25). These principles may help develop interpersonal and non-sport specific skills which would enhance the ability of the coach to utilize and teach their professional knowledge. In turn, this could foster increased feelings of technical and game-strategy efficacy.

The current study supports the findings of Chase and colleagues (2005) regarding sources of coaching efficacy. Chase et al. (2005) identified coaches' development and leadership skills as important sources of coaching efficacy, especially in regards to technical and game strategy efficacies. Coaches' development was centered on coach education and learning from experiences and those around the coach. Leadership skills 
focused on the development of interpersonal skills and a coaching philosophy. Both of these sources were directly addressed by the Missouri Institute for Positive Coaching program. As a non-formal education program, the MIPC Digital Workshop fits into the category of coach education. In terms of leadership skills, the program asks coaches to critically reflect and develop a coaching philosophy. Past research supports the role of these sources on impacting the domains of technical efficacy and game strategy efficacy. The current study supports the use of these sources in the development of all four domains of coaching efficacy.

The study also considered qualitative self-reports of behavior change. When considering the qualitative responses, there were specific changes that coaches reported making to their coaching behaviors. Forty-eight out of the 65 participants reported making changes, while 40 participants provided specific examples of the behavior changes in the open response portion of the survey. The study sought to understand the factors around coaching behavior changes and compared the behavior change item to participants' gender, experience, age, and enrollment status. Scores on the Coaching Efficacy Scale (CES), changes in CES scores, Revised Adult Attitudes towards Continuing Education Scale scores, and Resistance to Change Scale scores were also considered. Out of all these variables, enrollment status, scores on the pre-workshop Coaching Efficacy Scale (CES), and changes in CES were found to have a significant relationship with behavior change. This suggests several things. First, it suggests voluntary enrollment status may play a significant role in coaches' willingness to learn new strategies and change. Coaches who voluntarily enrolled in the program were more likely to have behavioral change. Coach educators may have greater difficulty creating 
positive outcomes when coaches are required to attend education. This relates to the will to learn concept presented by researchers within the field of teacher education. Eekelen, Vermunt, \& Boshuizen (2006) describe will to learn as the "psychological state in which the learner has a desire to learn,” (p. 410). This concept is closely tied to tinkering, which is the implementation and experimentation with newly presented ideas (Hargreaves, 1999). The voluntary enrollment of the coach may suggest the presence of the "will to learn," which may provide an explanation for the increased behavioral changes. This justifies the application of this concept from teacher education to coach education and emphasizes its importance within the coach education field.

Secondly, the findings regarding the positive relationship between pre-workshop coaching efficacy and behavioral change suggest that coaches who are initially more confident in their abilities are more likely to change their behavior. These coaches' increased efficacy at the start of the course may reflect a confidence to correctly implement the new ideas into practice and have positive outcomes.

Finally, the findings regarding changes in coaching efficacy and behavior change suggest that there is a possible threshold of coaching efficacy increase that must be reached before behavior change can occur. Education that increases coaching efficacy may be helpful when attempting to create changes to coaching behavior. Receiving coach feedback during coach education programs to assess coaches' understandings may be important, as coaches suggest many education programs only provide a basic understanding of knowledge (Jones, Armour, \& Potrac, 2004). Coaches have also mentioned that coach education fails to provide practical applications of learned skills to real world scenarios (Lemyre et al., 2007; Nash, 2003). Since communities of practice 
have been demonstrated to positively affect coaching efficacy (Bertram \& Gilbert, 2011), providing opportunities for coaches to discuss practical applications of educational material may positively enhance both coaching efficacy and behavioral outcomes.

Sixteen codes were identified from participant responses to open ended questions. The codes were sorted into 5 major themes, including intentional coaching, positivity, importance of mental skills, athlete autonomy, and gratitude. Consideration of these themes in relation to the educational content of the MIPC as well as Coté and Gilbert's (2009) definition of coaching effectiveness allows for interpretation of the results when considering the aims and purpose of the education program.

Intentional Coaching. Intentional coaching, the most commonly identified theme, had subthemes of understanding the science behind coaching, modeling desired behavior, developing team culture, and reflecting and planning coaching behavior. These results reinforce and reflect the educational goals outlined by the MIPC. These findings focus around the MIPC principle of "discovering the calling," which asks for coaches to reflect on their values, identify their coaching goals, establish their own coaching philosophy, and model positive character (McGuire, 2016, p. 27).

The specific changes that coaches made suggest a shift in their mindset towards coaching practices. Coaches discussed the need to plan their coaching behaviors ahead of time as opposed to reacting within the moment. This was reflected in both broad statements such as, "approaching coaching with a different mindset," as well as more specific statements. For example, "we are going to focus on how to prepare our athletes better when it comes to practice." The following statement accurately portrays the findings in this section: 
"through this program, I have come to learn that positive coaching also includes structuring practices and meets to be more supportive and developmental towards the focus, self-confidence, and value of athletes, and how to structure each day to help support those larger goals."

Coaches reported spending more time planning their activities and reported feeling empowered by having "science to back up [their] coaching." Additionally, coaches reported a need to display and model the behaviors they wished to see in their athletes and described this as a conscious, intentional process. These findings demonstrate a shift towards reflective practice.

Reflection is an intrapersonal skill. In Coté and Gilbert's (2009) model of coaching effectiveness, intrapersonal skill is shown to be one of the most critical components of effective coaching. Intrapersonal knowledge greatly affects the ability of coaches to improve their coaching effectiveness and expertise (Coté \& Gilbert, 2009; Gilbert \& Trudel, 2001). Reflection involves looking back at previous occurrences, making sense of what happened, and learning from these experiences. Without reflection, much of the value of experiential learning is diminished or lost (Cushion et al., 2010). The findings of this study suggest that participation in the workshop increased coaches' appraisal and use of reflective practices. This increase in appraisal led coaches to positively regard the workshop and implement positive behavioral changes into their coaching behavior.

Positivity. Positivity was characterized as providing positive feedback and focusing on what went right. These findings reflect the content of positive coaching as outlined by the workshop, particularly with the principles of cultivating positive/caring 
relationships and inspiring passionate hearts. These principles state goals of "demonstrating and utilizing positive, active, constructive instruction/responding," as well as "modeling, promoting, and nurturing positive emotions" (McGuire, 2016, p. 25). The responses of participants suggest that the principles of the workshop were being implemented into behavioral change.

Coaches stated the workshop "will allow me to be more positive with the students." Other coaches stated they were "choosing to be more positive in every aspect," and were "going to seek out opportunities to give positive feedback." In terms of focusing on what went right, coaches stated a desire to "catch them doing something good," and "choosing to not focus on what went wrong."

These findings closely resemble the principles and findings of positive psychology. First, the model and acronym of PERMA (Seligman, 2011) has been demonstrated to be an effective tool in increasing well-being. PERMA includes aspects of positivity as the "P" stands for positive emotions. These positive emotions are defined as the "happiness" component of well-being. Additionally, positive psychology focuses on what went right as opposed to failures and shortcomings. This has been shown to reduce depression in individuals who engage in this practice regularly (Seligman, 2011). Finally, positive psychology involves a shift towards analyzing and focusing on individuals' strengths rather than their weaknesses (Peterson \& Seligman, 2004).

Coaches reported making shifts towards being more positive in practice and game environments, focusing on what went right, and focusing on individuals' strengths instead of weaknesses. Although there can be no definitive claim as to what this will do to athletes' well-being, a shift towards these behaviors has been demonstrated to result in 
positive athlete outcomes. The findings of the current study suggest that the workshop prompted these shifts in behavior, and these behavior changes could potentially lead to more positive athlete experiences and enhanced coaching effectiveness.

Mental Skills/Toughness. Results of this study indicated that coaches experienced a shift in their perception and feelings towards mental skills and mental toughness. This was both a change in the coaches' perception of the importance of mental skills and a change in how coaches would implement these skills with their athletes. After their completion of the course, coaches stressed the need to devote more time to the development of mental skills, and even the need of "taking breaks from drills to work on team building/morale." This re-prioritization was reflected with statements like "I now know that mental strength is as important as physical strength." Coaches reported an increased knowledge and understanding of mental training, which empowered them to teach mental skills. The mental skills stressed by participants included the themes of self-talk, focus, thought anchoring, self-confidence, and providing positive feedback.

The mental skills listed by coaches are largely reflected in the MIPC's principles of positive coaching, with statements like "develop and model the skills of mental toughness, develop and model the skills of the 7 C's of SuCCCCCCCess, and develop and model the skills of focus and self-control" (McGuire, 2016, p. 25). The reported shift in ability to teach these skills provides generalized confidence that the Digital Workshop was successful at empowering coaches to become more effective at teaching mental skills/mental toughness to their athletes. 
These findings support those of other studies which suggest mental strength is a major part of athletic success (Zuleger, 2014), yet many coaches do not feel they have the skills or time to implement an effective mental skills training program (Gould, Medbery, Damarjian, \& Lauer, 2008). The coaches who underwent the workshop had an increased appraisal of mental skills training and an increase in confidence when it comes to teaching mental skills. Coaches reported seeing the need to focus on the psychological development of their athletes. This fits within the model of coaching effectiveness, which suggests that effective coaches focus on both psychological and performance outcomes (Coté \& Gilbert, 2009). The results of this study demonstrate the effectiveness of the MIPC education program in reframing the importance of mental skills training and empowering coaches to teach mental skills to their athletes.

Athlete Autonomy. After their completion of the workshop, coaches reported a shift in the role of the athlete in the athletic process. Instead of telling the athlete what to do all the time, coaches reported a need to explain their rationale behind their decisions, give the athletes choices, and understand their athletes' perspectives throughout the season. These findings were reflected with statements like "[I] listen and pay more attention to the athletes' view of my training," as well as, "I give my athletes practice and drill options at practice instead of forcing them into groups."

These findings fit within the goals of the Missouri Institute for Positive Coaching, which includes to "promote and protect the priority of each individual's wellbeing and happiness," and to "develop self-confidence by allowing individuals to make decisions for oneself, about oneself, and by oneself" (McGuire, 2016, p. 25). Again, the 
findings in this section suggest that coaches were attempting to implement ideas from the course into their coaching behavior.

The findings related to athlete autonomy are grounded in leadership style and selfdetermination theory. First, coaches were making a move towards more transformational-style coaching practices, as they sought to understand and listen to the perspectives of their athletes more frequently (Bass \& Steidlmeier, 1999). Secondly, the results also support Ryan and Deci’s (2000) self-determination theory (SDT). SDT suggests that autonomy is a necessary component of the intrinsically motivated individual, and the addition of choices within the practice environment can enhance athlete buy in and intrinsic motivation. Matosic and Cox (2014) determined that when coaches created autonomy supportive environments, athletes reported the highest levels of psychological need satisfaction.

The findings related to athlete autonomy represent a departure from the traditional, "my way or the highway" coaching practices which have been so prevalent. Because choice has been shown to positively enhance both psychological and performance outcomes (Amorose \& Anderson-Butcher, 2009), these findings represent a shift in coaching behavior towards coaching effectiveness (Coté \& Gilbert, 2009: Matosic \& Cox, 2014).

Gratitude. Coaches reported expressing more gratitude towards the athletes they coached and expected their athletes to show more gratitude towards others. Coaches said, "I thank them for coming to workouts" and "I am grateful to my athletes and thank them for their effort." Other coaches took it a step further, and "had [the athletes] write 
letters of gratitude to their parents for their help getting them to practice and attending their games."

These themes are reflected in the lessons of the Missouri Institute for Positive Coaching and suggest the program is effective at changing the perspective of the coaches. The concept of gratitude is included in the MIPC principles related to cultivating positive and caring relationships, and "developing and modeling the regular sharing of gratitude" (McGuire, 2016, p. 25). Again, these findings suggest a shift towards more transformational and servant styles of leadership. They also relate to the findings within positive psychology related to gratitude.

The coach-athlete relationship has been shown to be a huge determinant of success across many levels of sport (Felton \& Jowett, 2015; Sagar \& Jowett, 2015). At the highest levels, this relationship is characterized by an other-centered approach (Zuleger, 2014). Gratitude can be viewed as a relationship maintenance strategy, designed to foster a relationship that can withstand turbulence and create a shared focus. Gratitude has been demonstrated to enhance team satisfaction (Chen \& Kee, 2008) and resilience in difficult times of the season (Morton, 2014). Coaching effectiveness emphasizes the role of interpersonal relationships in fostering psychological and performance outcomes, as supported by the $3 \mathrm{C}+1$ model (Jowett, 2005). The shift in use of gratitude by coaches may potentially enhance the quality of the coach-athlete relationship, as has been demonstrated by other studies.

The current study looked at the effects of a coach education program from both quantitative and qualitative perspectives. Coaches who attended the workshop experienced a significant increase in their coaching efficacy. Phenomenologically, 
coaches reported 5 themes in which they had made concrete and conscious changes to their coaching behavior due to their participation in the education program. There was no control group for this study, so no definitive claim can be made to whether coaches were better off than coaches who had not attended the workshop or some other form of coach education. However, there is generalized evidence that the program prompted coaches to make positive changes to their coaching behaviors. These accounts are self-reports of change, so it is uncertain the extent to which these changes are occurring. These responses do suggest that at the very least, coaches are considering the material in relation to their current behavior and attempting to make changes. This closely resembles the concept of "tinkering" as presented by Hargreaves (1999) in teacher education. This process of experimentation is frequently accompanied by reflection, which eventually leads to permanent changes in behavior. The changes detailed by the participants are labeled positive improvements as they are supported by the principles of the Missouri Institute for Positive Coaching and the literature on effective coaching practices.

Personal Variables. Research questions 2, 3, 4, and 5 looked at the participants' personal variables in relation to changes in coaching efficacy from the start of the program to its conclusion. Coaching efficacy was measured by the Coaching Efficacy Scale (CES). Age, gender, and experience were not found to be significant, while course enrollment (i.e. voluntary vs. mandated by an administrator) had significant differences in CES score changes.

It was hypothesized that females in the program would experience greater positive changes in coaching efficacy. This is because women are more likely to seek out continuing education, which may indicate a higher will to learn (McGivney, 2004). 
Women reported having a .17 higher increase in coaching than men (.57 vs .40$)$, but the change was not found to be significant. This could potentially be due to the low sample size of this study, as there were only 20 women (29\%) in the study. It will be necessary to obtain more female participants to increase the power of the study and further understand this phenomenon moving forward.

When considering age, there were no significant differences in changes of coaching efficacy. The findings regarding age did not support the findings of other research, which suggests that older coaches may be more resistant to change and new ideas (Oreg et al., 2008; Stan et al., 2013). This resistance may be due to experience, as age and experience are highly correlated.

Coaches with higher levels of experience reported higher coaching efficacy at the start of the study. This finding fits within other research which demonstrates that experience factors (i.e. professional experience, past winning seasons, coaching experience, ability of team, parental support) positively impact coaching efficacy (Feltz et al., 1999; Gilbert \& Trudel, 2001). When considering changes in coaching efficacy, there were no significant differences between experience groups. Teacher education research states that experience can both decrease a teacher's pursuit of educational opportunity (Richter et al., 2013) and increase routine seeking and cognitive rigidity (Oreg et al., 2008). The current study anticipated that higher levels of experience would decrease changes in coaching efficacy scores. The findings of the current study do not support the findings from the field of teacher education, and found that there were no significant differences in coaching efficacy based on experience. 
Enrollment status was the only demographic variable to have significant differences in coaching efficacy changes. Enrollment status also had some significant correlations and interactions with other variables from the study. Coaches who enrolled voluntarily had higher coaching efficacy at the start of the program and had larger increases in coaching efficacy after completing the course. This compounded change makes the enrollment status an incredibly important factor when it comes to coach education, as much of coach education is required. This finding may suggest these coaches have higher efficacy because they voluntarily seek out other continuing education opportunities and willingly engage in it. Additionally, coaches who voluntarily enrolled were more likely to report making behavior changes. The sum of these findings suggest that voluntary enrollment positively enhances learning outcomes. This may be evidence of the presence of the will to learn, which has been demonstrated to be a powerful factor when considering continuing education outcomes with teachers (Oosterheert \& Vermunt, 2001). These findings also fit within self-determination theory (Ryan \& Deci, 2000), which cites autonomy as one of the key components of intrinsic motivation.

Many programs and national governing bodies/sport associations require coaches to undergo some form of coach education. Even though these required education programs are typically sport specific, the current findings suggest that coaches who are required to participate in these programs will experience decreased benefits than those who voluntarily enroll. Programs, educators, and researchers must take on the challenge of motivating coaches to see the need for continuing education and furthering their skills. This will assist coaches forced to take continuing education programs, as well as 
potentially increase the voluntary attendance of other coaches. The current study recommends demonstrating to coaches the benefit of continuing education to both performance and psychological outcomes. Having prominent and well-respected coaches advocate for programs or teach the material may help with the perception of the education, as mentoring has been demonstrated to be a major factor in coach education (Cushion et al., 2010). Additionally, since coaches are predominantly result-focused, providing coaches with results outlining the effectiveness, benefit, and results of education may also help increase attendance. These recommendations may help coaches who are more resistant to continuing education be more open to the experience.

Attitudes towards Continuing Education. Attitudes and beliefs towards education has been shown to be a strong predictor of a teacher's participation in continuing education programs (Blunt and Yang, 2002). The current study considered these attitudes using the Revised Adult Attitudes towards Continuing Education Scale and did not find a significant correlation to changes in coaching efficacy.

Even though attitudes towards education did not correlate with coaching efficacy changes, attitudes towards education did see significant improvement after the completion of the course. This indicates a positive shift in participants' attitudes towards continuing education. This suggests that coaches who enroll in coach education programs like the Missouri Institute for Positive Coaching Digital Workshop may experience an increased positive appraisal of coach education in general. This could potentially influence the coach's future pursuit of other continuing education. It could also lead to coaches providing recommendations to others on behalf of education programs. Secondly, this suggests the most significant obstacle to coach education may 
be getting coaches in the door to their first workshop or seminar. After coaches enter the education program and their attitudes begin to shift, they may be more likely to see the benefit and usefulness of the material. Because of this, coach educators need to continue to brainstorm ways to shift coaches' perception of education. As recommended earlier, having accomplished and well-respected coaches represent and deliver education programs may help improve the attendance of education and coaches' attitudes towards continuing education.

Resistance to Change. Prior to the current study, resistance to change has not been considered in coach education research. Resistance to change is important, as it has been shown to impact teachers' pursuit of continuing education programs and the feelings they have towards making changes (Oreg et al., 2008; Ritcher et al., 2011; Stan el al., 2013). The current study applied this construct to coach education.

First, resistance to change scores from the pre-workshop survey were compared with other factors in the survey. There was a significant negative correlation that existed between resistance to change scores and pre-workshop coaching efficacy. Within the subscales of the Resistance to Change Scale, both routine seeking and short-term focus were significantly correlated with coaching efficacy scores. This indicates that coaches who have higher levels of resistance to change, particularly in regards to routine seeking and short-term focus, initially reported lower coaching efficacy scores. Conversely, coaches with higher coaching efficacy reported lower routine seeking and short-term focus. Although correlation does not imply causation, the connection may suggest a cycle in which coaches who are resistant to change do not reflect and alter their coaching behaviors. This may lead to a diminished belief in their ability to coach. These findings 
highlight the relevance of routine seeking and short-term focus to coaching populations. There were no other significant relationships between resistance to change and other variables. This was surprising, as resistance to change has been demonstrated to be related to both age and experience (Oreg et al., 2008).

Next, resistance to change was compared to changes in coaching efficacy after course completion. There was no significant correlation between the total score on the Resistance to Change Scale and changes in the Coaching Efficacy Scale score. When examining the RTCS subscales, routine seeking narrowly missed significance, $p=.06$, followed by the short-term focus subscale, $p=.101$. The fact that these subscales were closer to significance in this analysis may warrant further investigation, especially with the prior finding suggesting their correlation with pre-workshop coaching efficacy. Routine seeking reflects an individual's desire to enjoy stable environments (Oreg et al., 2008). Researchers suggest that there are traditional accepted methods of coaching, which are frequently engrained in coaches before they begin their coaching careers (Coakley, 1978; Cushion, Armour, \& Jones, 2003). Short-term focus is defined as how much an individual is "distracted by short-term inconveniences involved in change, such that they refrain from choosing a rationally valued long-term benefit" (Oreg et al., 2008, p. 683). Many coaches feel the pressure to win. Because of this pressure, coaches believe that they cannot take the risk to change their behavior. If new material proves ineffective, then coaches could potentially be out of a job. Coaches who are more prone to this type of thinking may report a smaller or more negative change in coaching efficacy. Because of their relevance to coaching populations, the current study suggests that routine seeking and short-term focus should receive further investigation. 
Ultimately, the current study investigated changes in coaching efficacy and behavior after the completion of a positive coaching-based coach education program. Coaches in the program experienced an increase in coaching efficacy, and the qualitative responses of coaches supported that behavior change was occurring. At the same time, the current study investigated the role of personal characteristics, attitudes towards continuing education, and dispositional resistance to change on changes in coaching efficacy. Only enrollment status proved to have significant differences in coaching efficacy, as coaches who voluntarily enrolled experienced larger increases in coaching efficacy and were more likely to report behavior change. Despite these significant findings, there were limitations to this study that may have impacted results. These are discussed in the next section.

\section{Limitations}

The following limitations accompanied this study. First, the study was a single group, pre-/post-test designed study. Because there was no control group, conclusions and applications of the current findings cannot be extrapolated to all coaching populations. This design was selected for three main reasons. First, the focus of the study was on investigating the relationship between personal variables and changes in coaching efficacy after the attendance of an online education program. This meant the study was more concerned with between subject interactions rather than on the causality of the intervention. Secondly, this design was used due to limited access to coaches. Coaches are notoriously hard to recruit, and it was unlikely administrators would sign coaches up for a study in which they did not receive the education program. Finally, the program featured continuous open enrollment, and the time participants took to complete 
the course was extremely variable. This was because most coaches did not have a deadline to complete the program. Some coaches completed the workshop in two weeks while others took 8 months. The situational and time variables surrounding the coaches made the use of a control group problematic, as a proper time frame to administer surveys was difficult to determine.

The amount of time coaches took to complete the workshop may have other effects as well. This may be evidence of how seriously some coaches took the workshop or evidence of other variables. Many of the coaches may have been undergoing different circumstances at the time of their enrollment. Coaches who were in season may have had different interactions with the program than coaches who were out of season. The availability of time to tinker with ideas and to think through coaching practices may have influenced behavioral outcomes. Tinkering has been shown to be an important part of the integration of new ideas into behavior (Hargreaves, 1999), but requires time for reflection in order to integrate new practices permanently.

Secondly, even though the study included a mixed methods design, the study relied entirely on self-report from coaches to measure the benefits of coach education. It is hard to assess the benefit of a coach education program without observing coaching behavior or recruiting the coaches' athletes to take part in the study. This is especially relevant when considering a two-directional model of coaching like coaching effectiveness (Coté \& Gilbert, 2009). Future research should consider long-term studies which use observation and survey athletes to determine the full effectiveness of these programs. 
Third, the sample size was small. Many of the results showed convincing trends, but lacked significance. Perhaps with a larger sample some of these findings may have been significant. Compared to the number of participants that were in the recruitment pool, the study experienced low participation rates and significant participant fall-off. Out of 4,500 potential coaches who were recruited for the project, only 242 coaches responded to the initial survey at the start of the course. Out of these 242 coaches, only 77 finished the course. Out of these 77, 65 responded to the final survey. The coaches who elected to participate and completed their involvement with the study may have unique characteristics, which may have impacted results. Additionally, coaches who elected to finish the workshop may also have certain group characteristics which may have skewed their results. For instance, perhaps the coaches who participated had a higher appreciation for continuing education than other coaches or demonstrated an increased motivation to improve their coaching behavior. Each of these factors could have impacted the findings of the study.

Finally, the study was primarily a regional sample, mostly taken from the Midwest. There was not enough data to draw conclusions about location, sport coached, gender of athletes coached, etc. With a larger population size, these factors could be variables that would further inform the research in relation to coach education outcomes. Sport coached is particularly relevant, as different sports have their own traditionally held beliefs (Coakley, 1978). These beliefs could vary in the amount of conflict they create with the new ideas presented by two-directional, non-sport specific education programs.

\section{Recommendations for Future Research}


This focus of this study was to better understand coaching populations and their individual variables that might affect the way they encounter, experience, and respond to coach education. This is the first study of its kind to look directly at the relationship between these variables and coach education. The study also provides evidence that coaches who enrolled in the Missouri Institute for Positive Coaching program had increases in their coaching efficacy and implemented conscious behavior changes to their coaching practices.

This study began the process of looking at these variables and how they relate to education outcomes. Future research should focus on using larger sample sizes to validate the trends that were discovered. Larger samples will provide more power, which may discover additional significant findings.

Coach education studies that are longitudinal and grounded in observation are necessary to fully understand the effects of coach education. As educators and coaches begin to understand that coach education must expand outside the realm of traditional sport practices and the "what" of sport, it will be of paramount importance to understand how these programs affect coaches in practice and competitive environments. To have an accurate picture of these behavioral changes, educators must be able to observe coaches both before and after their completion of a program and have access to the experiences of the athletes who work with these coaches.

The findings of this study suggest that coaches who do not voluntarily attend continuing education programs have significantly decreased benefit when it comes to their outcomes, particularly regarding changes in coach efficacy. However, participants in the MIPC program reported a positive increase in their attitudes and beliefs towards 
continuing education after their completion of the workshop. This suggests that if educators can get participants in the door of education programs, they are likely to shift their attitudes towards continuing education entirely. This may make them more likely to pursue more education in the future. Researchers should seek to better understand this phenomenon and how to improve coaches' attitudes and appraisals towards continuing education. Additionally, an increase in appraisal of continuing education does not always lead to increased consumption. Longitudinal studies are needed to understand the education habits of coaches through their career.

One suggestion to enhance coach participation and learning is the use of the mentoring effect. Along with experiential learning, mentoring is considered to be one of the primary pathways of coach learning (Cushion et al., 2010). To take advantage of this effect, continuing education programs should have their programs endorsed or taught by well-respected coaches. Future research should consider whether having coaches versus educators teach material impacts the effectiveness of coach education.

Finally, it is imperative that the field of coach education begins to distinguish between coach education programs that are focused on the technical and tactical components of sport and programs that are focused on the intrapersonal and interpersonal domains of coaching. The goals of these two types of education programs are separate in content and mission. Because of this, they must be separated when considered in research. The current study suggests the terms "sport specific programs" versus "nonsport specific programs" or "character/psychological programs" for use when discussing the different types of education programs. The differentiation of these terms will help educators and researchers understand the goals of programs and their effectiveness at 
changing specific coaching behaviors. This differentiation will also help coaches understand the purpose of the coach education program they are attending. As coaches are traditionally result-driven, it is essential for programs to provide evidence that their methods are effective at creating both positive performance and psychological outcomes. 


\section{REFERENCES}

Abraham, A., Collins, D., \& Martindale, R. (2006). The coaching schematic: Validation through expert coach consensus, Journal of Sports Sciences, 24(6), 549-564.

Amorose, A. J., \& Horn, T. S. (2001). Pre- and post-season changes in intrinsic motivation of first year college athletes: Relationships with coaching behavior and scholarship status. Journal of Applied Sport Psychology, 13, 355-373.

Amorose, A. J., \& Anderson-Butcher, D. (2007). Autonomy-supportive coaching and self-determined motivation in high school and college athletes: A test of selfdetermination theory. Psychology of Sport and Exercise, 8, 654-670.

Argyle, M., \& Crossland, J. (1987). The dimensions of positive emotions. British Journal of Social Psychology, 26(2), 127-137.

Armour, K. M., \& Yelling, M. (2004). Professional "development"e and professional "learningee: Bridging the gap for experienced physical education teachers. European Physical Education Review, 10(1), 71-93.

Ashton, P. T., \& Webb, R. B. (1986). Making a difference: Teachers 'sense of efficacy and student achievement. NY: Longman.

Bandura, A. (1977). Self-efficacy: Toward a unifying theory of behavioral change. Psychological Review, 84, 191-215.

Bandura, A., \& National Institute of Mental Health. (1986). Prentice-Hall series in social learning theory. Social foundations of thought and action: A social cognitive theory. Englewood Cliffs, NJ, US: Prentice-Hall, Inc.

Bandura, A. (1997). Self-efficacy: The exercise of control. New York: Freeman.

Barnett, N. P., Smoll, F. L., \& Smith, R. E. (1992). Effects of enhancing coach-athlete 
relationships on youth sport attrition. The Sport Psychologist, 6, 111-127.

Bass, B. M. (1985). Leadership and performance beyond expectations. New York: Free Press.

Bass, B. M., \& Steidlmeier, P. (1999). Ethics, character, and authentic transformational leadership behavior. Leadership Quarterly, 10, 181-217.

Bass, B. M., \& Riggio, R. E. (2006). Transformational leadership (2nd ed.), Mahwah, NJ: Erlbaum.

Becker, A. J. (2009). It's not what they do, it's how they do it: Athlete experiences of great coaching. International Journal of Sports Science \& Coaching, 4(1), 93119.

Bertram, R., \& Gilbert, W. (2011). Learning communities as continuing professional development for sport coaches. Journal of Coaching Education, 4(2), 40-60.

Bloom, G. A., Durand-Bush, N., Schinke, R., \& Salmela, J. H. (1998). The importance of mentoring in the development of coaches and athletes. International Journal of Sport Psychology, 29, 267-281.

Blunt, A., \& Yang, B. (2002). Factor structure of the Adult Attitudes toward Adult and Continuing Education Scale and its capacity to predict participation behavior: Evidence for adoption of a revised scale. Adult Education Quarterly, 52(4), 299314.

Bowes, I., \& Jones, R. (2006). Working at the edge of chaos: Understanding coaching as a complex interpersonal system. The Sport Psychologist, 20, 235-245.

Calderhead, J. (1996). Teachers: Beliefs and knowledge. In D. C. Berliner, \& R. C. 
Calfee (Eds.), Handbook of educational psychology (pp. 709-725). New York: MacMillan.

Campbell, T., \& Sullivan, P. J. (2005). The effect of a standardized coaching education program on the efficacy of novice coaches. Avante, 11, 38-45.

Caron, J., Vargas, T. M., Hawn, S. (2018). Comparing coaches' and athletes' perceptions of coaching efficacy. Journal of Sport Behavior, 41(3), 351-369.

Cassidy, T., Potrac, P., \& McKenzie, A. (2006). Evaluating and reflecting upon a coach education initiative: The CoDe of rugby. The Sport Psychologist, 20, 145-161.

Cassidy, T., \& Kidman, L. (2010). Initiating a national coaching curriculum: A paradigmatic shift? Physical Education and Sport Pedagogy, 15(30), 307-322.

Cense, M., \& Brackenridege, C. (2001). Temporal and developmental risk factors for sexual harassment and abuse in sport. European Physical Education Review, 7(1), 61-79.

Chase M. A., Feltz, D. L., Hayashi, S. W., \& Hepler, T. J. (2005). Sources of coaching efficacy: The coaches' perspective. International Journal of Sport and Exercise Psychology, 1, 7-25.

Chelladurai, P. (1993). Leadership. In R. N. Singer, M. Murphey, \& L. K. Tennant (Eds.), Handbook on research on sport psychology (pp. 647-671). New York: Macmillan.

Chelladurai, P. (2007). Leadership in sports. In G. Tenebaum \& R. C. Eklund (Eds.), Handbook of sport psychology (3rd ed., pp. 113-135) Morgantown, WV: Fitness Information Technology.

Chelladurai, P., \& Saleh, S. D. (1980). Dimensions of leader behavior in sports: 
Development of a leadership scale. Journal of Sport Psychology, 2, 34-45.

Chelladurai, P., \& Reimer, H. A. (1998). Measurement of leadership in sport. In J. L. Duda (Ed.), Advances in sport and exercise psychology measurement (pp. 227256). Morgantown, WV; Fitness Information Technology.

Chen, L. H., \& Kee, Y. H. (2008). Gratitude and adolescent athletes' well-being. Social Indicators Research, 89(2), 361-373.

Chi, L. (2004). Achievement goal theory. In T. Morris \& J. Summers (Eds.), Sport psychology: Theory, applications, and issues (2nd ed., pp. 152-174). Milton, Australia: Wiley.

Coaching Association of Canada (2015). NCCP policy and implementation standards (ver 1.5).Retrieved from http://www.coach.ca/files/NCCP_Policies_ ImplementationStandards_Jan_2015.pdf

Coakley, J. J. (1978). Sport in society: Issues and controversies. St. Louis: The C. V. Mosby Company.

Coladarci, T. (1992). Teachers' sense of efficacy and commitment to teaching. Journal of Experimental Education, 60, 323-337.

Colley, H., James, D., Tedder, M., \& Diment, K. (2003). Learning as becoming in vocational education and training: Class, gender and the role of vocational habitus. Journal of Vocational Education and Training, 55(4), 471-496.

Collison, V. (1996). Becoming an exemplary teacher: Integrating professional, interpersonal, and intrapersonal knowledge, JUSTEC Annual Conference. ERIC Document Reproduction Service No. ED 401227.

Conroy, D. E., \& Coatsworth, J. D. (2004). The effects of coach training on fear of failure 
in youth swimmers: A latent growth curve analysis from a randomized controlled trial. Journal of Applied Developmental Psychology, 25, 193-214.

Coté, J., \& Fraser-Thomas, J. (2007). Youth involvement in sport. In P. R. E. Crocker (Ed.), Introduction to sport psychology: A Canadian perspective (pp. 266-294). Toronto: Pearson Prentice Hall.

Coté, J., \& Gilbert, W. (2009). An integrative definition of coaching effectiveness and expertise. International Journal of Sports Science \& Coaching. 4(3), 307-323.

Coombs, P. H., \& Ahmed, M. (1974). Attacking rural poverty: How non-formal education can help. Baltimore: John Hopkins University Press.

Cushion, C. J., Armour, K. M., \& Jones, R. L. (2003). Coach education and continuing professional development: Experience and learning to coach, Quest, 55, 215-230.

Cushion, C. J., Armour, K. M., \& Jones, R. L. (2006). Locating the coaching process in practice: Models "for" and "of" coaching. Physical Education and Sport Pedagogy, 11(1) 83-99.

Cushion, C., Nelson, L., Armour, K., Lyle, J., Jones, R., \& O’Callaghan, C. (2010). Coach learning and development: A review of literature. Sports Coach UK. Csikszentmihalyi, M. (2000). Flow: The psychology of optimal experience. New York: Harper Collins.

Darkenwald, G. G., \& Hayes, E. R. (2006). Assessment of adult attitudes towards continuing education. International Journal of Lifelong Education, 7(3), 197-204.

Demers, G., Woodburn, A. and Savard, C. (2006). The development of an undergraduate competency-based coach education program. The Sport Psychologist 20(2), 162173. 
Denison, J., \& Avner, Z. (2012). Positive coaching: Ethical practices for athlete development. Quest. 63(2), 209-227.

Duda, J. L., \& Hall, H. K. (2001). Achievement goal theory in sport: Recent extensions and future directions. In R. Singer, H. Hausenblas, \& C. Janelle (Eds.), Handbook of sport psychology (2nd ed., pp. 417-443). New York: Wiley.

Duda, J. L., \& Ntoumanis, N. (2005). After-school sport for children: Implications of a task involving motivational climate. In J. L. Mahoney, R. W. Larson, \& J. S. Eccles (Eds.), Organized activities as contexts of development: Extracurricular activities, after school, and community programs (pp. 311-330). Mahwah, NJ: Erlbaum.

Duffy, P. (2008). Implementation of the Bologna Process and Model Curriculum Development in coaching. In K. Petry, K. Froberg, A. Madella, \& Tokarsky (Eds.), Higher education in sport in Europe. From labour market demand to training supply (pp. 80-108). W. Maindenhead: Meyer \& Meyer Sport.

Eekelen, V., Vermunt, J. D., \& Boshuizen, H. P. A. (2006). Exploring teachers will to learn. Teaching and Teacher Education. 22, 408-423.

Efthymios, A., Giossi, S., \& Anastasiadou, S. (2010). Certified adult educators' attitudes towards continuing education. Review of European studies, 2(1), 61-71.

Emmons, R. A. (1999). Religion in the psychology of personality: An introduction. Journal of Personality, 67(6), 874-888.

Erickson, K., Coté, J., \& Fraser-Thomas, J. (2008). Sport experiences, milestones, and educational activities associated with high-performance coaches' development. The Sport Psychologist, 21(3), 302-316. 
Falcao, W. R., Bloom, G. A., \& Gilbert, W. D. (2012). Coaches' perceptions of a coaching training program designed to promote youth developmental outcomes. Journal of Applied Sport Psychology, 24, 429-444.

Felton, L., \& Jowett, S. (2015). On understanding the role of need thwarting in the association between athlete attachment and well/ill-being. Scandinavian Journal of Medicine Sciences and Sports, 25(2), 289-298.

Feltz, D. L., Chase, M. A., Moritz, S. E., \& Sullivan P. J. (1999). A conceptual model of coaching efficacy: Preliminary investigation and instrument development. Journal of Educational Psychology, 91, 765-776.

Fung, L. (2003). Assessment: Coaching efficacy as indicators of coach education program needs. Athletic Insight: The Online Journal of Sport Psychology, 5(1), np.

Gautheir, A. P., Schienke., J. R., \& Pickard, P. (2005). Coaching in northern Canadian communities: Reflections of elite coaches. Journal of Sports Science and Medicine, 4, 113-123.

Gervis, M., \& Dunn, N. (2004). The emotional abuse of elite child athletes by their coaches. Child Abuse Review, 13(3), 215-233.

Giacobbi Jr., P. R., Whitney, J., Roper, E., \& Butryn, T. (2002). College coaches' views about the development of successful athletes: A descriptive exploratory investigation. Journal of Sport Behavior, 25, 164-180.

Gilbert, W. D., \& Trudel, P. (1999). An evaluation strategy for coach education programs. Journal of Sport Behavior, 22(2), 234-250.

Gilbert, W. D., \& Trudel, P. (2001). Learning to coach through experience: Reflection in 
model youth sport coaches. Journal of Teaching in Physical Education, 21(1), 1634.

Gilbert, W. D., \& Trudel, P. (2006). The coach as a reflective practitioner. In R. L. Jones (Ed.), The sports coach as educator: Re-conceptualizing sports coaching (pp. 114-127). London: Routledge.

Gordon, S., \& Gucciardi, D. F. (2011). A strengths-based approach to coaching mental toughness. Journal of Sport Psychology in Action, 2, 143-155.

Gould, D., Gianinni, J., Krane, V., \& Hodge, K. (1990). Educational needs of elite U.S. national Pan American and Olympic coaches. Journal Teaching in Physical Education, 9, 332-344.

Gould. D., Lauer, L., Rolo, C., Jannes, C., \& Pennisi, N. (2006). Understanding the role parents play in tennis success: A national survey of junior tennis coaches. British Journal of Sports Medicine, 40(7), 632-635.

Gould, D., Medbery, R., Damarjian, N., \& Lauer, L. (2008). A survey of mental skills training knowledge, opinions, and practices of junior tennis coaches. Journal of Applied Sport Psychology, 11, 28-50.

Greenleaf, R.K. (1977). Servant leadership: A journey into the nature of legitimate power and greatness. New York: Paulist Press.

Hammermeister, J. J., Burton, D., Pickering, T., Chase M., Westre, K., \& Baldwin, N. Servant leadership in sport: A concept whose time has arrived. International Journal of Servant Leadership, in Press.

Hammond, J., \& Perry, J. (2005). A multi-dimensional assessment of soccer coaching course effectiveness. Ergonomics, 48(11-14), 1698-1710. 
Hargreaves, D. H. (1999). The knowledge of creating school. British Journal of Educational Studies, 47, 145-161.

Hollembeak, J., \& Amorose, A. J. (2005). Perceived coaching behaviors and college athletes' intrinsic motivation: A test of self-determination theory. Journal of Applied Sport Psychology, 17(1), 20-36.

Horn, T. S. (1987). The influence of teacher-coach behavior on the psychological development of children. In D. Gould \& M. R. Weiss (Eds.), Advances in pediatric sport sciences, Volume 2: Behavioral issues (pp 121-142). Champaign, IL: Human Kinetics.

Horn, T. S. (2005). The embodiment of learning. Educational philosophy and theory, $37(5), 745-760$.

Horn, T. S. (2008). Coaching effectiveness in the sport domain. In T. S. Horn (Ed.), Advances in sport psychology (3rd ed., pp 239-267). Champaign, IL: Human Kinetics.

Irwin, G., Hanton, S., \& Kerwin, D. G. (2004). Reflective practice and the origins of elite coaching knowledge. Reflective Practice, 5(3) 425-442.

Jeziorski, R. M. (1994). The importance of school sports in American education and socialization. Lanham, MD: University Press of America.

Jones, R. L., Armour, K. M., \& Potrac, P. (2004). Sports coaching cultures: From practice to theory. London: Routledge.

Jones, R. L., Armour, K. M., \& Potrac, P. (2003). Constructing expert knowledge: A case study of a top-level professional soccer coach. Sport, Education and Society, 8(2), 213-229. 
Jowett, S. (2003). When the "honeymoon" is over: A case study of a coach-athlete dyad in crisis. The Sport Psychologist, 17, 444-460.

Jowett, S. (2006). Interpersonal and structural features of Greek coach-athlete dyads performing in individual sports. Journal of Applied Sport Psychology, 18, 69-81.

Jowett, S., \& Cockerill, I. M. (2003). Olympic medalists' perspective of the athlete-coach relationship. Psychology of Sport Exercise, 4, 313-331.

Jowett, S., \& Ntoumanis, N. (2004). The Coach-Athlete Relationship Questionnaire (CART-Q): Development and initial validation. Scandinavian Journal of Medicine and Science in Sports, 14, 245-257.

Jowett, S., \& Lavallee, D. (2007). Sport psychology in sport. Champaign Illinois: Human Kinetics.

Jowett, P., \& Poczwardowski, A. (2007). Understanding the coach-athlete relationship. Retrieved from researchgate.net

Jowett, S., \& Chaundy, V. (2004). An investigation into the impact of coach leadership and coach-athlete relationship on group cohesion. Group Dynamics Theory: Research and Practice, 8(4), 302-311.

Kelly, B., \& Carchia, C. (2013). Hey, data data - Swing! ESPN. Retrieved from http://www.espn.com/espn/story/_/id/9469252/hidden-demographics-youthsports-espn-magazine

Knight, P. (2002). A systematic approach to professional development: Learning as practice. Teaching and Teacher Education, 18, 229-241.

Kwakman, K. (2003). Factors affecting teachers' participation in professional learning activities. Teaching and Teacher Education, 19, 149-170. 
Knowles, Z., Borrie, A., \& Telfer, H. (2005). Toward the reflective sports coach: Issues of context, education and application, Ergonomics, 48(11-14), 1711-1720.

Langan, E., Blake, C., \& Lonsdale, C. (2013). Systematic review of the effectiveness of interpersonal coach education interventions on athlete outcomes. Psychology of Sport and Exercise, 14(1), 37-49.

Laios, A., Theodorakis, N., \& Gargalianos, D. (2003). Leadership and power: Two important factors for effective coaching. International Sports Journal, 7, 150-155.

Leduc, M., Culver, D. M., \& Werthner, P. (2012). Following a coach education programme: Coaches' perceptions and reported actions. Sports Coaching Review, 1(2), 135-150.

Lemyre, F., Trudel, P., \& Durand-Bush, N. (2007). How youth-sport coaches learn to coach. The Sport Psychologist, 21, 191-209.

Linver, M. R., Roth, J. L., \& Brooks-Gunn, J. (2009). Patterns of adolescents' participation in organized activities: Are sports best when combined with other activities? Developmental Psychology, 45(2), 354-367.

Lorimer, R., \& Jowett, S. (2009). Empathic accuracy, meta-perspective, and satisfaction in the coach-athlete relationship. Journal of Applied Sport Psychology, 21, 201212.

Ludlam, K. E., Butt, J., Bawden, M., Lindsay, P., \& Maynard, I. W. (2015). A strengthsbased consultancy approach in elite sport: Exploring super-strengths. Journal of Applied Sport Psychology, 2, 216-233.

Lyle, J. (2002). Sport coaching concepts: A framework for coaches' behavior. London: Routledge. 
Lyle, J. (2007). A review of the research evidence for the impact of coach education. International Journal of Coaching Science, 1(1), 17-34.

Malete, M. L., \& Feltz, D. L. (2000). The effect of a coaching education program on coaching efficacy. The Sport Psychologist, 14, 410-417.

Maehr, M. L., \& Zusho, A. (2009). Achievement goal theory: The past, present, and future. In Handbook of Motivation in School (pp. 76-104). Routledge.

Mallet, C., \& Coté, J. (2006). Beyond winning and losing: Guidelines for evaluating high performance coaches. The Sport Psychologist, 20(2), 213-221.

Matosic, D., \& Cox, A. E. (2014). Athletes' motivation regulations and need satisfaction across combinations of perceived coaching behaviors. Journal of Applied Sport Psychology, 26(3), 302-317.

Merriam, S. (1983). Mentors and protégés: A critical review of the literature. Adult Education Quarterly, 33(3), 161-173.

McCullick, B. A., Belcher, D., \& Schempp, P. G. (2005). What works in coaching and sport instructor certification programs? The participants view. Physical Education \& Sport Pedagogy, 10, 121-137.

McGivney, V. (2004). Understanding persistence in adult learning. Open Learning, 19(1), 33-46.

McGuire, R. (2012). Winning kids with sport. Ames, Iowa: Championship Productions.

McGuire, R. (2016). The power of positive coaching. Columbia, MO. University of Missouri.

Mielke, D. (2008). Coaching experience, playing experience and coaching tenure. International Journal of Sports Science and Coaching, 2, 105-108. 
Moon, J. A. (2004). A Handbook of reflection and experiential learning: Theory and practice. London, Kogan Page.

Morton, S. (2014). A win at all values mentality: A phenomenological investigation of lived experiences of college gymnasts and volleyball in a comprehensive positive psychology intervention (Doctoral dissertation). Retrieved from http://mospace.umsystem.edu

Myers, N. D., Park, S. E., Ahn, S., Lee, S., Sullivan, P. J., \& Feltz, D. L. (2017). Proposed sources of coaching efficacy: A meta-analysis. Journal of Sport \& Exercise Psychology, 39, 261-276.

Myers, N. D., Feltz, D. L., \& Wolfe, E. W. (2008). A confirmatory study of rating scale category effectiveness for the Coaching Efficacy Scale. Research Quarterly for Exercise and Sport, 79, 300-311.

Myers, N. D., Feltz, D. L., Chase, M. A., Reckase, M. D., \& Hancock, G. R. (2008). The Coaching Efficacy Scale II-High School Teams. Educational and Psychological Measurement. 68(6), 1059-1076.

Nash, C. (2003). Coaching effectiveness and coach education programmes: Perceptions of Scottish and US coaches. International Sports Studies, 25(2), 21- 31.

Nash, C., \& Collins, D. (2006). Tacit knowledge in expert coaching: Science or art? Quest. 58, 465-477.

National Commission on Teaching \& America's Future (U.S.). (1996). What matters most: Teaching for America's future: Report of the National Commission on Teaching \& America's Future. New York, NY: The Commission.

Nelson, L. J., \& Cushion, C. J. (2006). Reflection in coach education: The case of the 
national governing body coaching certificate. The Sport Psychologist, 20,174183.

Nicolas, M., Gaudreau, P., \& Franche, V. (2011). Perception of coaching behaviors, coping and achievement in a sport competition. Journal of Sport and Exercise Psychology, 33(3), 460-468.

Northouse, P. G. (2004). Leadership: Theory and practice. Thousand Oaks, CA: Sage.

Nyberg, A., Bernin, P., \& Theorell, T. (2005). The impact of leadership on the health of subordinates. Stockholm, Sweden: National Institute for Working Life.

Oishi, S., Schimmack, U., Diener, E., \& Suh, E. M. (1998). The measurement of values and individualism-collectivism. Personality and Social Psychology Bulletin, 24, $1177-1189$.

Olympiou, A., Jowett, S., \& Duda, J. L. (2008). The psychological interface between the coach-created motivational climate and the coach-athlete relationship in team sports. The Sport Psychologist, 22(4), 423-438.

Oosterheert, I. E., \& Vermunt, J. D. (2001). Individual differences in learning to teachRelating cognitions, regulation and affect. Learning and Instruction, 11, 133-156.

Oreg, S. (2003). Resistance to change: Developing an individual differences measure. Journal of Applied Psychology, 88(4), 680-693.

Oreg, S., Bayazit, M., Vakola, M., Arciniega, L., Armenakis, A. A., Barkauskiene, R., van Dam, K. (2008). Dispositional resistance to change: Measurement equivalence and the link to personal values across 17 nations. Journal of Applied Psychology, 93(4), 935-944.

Page, D., \& Wong, P. T. P. (2000). A conceptual framework for measuring servant 
leadership. In S. Adjiboloos (Ed.), The human factor in shaping the course of history and development (pp. 69-111). Lanham, MD: American University Press.

Patton, K., \& Griffin, L. L. (2008). Experiences and patterns of change in a physical education teacher development project. Journal of Teaching in Physical Education, 27, 272-291.

Pepitas, A. J., Giges, B., \& Danish, S. J. (1999). The sport psychologist-athlete relationship: Implications for training. The Sport Psychologist, 13(3), 344-357

Peterson, C., \& Seligman, M. E. P. (2004). Character strengths and virtues: A handbook and classification. New York: Oxford University Press/Washington, DC: American Psychological Association

Price, M. S., \& Weiss, M. R. (2013). Relationships among coach leadership, peer leadership, and adolescent athletes' psychosocial and team outcomes: A test of transformational leadership theory. Journal of Applied Sport Psychology, 2, 265279.

Reade, I., Rodgers, W., \& Hall, N. (2008). Knowledge transfer: How do high performance coaches access the knowledge of sport scientists? International Journal of Sports Science and Coaching, 3(3), 319-334.

Rieke, M., Hammermeister, J., \& Chase, M. (2008). Servant leadership in sport: A new paradigm for effective coach behavior, International Journal of Sport Sciences and Coaching, 3, 227-239.

Richter, D., Kunter, M., Lüdtke, O., Klusmann, U., Anders, Y., \& Baumert, J. (2013). How different mentoring approaches affect beginning teachers' development in the first years of practice. Teaching and Teacher Education, 36, 166-177. 
Robertson, J. (2005). Coaching leadership: Building leadership capacity through coaching partnerships. New Zealand Council for Educational Research. Wellington.

Rudd, A. (2005). Which 'character' should sport develop? Physical Educator, 62(4), 170178. Ryan, R. M., \& Deci, E. L. (2000). Self-determination theory and the facilitation of intrinsic motivation, social development, and well-being. American Psychologist, 55(1), 68-78.

Sagar, S., \& Jowett, S. (2015). Fear of failure and self-control in the context of the coachathlete relationship quality. International Journal of Coaching Science, 9, 3-21.

Saksvik, I. B., \& Hetland, H. (2009). Exploring dispositional resistance to change. Journal of Leadership \& Organizational Studies, 16, 175-183.

Salmela, J. H. (1995). Learning from the development of expert coaches. Coaching and Sport Science Journal, 2(2), 3-13.

Salmela J. H., Draper, S. P., \& Desjardins, G. (1994). Transitional phases of expert ice and field hockey coaches' careers. In Access to Active Living (pp. 570-575). Victoria, CA: University of Victoria.

Santos, S., Mesquita, I., Graca, A., \& Rosado, A. (2010). Coaches' perceptions of competence and acknowledgement of training needs related to professional competencies. Journal of Sports and Medicine, 9, 62-70.

Saury, J., \& Durand, M. (1998). Practical knowledge in expert coaches: On-site study of coaching in sailing. Research Quarterly for Exercise and Sport, 69(3), 246-256.

Schempp, P. G., Templeton, C. L., \& Clark, B. (1998). The knowledge acquisition of 
expert golf instructors. In M. Farrally \& A. J. Cochran (Eds.), Science and golf III: Proceedings of the world scientific congress of golf (pp. 295-301). Leeds, UK, Human Kinetics.

Schon, D. A. (1983). The reflection practitioner: How professionals think in action. Aldershot: Arena.

Seligman, M. E. P. (2011). Flourish: A visionary new understanding of happiness and well-being, New York: Free Press.

Seligman, M. E. P., \& Csikszentmihalyi, M. (2000). Positive psychology: An introduction. American Psychologist, 55(1), 5-14.

Seligman, M. E. P., Steen, R. A., Park, N., \& Peterson, C. (2005). Positive psychology progress: Empirical validation of interventions. American Psychologist, 60, 410421.

Sheldon, K. M., \& King, L. (2001). Why positive psychology is necessary. American Psychology, 56(3), 216-217.

Smith, R. E., Smoll, F. L., \& Curtis, B. (1979). Coach effectiveness training: A cognitive behavioral approach to enhancing relationship skills in youth sport coaches. Journal of Sport Psychology, 1, 59-75.

Smith, R. E., Smoll, F. L., \& Barnett, N. P. (1995). Reduction of children's sport performance anxiety through social support and stress-reduction training for coaches. Journal of Applied Developmental Psychology, 16, 125-142.

Smith, R. E., \& Smoll, F. L. (1996). The coach as a focus of research and intervention in youth sports. In F. L. Smoll, \& R. E. Smith (Eds.), Children and youth in sport. A biopsychosocial perspective (pp. 125-141). Dubuque, IA: Brown \& Benchmark. 
Smith, R. E., \& Smoll, F. L. (2005). Assessing psychosocial outcomes in coach training programs. In D. Hackfort, J. L. Duda, \& R. Lidor (Eds.), Handbook of research in applied sport and exercise psychology: International perspectives (pp. 293-316). Morgantown, WV: Fitness Information Technology.

Smith, R. E., Smoll, F. L., \& Cumming, S. P. (2007). Effects of a motivational climate intervention for coaches on young athletes' sport performance anxiety. Journal of Sport and Exercise Psychology, 29, 39-59.

Smoll, F. L., Smith, R. E., Barnett, N. P., \& Everett, J. J. (1993). Enhancement of children's self-esteem training through social support training for youth sport coaches. Journal of Applied Psychology, 78, 602-610.

Smoll, F. L., \& Smith, R. E. (1997). Coaches who never lose: A 30-minute primer for coaching effectiveness. Protola Valley, CA: Warde Publishers.

Smoll, F. L., \& Smith, R. E. (2006). Conducting sport psychology training programs for coaches: Cognitive-behavioral principles and techniques. In J. M. Williams (Ed.), Applied sport psychology: Personal growth to peak performance (5th ed., pp. 458-480). Boston: McGraw-Hill.

Smylie, M. A. (1988). The enhancement function of staff development: Organizational and psychological antecedents to teacher change. American Educational Research Journal, 25, 1-30.

Sparks, D. (2002). Designing powerful professional development for teachers and principals. Oxford OH: NSDC.

Stajkovic, A. D., \& Luthans, F. (1998). Self-efficacy and work-related performance: A meta-analysis. Psychological Bulletin, 124, 240-261. 
Stan, S. A., Sancovici, V., \& Palos, R. (2013). Teachers' attitudes toward continuous professional training. Procedia-Social and Behavioral Sciences, 84, 1722-1726.

Stirling, A. E. (2013). Understanding the use of emotionally abusive coaching practices. International Journal of Sports Science \& Coaching, 8(4), 625-639.

Stirling. A. E., \& Kerr, G. (2009). Abused athletes' perceptions of the coach-athlete relationship. Sport in Society, 12(2), 228-339.

Stirling, A. E., \& Kerr, G. (2013). The Perceived effects of elite athletes' experiences of emotional abuse in the coach-athlete relationship. International Journal of Sport and Exercise Psychology, 11, 1-14.

Sullivan, P. J., \& Kent, A. (2003). Coaching efficacy as a predictor of leadership style in intercollegiate athletics. Journal of Applied Sport Psychology, 15, 1-11.

Sullivan, P., Paquette, K. J., Holt, N. L., \& Bloom, G. A. (2012). The relation of coaching context and coach education to coaching efficacy and perceived leadership behaviors in youth sport. The Sport Psychologist, 216, 122-134.

Sproule, J. (2012). Coaches perceptions of their coach education experiences. International Journal of Sports Science \& Coaching, 43, 33-52.

Sullivan, P., Paquette, K. J., Holt, N. L, \& Bloon, G. A. (2012). The relation of coaching context and coach education to coaching efficacy and perceived leadership behaviors in youth sport. The Sport Psychologist, 26, 122-134.

Thompson, J. (1995). Positive coaching: Building character and self-esteem through sports. Portola Valley, California: Balance Sports Publishing.

Thompson, J. (2010). The power of double-goal coaching. Portola Valley, California: Balance Sports Publishing. 
Tofler, I. R., Stryer, B. K., Micheli, L. J., \& Herman, L. R. (1996). Physical and emotional problems of elite female gymnasts. New England Journal of Medicine, $335,281-283$.

Trudel, P., Gilbert, W. D., \& Werthner, P. (2010). Coach education effectiveness. In J. Lyle \& C. Cushion (Eds.), Sports coaching: Professionalization and practice (pp. 135-152). London: Elsevier.

Turnman, P. D. (2001). Situational coaching styles: The impact of success and athlete maturity level on coaches' leadership styles over time. Small Group Research, $32(5), 576-594$.

Turner, D., \& Nelson, L. J. (2009). Graduate perceptions of a UK university based coach education programme, and impacts on development and employability. International Journal of Coaching Science, 3(2), 3-28.

Vargas-Tonsing, T. M. (2007). Coaches' preferences for continuing coaching education. International Journal of Sports Science \& Coaching, 2(1), 25-35.

Verloop, N., Van Driel, J., \& Meyer, P. (2001). Teacher knowledge and the knowledge base of teaching. International Journal of Educational Research, 35, 441-461.

Visek, A. J., Achrati, S. M., Manning, H., McDonnell, K., Harris, B. S., \& DiPietro, L. (2015). The fun integration theory: Towards sustaining children and adolescents sport participation. Journal of Physical Activity and Health, 12(3), 424-433.

Waigandt, A. \& Wang, Z. (2010). An introduction to statistical reasoning in quantitative research. Morris Publishing, Nebraska.

Walling, M. D., Duda, J. L., \& Chi, L. (1993). The Perceived Motivational Climate in 
Sport Questionnaire: Construct and predictive validity. Journal of Sport \& Exercise Psychology, 15, 172-183.

Wayne, A. J., Suk Yoon, K., Zhu, P., Cronen, S., \& Garet, M. S. (2008). Experimenting with teacher professional development: Motives and methods, Educational Researcher, 37(8), 469-479.

Wenger, E. (1998). Communities of practice: Learning, meaning and identity. Cambridge: Cambridge University Press.

Wood, R. E., Bandura, A., \& Bailey, T. (1990). Mechanisms governing performance in complex decision-making environments. Organizational Behavior and Human Decision Processes, 46, 181-201.

Woods, B. (2016). An exploratory factor analysis of the positive coaching inventory (Doctoral dissertation). Retrieved from mospace.umsystem.edu.

Woolfolk, A. E., Rossoff, B., \& Hoy, W. K. (1990). Teachers' sense of efficacy and their beliefs about managing students. Teaching and Teacher Education, 6, 137-148.

Wright, T., Trudel, P., Culver, D. (2007). Learning how to coach: The different learning situations reported by youth ice hockey coaches. Physical Education and Sport Pedagogy, 12(2), 127-144.

Zuleger, B. M. (2014). Positive coaching and Olympic success: Case studies of track and field Olympic medalist coach-athlete relationships (Doctoral dissertation). Retrieved from gradworks.umi.com. 


\section{APPENDIX A}

\section{Demographics}

What is your age?

B. $18-24$

C. $25-34$

D. $35-44$

E. $45-54$

F. $55-64$

G. $65-74$

H. 75 or older

How many years have you been a coach?
A. $0-4$ years
B. 5-10 years
C. 11-15 years
D. More than 15 years

Please select your gender:
A. Female
B. Male
C. Other

What sport(s) do you coach?

What is your highest level of education?
A. No high school
B. Some high school 
C. High school diploma

D. Some college

E. Associate's degree

F. Bachelor's degree

G. Some postgraduate work

H. Master's Degree

I. Doctoral Degree

Have you taken a continuing education course related to coaching before?
A. Yes
B. No

What is your position in your school?
A. Teacher
B. School employee
C. Unaffiliated with school, working as a coach only
D. Other

Did you choose to enroll in this program independently, or was participation mandated?
A. Independent enrollment
B. Mandated by administrator
C. Unknown

On a scale of 1-9 (1 being very unfavorable, and 9 being very favorable) what are your feelings towards the term "positive coaching?" 
On a scale of 1-9 (1 being very unfavorable, and 9 being very favorable) how useful do you perceive "positive coaching" towards your coaching practice? 


\section{APPENDIX B \\ Revised Adult Attitudes towards Continuing Education Scale}

\section{5-point Likert}

\section{Strongly Disagree. 2. Disagree. 3. Neither agree nor disagree. 4. Agree. 6. Strongly}

\section{$\underline{\text { Agree }}$}

1. Continuing education is mostly for people with little else to do.

2. I dislike studying.

3. Successful people do not need continuing education.

4. I am fed up with teachers and classes.

5. Money spent on continuing education for employees is money well spent.

6. Continuing my education would make me feel better about myself.

7. I enjoy educational activities that allow me to learn with others.

8. Continuing education is an important way to help people cope with changes in their lives.

9. Continuing education helps people make better use of their lives. 


\section{APPENDIX C \\ Resistance to Change Scale}

1. Strongly Disagree. 2. Disagree. 3. Inclined to disagree. 4. Inclined to agree. 5. Agree. 6. Strongly Agree

\section{$\underline{\text { Routine seeking }}$}

1. I generally consider changes to be a negative thing.

2. I'll take a routine day over a day full of unexpected events any time.

3. I like to do the same old things rather than try new and different ones.

4. Whenever my life forms a stable routine, I look for ways to change it.

5. I'd rather be bored than surprised.

\section{$\underline{\text { Emotional reaction }}$}

6. If I were to be informed that there's going to be a significant change regarding the way things are done at my job, I would probably feel stressed.

7. When I am informed of a change of plans, I tense up a bit.

8. When things don't go according to plans, it stresses me out.

9. If one of my professors changed my evaluation criteria, it would probably make me feel uncomfortable even if I thought I'd do just as well without having to do any extra work.

\section{$\underline{\text { Short-term focus }}$}

10. Changing plans seems like a real hassle to me.

11. Often, I feel a bit uncomfortable even about changes that may potentially improve my life. 
12. When someone pressures me to change something, I tend to resist it even if I think the change may ultimately benefit me.

13. I sometimes find myself avoiding changes that I know will be good for me.

\section{$\underline{\text { Cognitive rigidity }}$}

14. I often change my mind.

15. I don't change my mind easily.

16. Once I've come to a conclusion, I'm not likely to change my mind.

17. My views are very consistent over time. 


\section{APPENDIX D}

\section{Coaching Efficacy Scale}

\section{4 subcategories: Motivational Efficacy (ME), Game Strategy (GS), Technical}

\section{Efficacy (TE), Character Building (CB)}

$\underline{10 \text {-point likert scale }(0) \text { Not at all confident - (9) extremely confident }}$

\section{How confident are you in your ability to...}

1. maintain confidence in your athletes? (ME1)

2. recognize opposing team's strengths during competition? (GS2)

3. mentally prepare athletes for game/meet strategies? (ME3)

4. understand competitive strategies? (GS4)

5. instill an attitude of good moral character? (CB5)

6. build the self-esteem of your athletes? (ME6)

7. demonstrate the skills of your sport? (TE7)

8. adapt to different game/meet situations? (GS8)

9. recognize opposing team's weakness during competition? (GS9)

10. motivate your athletes? (ME10)

11. make critical decisions during competition? (GS11)

12. build team cohesion? (ME12)

13. instill an attitude of fair play among your athletes? (CB13)

14. coach individual athletes on technique? (TE14)

15. build the self-confidence of your athletes? (ME15)

16. develop athletes' abilities? (TE16) 
17. maximize your team's strengths during competition? (GS17)

18. recognize talent in athletes? (TE18)

19. promote good sportsmanship? (CB19)

20. detect skill errors? (TE20)

21. adjust your game/meet strategy to fit your team's talent? (GS21)

22. teach the skills of your sport? (TE22)

23. build team confidence? (ME23)

24. instill an attitude of respect for others? (CB24) 


\section{APPENDIX E}

\section{Measures of Behavioral Change and Perception of Education Program}

Has this program changed your view of continuing education?
A. Yes, for the better
B. Yes, for the worse
C. No

Have you changed your coaching practices in some way?
A. Yes
B. No

If yes, please give up to three examples:

On a scale of 1-10 (1 being not at all, and 10 being greatly), how much do you feel the positive coaching program has impacted your coaching?

On a scale of 1-10 (1 very unlikely, and 10 being very likely), how likely are you to recommend the MIPC Digital Workshop to other coaches? 


\section{APPENDIX F}

Qualitative Reponses: Self-reports of Behavioral Change

\begin{tabular}{|c|c|c|c|}
\hline Participant & $1^{\text {st }}$ Item & $2^{\text {nd }}$ Item & $3^{\text {rd }}$ Item \\
\hline 1 & $\begin{array}{l}\text { "I listen and pay more } \\
\text { attention to the } \\
\text { athletes view of my } \\
\text { training!" }\end{array}$ & & \\
\hline 2 & $\begin{array}{l}\text { "1. Catch them doing } \\
\text { something good." }\end{array}$ & $\begin{array}{c}\text { "2. Begin each } \\
\text { workout with a prayer" }\end{array}$ & $\begin{array}{l}\text { "3. Thank them for } \\
\text { coming to workouts." }\end{array}$ \\
\hline 3 & $\begin{array}{l}\text { "I am focusing more } \\
\text { on recognizing and } \\
\text { working on the good } \\
\text { things rather than } \\
\text { pointing out things } \\
\text { that are wrong." }\end{array}$ & & \\
\hline 4 & $\begin{array}{l}\text { "Learning the science } \\
\text { behind what it takes to } \\
\text { perform at our best." }\end{array}$ & $\begin{array}{l}\text { "Use of construction } \\
\text { models to help with } \\
\text { planning and } \\
\text { modeling." }\end{array}$ & $\begin{array}{l}\text { "Understanding the } \\
\text { value of gratitude and } \\
\text { working to build a team } \\
\text { culture of inclusion." }\end{array}$ \\
\hline 5 & $\begin{array}{l}\text { "I haven't been able to } \\
\text { use this yet, but when } \\
\text { I do it will allow me } \\
\text { to be more positive } \\
\text { with the students." }\end{array}$ & & \\
\hline 6 & "1. Give choices" & $\begin{array}{l}\text { "2. Model desired } \\
\text { behavior" }\end{array}$ & $\begin{array}{l}\text { "3. Seek out } \\
\text { opportunities to give } \\
\text { positive feedback" }\end{array}$ \\
\hline 7 & "Motivation" & "self confidence" & "fair evaluation" \\
\hline 8 & $\begin{array}{l}\text { "I am grateful to my } \\
\text { athletes and thank } \\
\text { them for their effort at } \\
\text { practice" }\end{array}$ & $\begin{array}{l}\text { "2.) I sit my athletes } \\
\text { down and explain to } \\
\text { them the reasons } \\
\text { behind thinking and } \\
\text { practice exercises" }\end{array}$ & \\
\hline 9 & $\begin{array}{l}\text { "1.) I give my athletes } \\
\text { practice and drill } \\
\text { options at practice } \\
\text { instead of forcing } \\
\text { them into groups." }\end{array}$ & $\begin{array}{l}\text { "2.) I had them write } \\
\text { letters of gratitude to } \\
\text { their parents for their } \\
\text { help getting them to } \\
\text { practice and attending } \\
\text { their games." }\end{array}$ & $\begin{array}{l}\text { "3.) I had them set } \\
\text { practice rules for the } \\
\text { group and decide on } \\
\text { punishments" }\end{array}$ \\
\hline 10 & "Sportsmanship" & "Dedication" & "Moral character" \\
\hline 11 & $\begin{array}{l}\text { "I plan to use what i } \\
\text { have learned when we } \\
\text { start practice this } \\
\text { summer. As a staff we }\end{array}$ & & \\
\hline
\end{tabular}




\begin{tabular}{|c|c|c|c|}
\hline & $\begin{array}{l}\text { are going to use the } \\
\text { model of mental } \\
\text { toughness." }\end{array}$ & & \\
\hline 12 & $\begin{array}{l}\text { "I've talked about my } \\
\text { student-athletes } \\
\text { making a choice to } \\
\text { think positively and it } \\
\text { really has been shown } \\
\text { on and off the field. } \\
\text { Confidence has } \\
\text { improved, especially } \\
\text { at the plate." }\end{array}$ & & \\
\hline 13 & $\begin{array}{l}\text { "approach coaching } \\
\text { with a different mind } \\
\text { set." }\end{array}$ & & \\
\hline 14 & $\begin{array}{c}\text { "Ways to be } \\
\text { demanding not } \\
\text { demeaning...to have } \\
\text { expectations, difficult } \\
\text { ones, and to } \\
\text { encourage athletes to } \\
\text { strive for those } \\
\text { expectations knowing } \\
\text { that I fully believe } \\
\text { they can achieve them } \\
\text { (vs hand holding)" }\end{array}$ & & \\
\hline 15 & $\begin{array}{l}\text { "LIke the anchor idea, } \\
\text { will use more right } \\
\text { thinking ideas, use } \\
\text { more mental skill } \\
\text { development ideas" }\end{array}$ & & \\
\hline 16 & $\begin{array}{l}\text { "Allow students more } \\
\text { expression of making } \\
\text { right choices." }\end{array}$ & & \\
\hline 17 & $\begin{array}{l}\text { "Give more credit to } \\
\text { positives" }\end{array}$ & $\begin{array}{l}\text { "Convince Self Talk } \\
\text { should be positive" }\end{array}$ & $\begin{array}{l}\text { "Thank athletes more } \\
\text { for their time and } \\
\text { effort" }\end{array}$ \\
\hline 18 & $\begin{array}{l}\text { "We are going to } \\
\text { focus on how to } \\
\text { prepare our athletes } \\
\text { better when it comes } \\
\text { to practice" }\end{array}$ & $\begin{array}{c}\text { "we are already } \\
\text { installing the } 7 \text { c's of } \\
\text { success" }\end{array}$ & $\begin{array}{l}\text { "working on mental } \\
\text { toughness, with better } \\
\text { situations in our } \\
\text { practice and lifting } \\
\text { routines." }\end{array}$ \\
\hline 19 & $\begin{array}{l}\text { "Make sure we } \\
\text { include time for } \\
\text { players to mentally }\end{array}$ & & \\
\hline
\end{tabular}




\begin{tabular}{|c|c|c|c|}
\hline & $\begin{array}{l}\text { focus on their job and } \\
\text { role on the team." }\end{array}$ & & \\
\hline 20 & $\begin{array}{l}\text { "1.) I ask my athletes } \\
\text { to think of three things } \\
\text { that we did a good job } \\
\text { of at practice that day" }\end{array}$ & $\begin{array}{l}\text { "2.) I let me athletes } \\
\text { guide and come up } \\
\text { with their own warm- } \\
\text { ups on certain days" }\end{array}$ & $\begin{array}{c}\text { “3.) I have more } \\
\text { opportunities for } \\
\text { interaction with team } \\
\text { members in dryland } \\
\text { activities" }\end{array}$ \\
\hline 21 & $\begin{array}{c}\text { "Allow students more } \\
\text { expression of making } \\
\text { right choices." }\end{array}$ & & \\
\hline 22 & $\begin{array}{l}\text { "Through this } \\
\text { program, I have come } \\
\text { to learn that positive } \\
\text { coaching also includes } \\
\text { structuring practices } \\
\text { and meets to be more } \\
\text { supportive and } \\
\text { developmental } \\
\text { towards the focus, } \\
\text { self-confidence, and } \\
\text { value of athletes, and } \\
\text { how to structure each } \\
\text { day to help support } \\
\text { those larger goals." }\end{array}$ & & \\
\hline 23 & $\begin{array}{l}\text { "Ways to promote } \\
\text { focus." }\end{array}$ & $\begin{array}{l}\text { "Ways to teach mental } \\
\text { toughness." }\end{array}$ & $\begin{array}{l}\text { "Coming up with a } \\
\text { coaching philosophy." }\end{array}$ \\
\hline 24 & $\begin{array}{c}\text { "Stress } \\
\text { sportsmanship." }\end{array}$ & $\begin{array}{l}\text { "Stress positive } \\
\text { thought." }\end{array}$ & "Lead by example." \\
\hline 25 & $\begin{array}{c}\text { "choosing to be more } \\
\text { positive in every } \\
\text { aspect." }\end{array}$ & $\begin{array}{l}\text { "Choosing to not focus } \\
\text { on what went wrong." }\end{array}$ & $\begin{array}{l}\text { "Helping the athlete } \\
\text { choose right thoughts } \\
\text { as a method of getting } \\
\text { rid of the negative } \\
\text { thoughts haunting } \\
\text { them." }\end{array}$ \\
\hline 26 & $\begin{array}{l}\text { "Just the concept of } \\
\text { taking breaks from } \\
\text { drills to work on team } \\
\text { building/morale. } \\
\text { Getting the 'mind } \\
\text { right' as well the } \\
\text { body." }\end{array}$ & $\begin{array}{l}\text { "Based on this course } \\
\text { we've been using the } \\
\text { line 'There's no 'I' in } \\
\text { team, but there's an 'I' } \\
\text { in win. Ask yourself, } \\
\text { 'what can I do to help } \\
\text { us win." }\end{array}$ & $\begin{array}{c}\text { "We had already been } \\
\text { using a lot of the } \\
\text { positive coaching } \\
\text { technique. We have a } \\
\text { large number of girls } \\
\text { quitting other sports to } \\
\text { join our team because } \\
\text { we have such a good } \\
\text { culture and some of } \\
\text { other teams in our } \\
\text { school have such a } \\
\text { negative culture. It is }\end{array}$ \\
\hline
\end{tabular}




\begin{tabular}{|c|c|c|c|}
\hline & & & $\begin{array}{c}\text { clear 'positive coaching' } \\
\text { is the way to go." }\end{array}$ \\
\hline 27 & $\begin{array}{l}\text { "1. more positive } \\
\text { strategies" }\end{array}$ & "2. Ideas to consider" & $\begin{array}{l}\text { "3. science to backup } \\
\text { my coaching" }\end{array}$ \\
\hline 28 & $\begin{array}{l}\text { "I can do a better job } \\
\text { of teaching my } \\
\text { athletes the skills } \\
\text { necessary to achieve } \\
\text { Mental Toughness. } \\
\text { Getting more specific } \\
\text { on this - I can help my } \\
\text { students understand } \\
\text { the Focus component } \\
\text { of Mental toughness } \\
\text { much better - by } \\
\text { guiding them through } \\
\text { time orientation, } \\
\text { positive self-talk, } \\
\text { composure, } \\
\text { concentration and } \\
\text { confidence." }\end{array}$ & $\begin{array}{l}\text { "Also I plan to be a } \\
\text { better model of } \\
\text { stability for my } \\
\text { athletes!" }\end{array}$ & \\
\hline 29 & $\begin{array}{l}\text { "I'm providing more } \\
\text { positive feedback to } \\
\text { our athletes." }\end{array}$ & & \\
\hline 30 & $\begin{array}{l}\text { "I am new, so I am } \\
\text { looking for a good } \\
\text { foundation to start a } \\
\text { coaching career. This } \\
\text { program, and the } \\
\text { items within, seem } \\
\text { like a fit for what I } \\
\text { want to accomplish as } \\
\text { a coach and teacher." }\end{array}$ & & \\
\hline 31 & $\begin{array}{l}\text { "I now know that } \\
\text { mental strength is as } \\
\text { important as physical } \\
\text { strength." }\end{array}$ & & \\
\hline 32 & $\begin{array}{l}\text { "Just the concept of } \\
\text { taking breaks from } \\
\text { drills to work on team } \\
\text { building/morale." }\end{array}$ & $\begin{array}{l}\text { "Getting the 'mind } \\
\text { right' as well the body. } \\
\text { Based on this course } \\
\text { we've been using the } \\
\text { line 'There's no 'I' in } \\
\text { team, but there's an 'I' } \\
\text { in win. Ask yourself, } \\
\text { 'what can I do to help } \\
\text { us win." }\end{array}$ & $\begin{array}{l}\text { "We had already been } \\
\text { using a lot of the } \\
\text { positive coaching } \\
\text { technique. We have a } \\
\text { large number of girls } \\
\text { quitting other sports to } \\
\text { join our team because } \\
\text { we have such a good } \\
\text { culture and some of }\end{array}$ \\
\hline
\end{tabular}




\begin{tabular}{|c|c|c|c|}
\hline & & & $\begin{array}{l}\text { other teams in our } \\
\text { school have such a } \\
\text { negative culture. It is } \\
\text { clear 'positive coaching' } \\
\text { is the way to go." }\end{array}$ \\
\hline 33 & $\begin{array}{l}\text { "I have yet to coach a } \\
\text { practice, but will use" }\end{array}$ & & \\
\hline 34 & $\begin{array}{l}\text { "I didn't change much, } \\
\text { more because what I } \\
\text { did was already pretty } \\
\text { close to what was } \\
\text { talked about, than } \\
\text { because I didn't agree } \\
\text { with it." }\end{array}$ & & \\
\hline 35 & $\begin{array}{l}\text { "Pre-Practice } \\
\text { Meetings: Individual } \\
\text { Position Groups } \\
\text { FOCUS training time } \\
\text { with position } \\
\text { coaches." }\end{array}$ & $\begin{array}{l}\text { "Post-Practice } \\
\text { Meetings: Each } \\
\text { position coach picks } \\
\text { out one player and } \\
\text { coach him UP. Look } \\
\text { for what he did GOOD } \\
\text { in practice and get him } \\
\text { excited about that. } \\
\text { May be more than one } \\
\text { player for each coach } \\
\text { but look for all players } \\
\text { to get positive } \\
\text { feedback thru the } \\
\text { week." }\end{array}$ & $\begin{array}{l}\text { "Post-Practice } \\
\text { COACHES MEETING } \\
\text { - Take the time to go } \\
\text { over individual } \\
\text { positives in practice } \\
\text { and COACH the } \\
\text { coaches UP in this } \\
\text { meeting letting them } \\
\text { know what they did } \\
\text { good each day!" }\end{array}$ \\
\hline 36 & $\begin{array}{l}\text { "Better understanding } \\
\text { of how to build mental } \\
\text { toughness with } \\
\text { athletes." }\end{array}$ & & \\
\hline 37 & $\begin{array}{l}\text { "1.) I have written my } \\
\text { philosophy of } \\
\text { coaching and given it } \\
\text { a lot of thought. It has } \\
\text { changed the way I } \\
\text { approach each day" }\end{array}$ & $\begin{array}{c}\text { "2.) I am having } \\
\text { difficult and honest } \\
\text { conversations, instead } \\
\text { of avoiding the } \\
\text { troubled on my team." }\end{array}$ & $\begin{array}{l}\text { "3.) I have tought the } \\
\text { skills of focus to my } \\
\text { team, and emphasized } \\
\text { process over outcome } \\
\text { and redefined the } \\
\text { concept of success." }\end{array}$ \\
\hline 38 & $\begin{array}{l}\text { "Reinforced the need } \\
\text { to be positive as the } \\
\text { most effective way to } \\
\text { motivate." }\end{array}$ & $\begin{array}{l}\text { "Reading through the } \\
12 \text { questions of } \\
\text { fulfilling team } \\
\text { experiences made me }\end{array}$ & $\begin{array}{l}\text { "I want to know more } \\
\text { about the scientific } \\
\text { foundations lesson and } \\
\text { some of the books }\end{array}$ \\
\hline
\end{tabular}




\begin{tabular}{|c|c|c|c|}
\hline & & $\begin{array}{l}\text { realize some areas that } \\
\text { I am deficient in. I do } \\
\text { not praise or check in } \\
\text { with my athletes } \\
\text { enough." }\end{array}$ & $\begin{array}{l}\text { mentions throughout } \\
\text { the course." }\end{array}$ \\
\hline 39 & $\begin{array}{l}\text { As the assistant coach, } \\
\text { I feel I am doing a } \\
\text { better job of helping } \\
\text { to build the athletes } \\
\text { up. }\end{array}$ & $\begin{array}{l}\text { I also am working at } \\
\text { turning negatives into } \\
\text { positive statements. }\end{array}$ & $\begin{array}{l}\text { I am working on being } \\
\text { a better example in all } \\
\text { aspects of the sport to } \\
\text { my athletes. }\end{array}$ \\
\hline 40 & $\begin{array}{l}\text { Reinforced the need to } \\
\text { be positive as the most } \\
\text { effective way to } \\
\text { motivate. }\end{array}$ & $\begin{array}{l}\text { Reading through the } \\
12 \text { questions of } \\
\text { fulfilling team } \\
\text { experiences made me } \\
\text { realize some areas that } \\
\text { I am deficient in. I do } \\
\text { not praise or check in } \\
\text { with my athletes } \\
\text { enough. }\end{array}$ & $\begin{array}{l}\text { I want to know more } \\
\text { about the scientific } \\
\text { foundations lesson and } \\
\text { some of the books } \\
\text { mentions throughout } \\
\text { the course. }\end{array}$ \\
\hline
\end{tabular}




\section{VITA}

Jack Brown was born and raised in Atlanta, Georgia. While in Atlanta, Jack attended The Westminster Schools, where he is a member of the Breithaupt Sports Hall of Fame. Afterwards, Jack attended the University of Arizona where he received his Bachelors of Science in Psychology in 2010. Following graduation, Jack made his way to Columbia, MO in 2011 and obtained a Master of Education in Health Promotion and Education with an emphasis in Sport Psychology in 2013.

While at the University of Missouri, Jack has made numerous conference presentations to the Association for Applied Sport Psychology, the National Coaching Conference, and the Missouri Board of Educators. He served as a graduate assistant for sport psychology and worked with the Missouri Institute for Positive Coaching as a presenter, facilitator, and researcher.

Currently, Jack is an Assistant Swim Coach at the University of Missouri and he is still involved with the Missouri Institute for Positive Coaching. He lives in Columbia, MO with his wife, Sarah, and his dog, Oliver. 